University of Redlands

\title{
Proposing New Bus Stops for the Recipients of Building Stable Lives Program in Chattanooga, Tennessee
}

A Major Individual Project submitted in partial satisfaction of the requirements

for the degree of Master of Science in Geographic Information Systems

by

Abdulrahman Ali Algarni

Fang Ren, Ph.D., Committee Chair

Douglas M. Flewelling, Ph.D.

June 2013 
Proposing New Bus Stops for the Recipients of Building Stable Lives Program in Chattanooga, Tennessee

June 2013

by

Abdulrahman Ali Algarni 
The report of Abdulrahman Ali Algarni is approved.
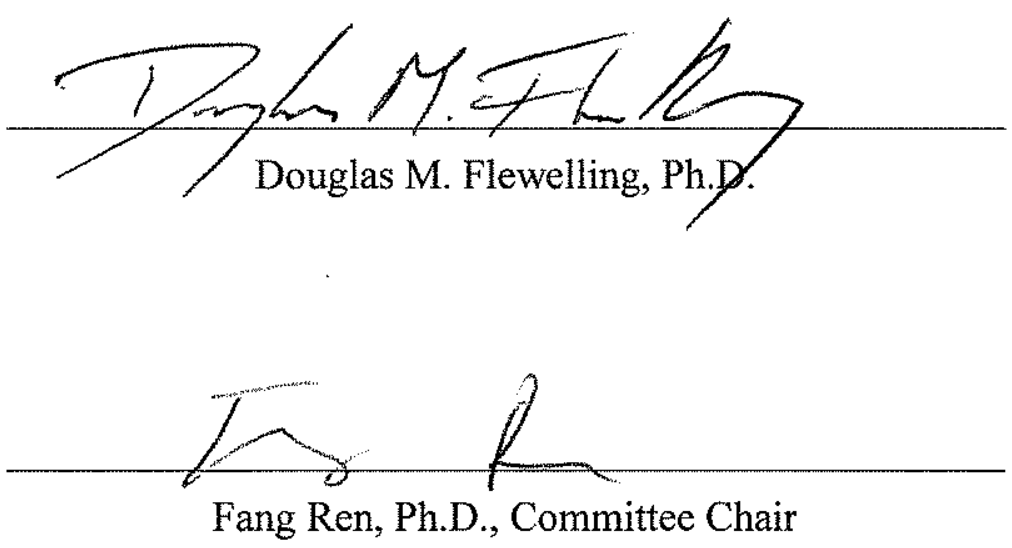

June 2013 



\section{Acknowledgements}

I would like to express my gratitude and thanks to Allah for putting all of the following people in my way so, I got all the support and assistance.

I would like to thank His Royal Highness Prince Mohammed Bin Nayef the Minister of Interior- Kingdom of Saudi Arabia, for his , lieutenant general Saad Bin Abdullah AlTuwaijri-Director of Civil Defense in Kingdom of Saudi Arabia, General major Mohammed Bin Abdullah Algarni-Assistant Director of Civil Defense for Training Affairs, and General Major Abdulla Bin Hammed Al Ghashaam-Director of Civilian Protection for giving me this great opportunity and guidance that enabled me to study Masters of Science in Geographic Information System at University of Redlands- USA.

I would like to thank all professors and staff at the University of Redlands for the support, opportunity, education, and guidance that enabled me to complete this project.

In particular, I give my gratitude and thank to my advisor Dr. Fang Ren, Committee Chair for all of her support, help, and advice throughout the development of this project. It was hard starting this project later than everybody else but with her continued support and guidance I was able to make it. Thank you, Dr. Fang for your patience and encouragement. I would like to give many deep thanks to Douglas Flewelling, Ph.D. for his guidance for his support and enthusiasm with the project that allowed me to ensure successful completion. I would like to give big and special thanks to Debra Riley, the MS GIS Program Coordinator, for her help, efforts, and assistance to me and my family. From my heart, thank you Debbie.

I would give many thanks to the project client, Dr. Eileen and Mr. Reed. Thank you for your collaboration and support through the project development process.

To Cohort 19, thank you for your support and assistance cannot imagine a better group of people to have shared this experience with. I would give special and deep thank you to April Villagomez-Roe who really encouraged and guided me to learn a lot of the ArcGIS program. Thank you for my fellow cohort members especially Cohort 20 and Cohort 21.

To all MS GIS staff, thank you for assistance and support and especial thank you to Ruben Ortiz, and Steve Paplanus for their excellent IT support.

I would to thank Jack Dangermond - founder and president of ESRI and all Esri instructors and staff who help me to complete this project successfully.

I would thank my co-worker Dr. Abdullah Alshomrani, Khalid Alzahrani for their behind-the-scenes support.

I acknowledge my brother Dr. Algarni, Abdullah the GIS professor who encourage me to get the GIS field. My brother I would not make this without your support, guidance, and help. Thank you bro and you are the golden role models for our family.

To my parents, brothers, and sisters thank you for encouragement, prayers, and tremendous support. I did not see you from long time but you always with me in my heart.

Finally, I would like to express my deepest gratitude and heartfelt thanks to my wife and my children. Thank you my wife for your support, patience, taking care and responsibility of kids. Thank you to my son Nawaf for your helping me out typing some 
papers. Thank you for Ghadi and Bassil for your patience and giving me a quite environment to study. Thank you to Allah for giving me a cute girl like Danna. 


\section{Abstract \\ Proposed New Bus Stops in Chattanooga, Tennessee}

by

Abdulrahman Ali Algarni

The priority of public transportation is to promote ridership for residents through easy access to employment opportunities. In this way, public transportation contributes to financial stability in poorer communities by connecting people with jobs and reducing the impact of spatial mismatch. Welfare to work programs has rolls of moving welfare recipients off assistant into the workplace. The United Way has a BSL program in Chattanooga that provides social services to low-income individuals living in areas of high unemployment with low educational levels. The BSL aims to increase employment opportunities for unemployed people who call the BSL program at 2-1-1 which would decrease their dependence on the BSL social services. The purpose of this project was to facilitate the 2-1-1 callers' access to major employment opportunities through public transit. The impact of spatial mismatch between residential areas and job growth was analyzed and optimal locations for new bus stops were then proposed. Optimal bus routes that connected each proposed bus stop in residential areas with individual major employer locations were suggested. This would facilitate the 2-1-1 callers' access to prospective jobs to find job and improve their financial stability. 



\section{Table of Contents}

Chapter 1 - Introduction $\quad 1$

1.1 Client 1

1.2 Problem Statement 2

1.3 Proposed Solution 2

1.3.1 Goals and Objectives 2

1.3.2 Scope 2

1.3.3 Methods 4

1.4 Audience 4

1.5 Overview of the Rest of this Report 4

Chapter 2 - Background and Literature Review $\quad 7$

2.1 Spatial Mismatch and Job Accessibility 7

2.1.1 Building Suitable Lives' callers in the Predefined ZIP Codes 7

2.1.2 The CARTA Current Bus Services 8

2.2 Evaluate Transit Bus Stop Service Coverage 9

2.2.1 Circular buffer zone 9

$\begin{array}{ll}\text { 2.2.2 Actual transit bus stop service coverage } & 10\end{array}$

$\begin{array}{ll}2.3 & \text { Criteria for Locating New Bus Stops } \\ & 11\end{array}$

$\begin{array}{lll}2.4 & \text { Summary } & 12\end{array}$

Chapter 3 - Systems Analysis and Design 13

3.1 Problem Statement 13

3.2 Requirements Analysis 13

$\begin{array}{lll}3.2 .1 & \text { Functional Requirements } & 13\end{array}$

3.2.2 Non- Functional Requirements 14

$\begin{array}{lll}3.3 & \text { System Design } & 15\end{array}$

$\begin{array}{ll}3.4 & \text { Project Plan } \\ 3.4 .15\end{array}$

$\begin{array}{ll}\text { 3.4.1 Phase 1 Requirements Analysis } & 16\end{array}$

$\begin{array}{ll}\text { 3.4.2 Phase 2: Research } & 16\end{array}$

$\begin{array}{ll}\text { 3.4.3 Phase 3: Data Preparation } & 16\end{array}$

3.4.4 Phase 4: Spatial Mismatch Geodatabase and Analysis 17

$\begin{array}{ll}\text { 3.4.5 Phase 5: Transportation Network Dataset } & 17\end{array}$

$\begin{array}{ll}\text { 3.4.6 Phase 6: Presenting Analysis Results } & 17\end{array}$

$\begin{array}{lll}3.5 & \text { Summary } & 18\end{array}$

Chapter 4 - Database Design $\quad 19$

$\begin{array}{llr}4.1 & \text { Conceptual Data Model } & 19\end{array}$

$\begin{array}{ll}4.2 & \text { Logical Data Model } \\ & 20\end{array}$

4.2.1 Demographic Geodatabase Logical Model 21

4.2.2 Transportation Geodatabase Logical Model 22

$(23$

4.4 Data Collection Methods 23

4.5 Data Scrubbing and Loading 23

$\begin{array}{lll}4.5 .1 & \text { Esri Data } & 23\end{array}$

$\begin{array}{lll}\text { 4.5.2 Client Data } & 24\end{array}$

4.5.3 American Community Survey (ACS) Data 24

4.5.4 Locations with Specified Job Opportunities 25 
4.6 Data Preparation $\quad 25$

$\begin{array}{lll}\text { 4.6.1 Street Feature Class } & 25\end{array}$

4.6.2 Network Dataset 27

4.6.3 Additional Network Dataset 33

$\begin{array}{lll}4.7 & \text { Summary } & 33\end{array}$

Chapter 5 - Implementation $\quad 35$

5.1 Spatial Mismatch $\quad 35$

5.2 Network Analyst Solvers $\quad 35$

5.2.1 Service Area Solver $\quad 35$

5.2.2 Location-Allocation 38

$\begin{array}{ll}5.2 .3 & \text { Route Solver } \\ & 39\end{array}$

$\begin{array}{lll}5.3 & \text { Summary } & 42\end{array}$

Chapter 6 - Results and Analysis $\quad 43$

6.1 Analyzing Spatial Mismatch 43

6.1.1 Demographic of the Callers 43

6.1.2 Potential Job Opportunities $\quad 50$

6.1.3 The CARTA Bus Stop Services Area $\quad 51$

6.2 Proposed Bus Stops Locations 53

6.3 Recommended Bus Stops and Routes 60

$\begin{array}{lll}\text { 6.3.1 } & \text { Recommended Bus Stops } & 60\end{array}$

6.3.2 Shortest Paths between Callers and Manufacturers 61

6.4 Summary 63

Chapter 7 - Conclusions and Future Work $\quad 65$

$\begin{array}{ll}\text { Works Cited } & 67\end{array}$ 


\section{Table of Figures}

Figure 1-1: Predefined ZIP Codes and prospect Jobs at Chattanooga, Tennessee ....... 3

Figure 2-1: Service Coverage Using Circular Buffer Method ................................. 10

Figure 2-2: Access Coverage Area Using Service Area Solver ............................. 11

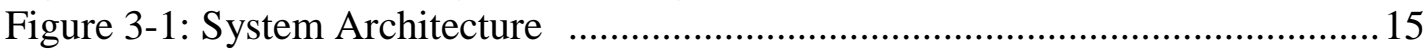

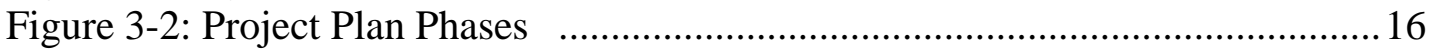

Figure 4-1: Satisfactory Route Conceptual Data Model .......................................20

Figure 4-2: Demographic Geodatabase Logical Model .........................................21

Figure 4-3: Transportation Geodatabase Logical Model .....................................22

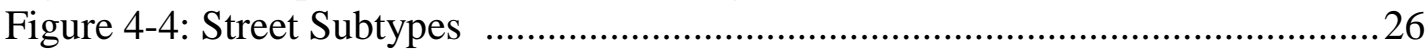

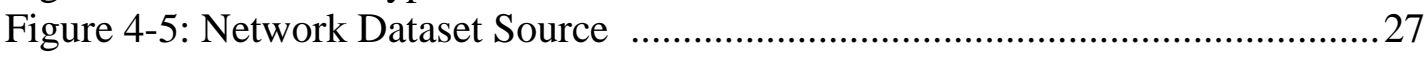

Figure 4-6: Network Dataset Connectivity ......................................................28

Figure 4-7: Network Dataset Attributes .............................................................29

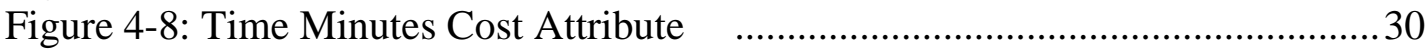

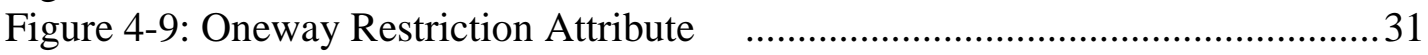

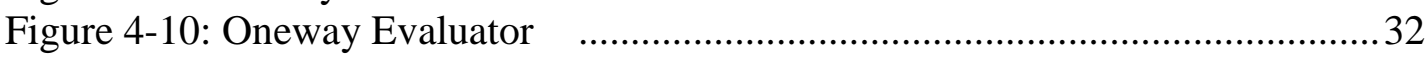

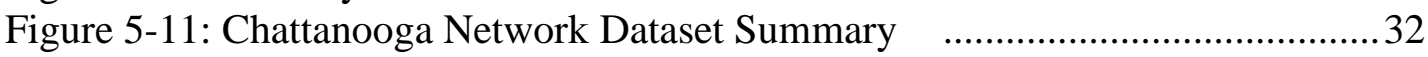

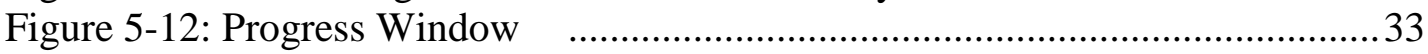

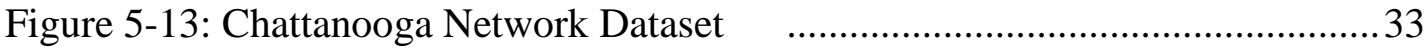

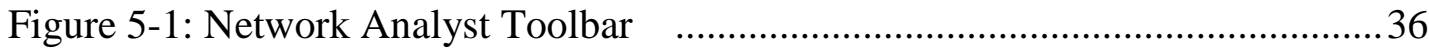

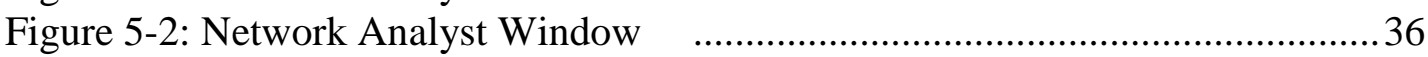

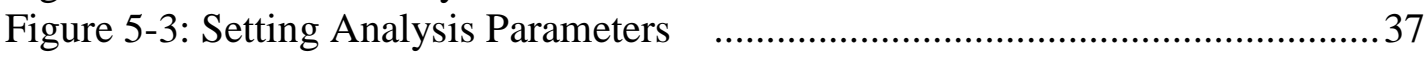

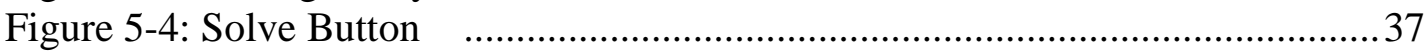

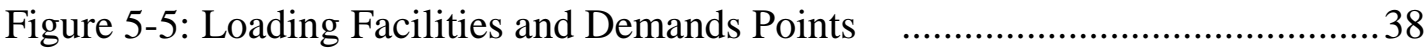

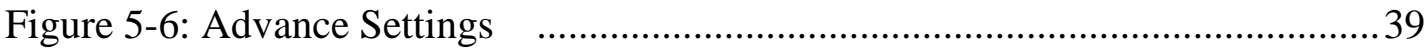

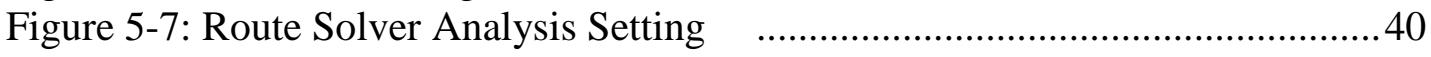

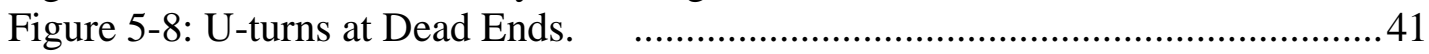

Figure 5-9: Direction Window …................................................................ 42

Figure 6-1: Distribution of 2-1-1 Callers in Chattanooga .....................................44

Figure 6-2: Percentage of Families below Poverty Level per Tracts .....................45

Figure 6-3: Distribution of 2-1-1 among Families below Poverty Level .............46

Figure 6-4: Unemployment Rate in the City per Tracts $\quad$.......................................4

Figure 6-5: Unemployed Callers' Distribution among Unemployment Rate $\quad$........48

Figure 6-6: Population with High School Degree or Less, Chattanooga ...............49

Figure 6-7: Callers with High School Degree or Less ..........................................50

Figure 6-8: Locations with more Job Opportunities $\quad$............................................. 51

Figure 6-9: The CARTA Bus Service .................................................................52

Figure 6-10: Distribution of Unserved Callers and Current Bus Services ............53

Figure 6-11: The 147 Proposed Bus stops Using Unserved Callers as Demands 55

Figure 6-12 Proposed Bus Stops in the Predefined Zip Codes ..............................56

Figure 6-13: Service Areas of the 147 Proposed Bus Stops $\quad$...................................57

Figure 6-14: The 131 Proposed Bus stops Using Block Centroids as Demands $\quad . .58$

Figure 6-15: Service Areas of the 131 Proposed Bus Stops ...............................59

Figure 6-16: Proposed Stops and Service Ares around Major Employers ...........60 
Figure 6-17: The Most Recommended Bus Stops .............................................6 61

Figure 6-18: the Shortest Paths from Recommended Bus Stops to Amazon ....... 62

Figure 6-19: Recommended Street Segments to be included in the Future Routes .. 63 


\section{List of Tables}

Table 1. Functional requirements.................................................................... 14

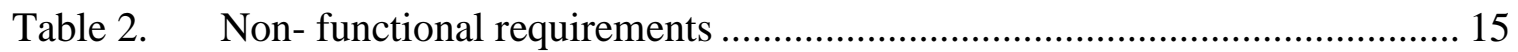

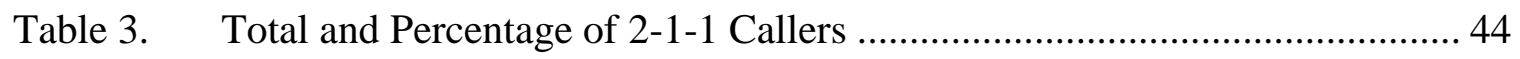





\section{List of Acronyms and Definitions}

$\begin{array}{ll}\text { ACS } & \text { American Community Survey } \\ \text { BSL } & \text { Building Stable Lives Program } \\ \text { CARTA } & \text { Chattanooga Area Regional Transit Authority } \\ \text { CBD } & \text { Central Business District } \\ \text { CFCC } & \text { Census Feature Class Codes } \\ \text { CSV } & \text { A comma-Separated Values File } \\ \text { Esri } & \text { Environmental Systems Research Institute } \\ \text { GIS } & \text { Geographic Information System } \\ \text { mph } & \text { miles per hour } \\ \text { NAD } & \text { North America Datum } \\ \text { NAICS } & \text { North American Industry Classification System } \\ \text { ND } & \text { Network Dataset } \\ \text { TCRP } & \text { Cooperative Research program } \\ \text { TOD } & \text { Planning Commission Committee }\end{array}$





\section{Chapter 1 - Introduction}

Public transportation systems are considered a critical part of the economic and social construction of metropolitan areas (Tomer, Kneebone, Puentes, and Berube, 2011). They can contribute to financial stability in poorer communities by connecting people with jobs and reducing the impact of geographic separation known as transportation mismatch. Thus, one of the highest priorities of public transportation is to promote ridership for residents through easy access to employment opportunities. Bus stops are important hubs in public transit systems because they connect people with the transit service to ensure reasonable accessibility. It has been found that bus stop locations and spacing significantly affect the usage of bus services (El-Geneidy, Horning, and Krizek, 2010).

The focus of this project was to determine whether the Chattanooga Area Regional Transit Authority (CARTA) bus services can provide accessibility to job opportunities for the residents who live in the areas of low-income, high unemployment, and low educational attainment. The motivation of the project was based on the findings of Building Stable Lives (BSL) program of the United Way of Greater Chattanooga Program. BSL program provides social services to the vulnerable families and individuals living in Chattanooga and increases employment opportunities for the unemployed by facilitating transportation using the CARTA bus system. Local residents can call BSL program at 2-1-1 for assistance with food, utilities, and rent payments as often as needed. Typically, 2-1-1 callers reside in the areas of high unemployment, low educational attainment and poor access to transportation.

The purpose of this project was to facilitate the 2-1-1 callers' accessibility to major employment opportunities using the CARTA bus services. The project analyzed the effects of the geographic separation between the 2-1-1 callers' residences and the potential job opportunity lactations. Moreover, the project analyzed the CARTA bus system usage and its effectiveness in connecting 2-1-1 callers who reside in census tracts with high unemployment rates with areas of high employment opportunities. Finally, new bus stops and new bus routes were proposed in this project with the aid of a geographic information system (GIS).

\subsection{Client}

The client for this project is Dr. Eileen Robertson-Rehberg, the Director of the BSL program of Greater Chattanooga. The BSL is one of United Way organizations that work to lead and unite the communities by providing programs for health and human services to improve people's education, income, and health. In particular, one of United Way's major missions is to help low-income individuals and families achieve financial stability. Therefore, the BSL works with people who need assistance with food, utilities, and rental payments.

Dr. Robertson is an expert in demographic analysis, computer mapping, and geographic database management. She is also a GIS planner and has experience in both qualitative and quantitative research methods. The client needed a GIS solution that could be used to reduce the 2-1-1 callers' dependence on social service systems and encourage 
them to use the CARTA bus system to get to places of high job prospects. The client provided the primary data, including the data on the 2-1-1 callers and the CARTA bus systems. The client also defined the study area of five specific ZIP codes and some targeted location job opportunities.

\subsection{Problem Statement}

The BSL program provides 2-1-1 callers with social services. Typically, 2-1-1 callers are low-income individuals living in areas of high unemployment, low educational level, and poor access to public transportation. They were given a survey about local services. A subset of questions in the survey pertains to transportation. This gives the BSL program information about which high-unemployment communities use the bus system most. Results of the survey indicated that many 2-1-1 callers do not use CARTA because they have poor access to public transportation. Additionally, there has been growth in the eastern and northern areas of Chattanooga, but these areas are not covered by the CARTA bus services. The client needed a GIS solution to reduce callers' dependence on the social service and improve their accessibility to employment opportunities utilizing the CARTA bus services.

\subsection{Proposed Solution}

The proposed solution was divided into three phases. The first phase provided evidence of spatial mismatch between the job growth and low-income residential communities. The second phase evaluated how effectively the CARTA bus system connects the callers who lived in the five predefined ZIP codes with areas of specified job opportunities. The third phase found the optimum locations for new bus stops in the predefined ZIP codes and in areas with specified job opportunities and selected the optimal routes that incorporate the new bus stops.

\subsubsection{Goals and Objectives}

The goal of this project was to decrease the 2-1-1 callers' dependence on BSL's social services by facilitating them to find jobs. There were three objectives in this project. First, the project analyzed the impact of spatial mismatch on 2-1-1 callers. Second evaluate accessibility of the 2-1-1 callers to the CARTA bus service and how well these services connect them to the major locations with more job opportunities in Chattanooga. Third, the project identified the optimum locations to propose new bus stops in the predefined ZIP codes and in areas with specified job opportunities and then selected the optimal routes that incorporate the proposed new bus stops. Once the proposed new bus stops are built, the BSL program participants' usage of the CARTA's bus services is expected to increase and will facilitate the callers to get to locations with more jobs, eventually enhancing their financial stability.

\subsubsection{Scope}

The original scope of project was confined to examining how well the CARTA bus services can transport the 2-1-1 callers who reside in ZIP code 37407 to the major 
specified job opportunities. However, the scope of the project was increased to include the 2-1-1 callers residing in ZIP codes 37404, 37406, 37410, and 37411 (Figure 1-1).

Since most of the 2-1-1 callers have low education attainment, manufacturing jobs were identified as potential job opportunities by the client. Therefore, only specified major manufacturers in Chattanooga were considered in the analysis. The deliverables included a file geodatabase, recommended map and reports. The file geodatabase contained several layers, such as the caller's layer showing the distribution of the 2-1-1 callers within Hamilton County, the current bus stops layer, and the proposed new bus stops layer that illustrated their distribution within Chattanooga. It also contained a network dataset and network analysis layers that allowed the client to select routes that incorporated chosen bus stops, and the recommended maps and reports that show optimum locations for the proposed new bus stops and suggested routes for the proposed bus stops.

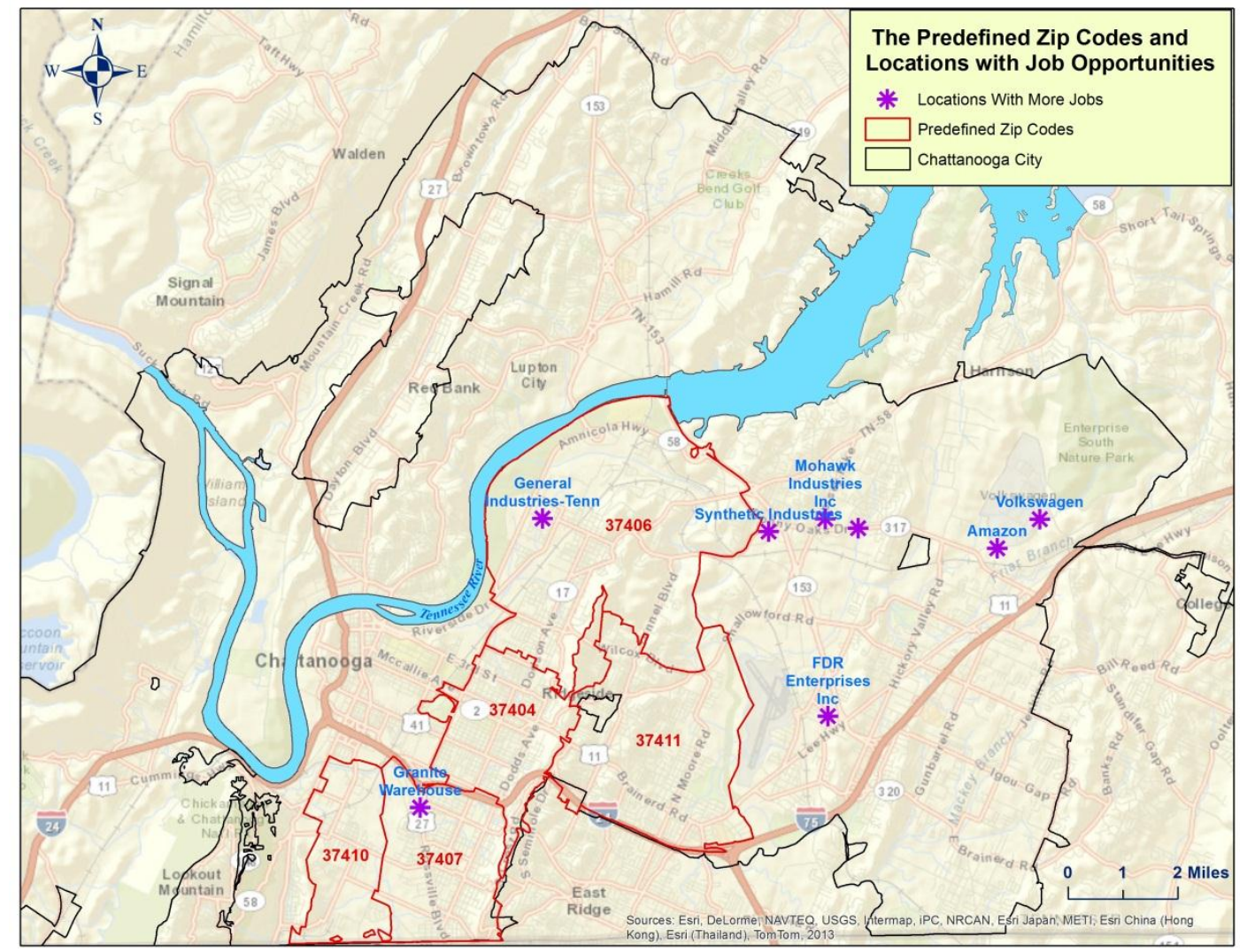

Figure 1-1: Predefined ZIP Codes and prospect Jobs at Chattanooga, Tennessee 


\subsubsection{Methods}

After gathering requirements and conducting a needs assessment, an assumed literature review was conducted, which was followed by data collection. Data involved in this project included: the locations of the people who call the 2-1-1 BSL program, demographic information of Chattanooga, the current CARTA bus stops and routes, the locations of manufacturers and enterprises, and the city street network. The data were gathered through different sources including the BSLs' database, the Census Bureau's American Community Survey (ACS), the Esri 2011 database, and Manta Inc.

Various methods and techniques were used in the analysis, which consisted of six main components: establishing the system requirements, conduct three types of research, preparing and organizing the database, analyzing the impact of spatial mismatch and evaluate accessibility of the 2-1-1 callers to the major locations with more job opportunities, proposing prospective bus stops and bus routes using the current standards, and creating recommended maps and reports.

ArcGIS Version 10.1 was used to create the maps to analyze the impact of spatial separation between the census tracts where the 2-1-1 callers live and where the targeted manufacturers are located. The Chattanooga Dataset was built to use Network Analyst solvers to examine how well the CARTA bus service provides the 2-1-1 callers with access to the targeted job sites, evaluate service areas of the current bus stops, find the optimum locations to propose new bus stops in the predefined ZIP codes and around the predefined locations with more job opportunities, and select the streets to be included in the future bus routes that are important for connecting the under-served callers and targeted manufactures.

\subsection{Audience}

The general audiences for this report are public transportation system planners and GIS analysts with introductory knowledge of the Network Analysis solvers. The specific intended audience for this project is the client of this project, Dr. Eileen Rehberg, the Director of the BSL program. Some terminologies used in this report may be technical in nature and not understood by laypersons. However, considerations were made in explaining unfamiliar language at list of acronyms and definitions section.

\subsection{Overview of the Rest of this Report}

There are six additional chapters included in the remainder of this report. Chapter Two explores various methods for visualizing and analyzing the impact of spatial mismatch on job opportunities and residential locations within urban areas, methods to evaluate the accessibility to the bus stops in urban areas and in central business districts, preview standard guidelines and regulations for the locations of bus stops to develop criteria for the proposed new bus stops, and how these methods have been used in GIS analysis. Chapter Three discusses an overview of the project plan and system design, including functional and non-functional requirements. Chapter Four covers the database design, as well as data scrubbing, loading, collecting, and preparing methods. Chapter Five reviews the implementation of the project and describes methods taken to prepare and build the geodatabase and the Network Analyst solvers. Chapter Six discusses the analysis results 
and producing the recommended maps. Final possibilities for future work are discussed in Chapter Seven. 



\section{Chapter 2 - Background and Literature Review}

This chapter discusses previous research on the effects of the spatial mismatch between job growth areas and residential communities with high unemployment rates and poor access to public transportation. It also describes approaches for evaluating accessibility to public transit. In addition, this chapter introduces research about the reasonable walking distance in urban areas and central business districts. Finally, developing criteria for choosing the optimum locations of new bus stops are also discussed in this chapter.

\subsection{Spatial Mismatch and Job Accessibility}

Spatial mismatch refers to physical separation between job growth areas and residential communities with high unemployment rate and poor access to public transportation (Eichenthal, Tharp, and Rehberg, 2006). Due to poor access to potential employment places, semi-skilled and marginalized people have great challenges in finding and maintaining employment opportunities. Spatial mismatch occurs in the basic geographical mismatch in relation to the residential and workplace (Ihlanfeldt, 1994). While the residential mobility and decision making have established research, studies on the household decision making processes in relation to employment are still required (Ihlanfeldt, 1994).

Spatial mismatch was first advanced by John Kain (1968) article. Kain examined the residential locations of African Americans and trends in the location of employment opportunities in in Detroit and Chicago. He found that businesses were decentralizing at a rapid pace and that housing discrimination prevented African Americans from following jobs to the suburbs (Jargowsky, 2002). In addition, suburban job growth centers were largely inaccessible to inner-city residents via public transit. Kain concluded that high unemployment rates of inner-city African Americans were partially attributable to job decentralization and the failure of public transit to connect inner-city residents with suburban job locations.

Kain's findings led to a voluminous body of literature on spatial mismatch which largely supports his thesis (Moss, Salzman, and Tilly C., 2000). The literature suggests that the patterns Kain observed during the 1960s have become more pronounced over time, as low-income and minority populations remain largely concentrated in central urban locations, while businesses continue to decentralize at a rapid pace (Jargowsky, 2002).

Studies show an increase in the share of metropolitan jobs while the concentration of the low income populations was in the central city neighborhoods away from job growth centers. An effective public transport is crucial for bridging the inner-city locations of the low income populations and the suburbs for job opportunities.

\subsubsection{Building Suitable Lives' callers in the Predefined ZIP Codes}

Typically, the 2-1-1 callers are families and individuals call Building Suitable Live (BSL) program at 2-1-1 for social services, assistance with food, and utilities. They reside in Chattanooga communities of high unemployment and have a low level of education and 
poor access to the Chattanooga Area Regional Transit Authority (CARTA) bus services. These areas identified as ZIP codes 37407, 37404, 37406, 37410, and 37411.

2-1-1 Callers are given a survey about local services including questions pertaining to transportation. This gave the BSL program information on which high unemployment communities use the bus system. The results indicated that many 2-1-1 callers do not use CARTA because they do not live near bus stops. Chattanooga is growing in several major industries and commercial activity in areas that may not covered by CARTA bus services such as Eastern and Northern Chattanooga (Eichenthal, Tharp, and Rehberg, 2006).

The 2000 census data revealed high poverty rates in Chattanooga's urban core The higher rates were observed from in the northern and Southern bands of ZIP codes, including the down town area of the south side. Some of these areas had poverty rates exceeding 50\% (Eichenthal, Tharp, and Rehberg, 2006).

A 2010 survey made by The Ochs Center showed availability of jobs and poverty level in Hamilton County was showed to be highly related to education attainment. In regard to employment, the 2010 survey on the residents of Hamilton County found that $45 \%$ of the respondents and interviewees had a high school education level or less. This rate was twice as high as that of college graduates. $26 \%$ of people of 25 years old and younger in the county without a high school education were below the poverty level, which was three times higher than the overall rate of $10 \%$ among adults with a college degree. Educational attainment had an enormous impact on an individual's employability $45 \%$ of high school and less educated rated the employment situation as poor compared to $20 \%$ for college graduates. There was a 275 of the college graduates who rated the employment levels as excellent in the 2010 survey, which was less than the $32 \%$ in 2006. However, it was still higher than the $20 \%$ from high school education, and some colleges had $18 \%$. The Ochs Center reported that employment in Hamilton County expanded at a rate of just over $3 \%$ from 2001 to 2007 , but the recession led to job losses in most sectors between 2007 and 2009. This job loss created high unemployment areas in some places of Chattanooga.

The employment has changed, which has created high unemployment areas in some places of Chattanooga. The unemployment probability was increased in the central city across racial groups. The effect, however, on the African Americans was twice that of the whites. There was a strong job growth in Chattanooga, from 1998 to 2003, but it did not reflect in the city center. Jobs were increasing at the outskirts of Hamilton County or in north Georgia. This was true in employment income and used the income variable to see how it "leaked" out of certain areas into others in the form of investments, employment and development (Eichenthal, Tharp, and Rehberg, 2006).

\subsubsection{The CARTA Current Bus Services}

Challenges in finding job opportunities for many low-income individuals are often caused by poor access to transportation to over the distance between home and job locations (Eichenthal, Tharp, and Rehberg, 2006). The Brookings Institution (2010) released a study showing that only half of the jobs are accessible through public means in Chattanooga, which ranks Chattanooga city at position 91 out 100 the nation large metro areas (Rehberg, 2009). Places such as Red Bank, Lookout Mountain, Soddy-Daisy and East Ridge no longer supply any funding to CARTA. This left the service with limited ability to serve Chattanooga area. Job seekers struggled to find companies and the 
companies struggled to find employees. For example, there is no public transit service for major employers such as Volkswagen and Amazon (O'Neil, 2012). The service uses its limited capabilities to serve the core city instead of the sprawling Chattanooga metro area. Deficiencies in the CARTA bus services make it necessary to develop new bus routes that can provide the low income earners access to jobs.

\subsection{Evaluate Transit Bus Stop Service Coverage}

Service coverage of bus stops can be determined by its surrounding area from which people can comfortably walk to the bus stops. When easy access to bus stops is not available, other aspects of service quality do not matter. A study by Calgary in 1970 about the relationship between transit ridership and walking distance in a low-density Florida retirement area found a strong relationship between walking distance and transit use (O'sullivan and Morrall, 2003). The study showed that transit use dropped by almost $70 \%$ as walking distance increased from 200 meters to 400 meters.

Planning Commission's TOD Committee reported that the optimal walking distance between a stop and a place of employment is 500 to 1,000 feet (Dittmar, and Ohland, 2004). Most residents are willing to walk slightly longer distances to get to transit, up to half of a mile. Based on an assumed average walking speed of about 1.3 meter/seconds, 5 minutes of walking is considered reasonable in urban areas, which is about 400 meters according to Levinson (Li, Abarbanell, Gleitman, and Papafragou, 2011). Therefore, most transit firms consider 400 meters an acceptable access/egress standard according to Ammons (Murray and $\mathrm{Wu}, 2003$ ). Transit-oriented design guidelines developed by the Ontario Ministry of Transportation also recommend 400 meters or a quarter of a mile walking distance (Dittmar, and Ohland, 2004).

When the reasonable walking distance is defined, service coverage of a bus stop can be calculated using circular buffer zones (Euclidean distance) or actual street network surrounding that bus stop (Path distance).

\subsubsection{Circular buffer zone}

Before advances in GIS technology, many studies did not consider true geographical obstacles when evaluating the access to bus stops. For example, the circular buffer analysis approach evaluates the service area of a bus stop by a circle with a predefined radius (Figure 2-1). 


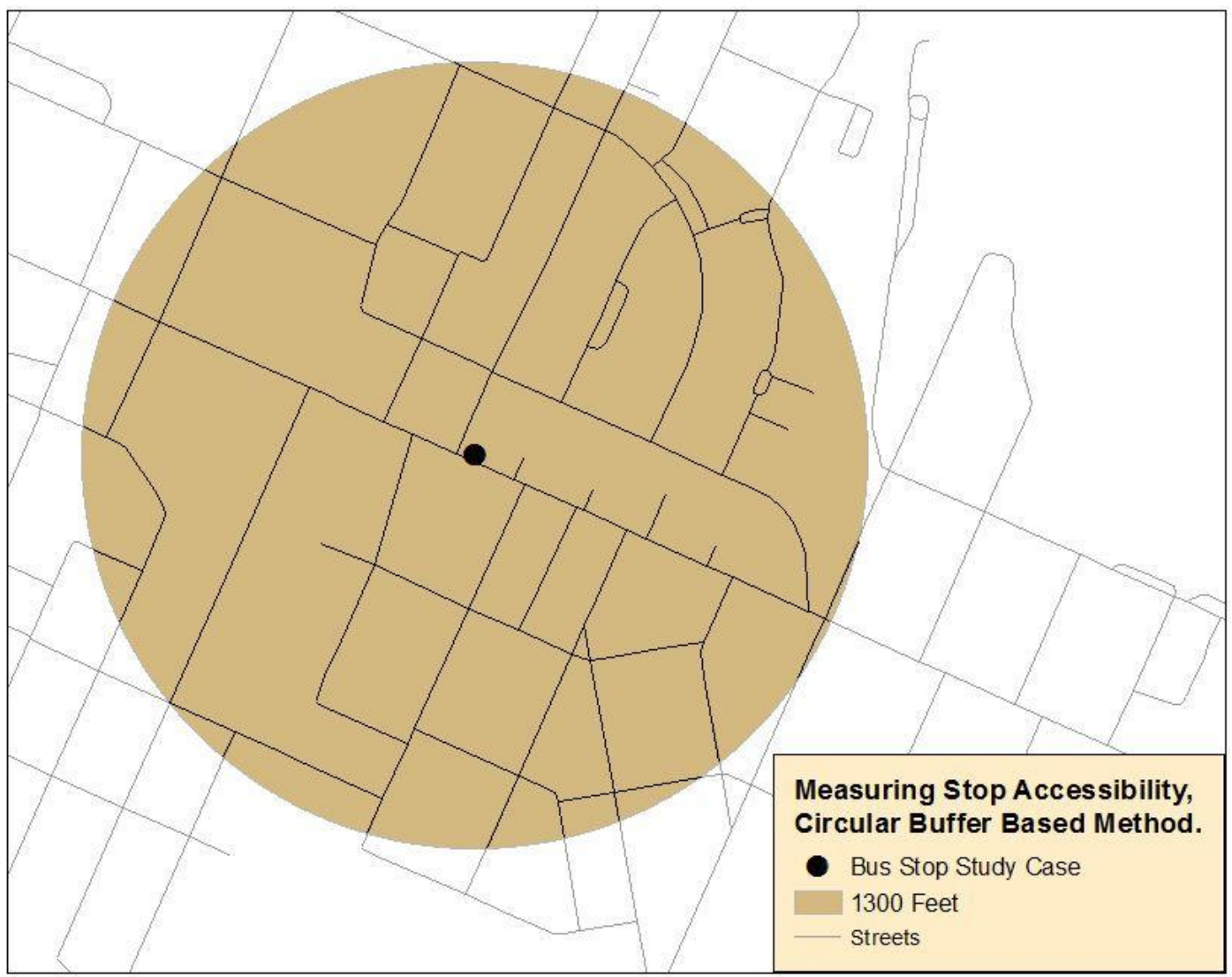

Figure 2-1: Service Coverage Using Circular Buffer Method

Figure 2-1shows the access coverage of a bus stop using circular buffer for measuring the accessibility with taking in the consideration 1,300 feet as the reasonable walking distance. Based on the population of the area, service coverage can be determined. This approach can cause an overestimation of service coverage, since it assumes bus ridership can reach the bus stop location from all points within the circular buffer taking the Euclidean path. This method does not consider or recognize the presence of the geographic obstacles and the actual streets network around the bus stop. Another estimation approach for access is calculating the distance between the centers of a spatial block to its nearest bus stop. The service area is achieved when the distance is within threshold (Murray and Wu, 2003). While this approaches provided estimations for service coverage areas, it was unrealistic and had potential error by measuring access distance in terms of a straight distance and ignoring the actual geographic obstacles and street networks.

\subsubsection{Actual transit bus stop service coverage}

Using street network to evaluate the actual service area of a bus stop is possible with the powerful of GIS. According to Salvo and Sabatini, there are suggestions on using spatial approaches to identifying optimal stop locations (Murray and $\mathrm{Wu}, 2003$ ). They proposed 
a GIS solution for accessing public transportation coverage in urban areas. This system involves a pedestrian network with the presence of obstacles (Figure 2-2).

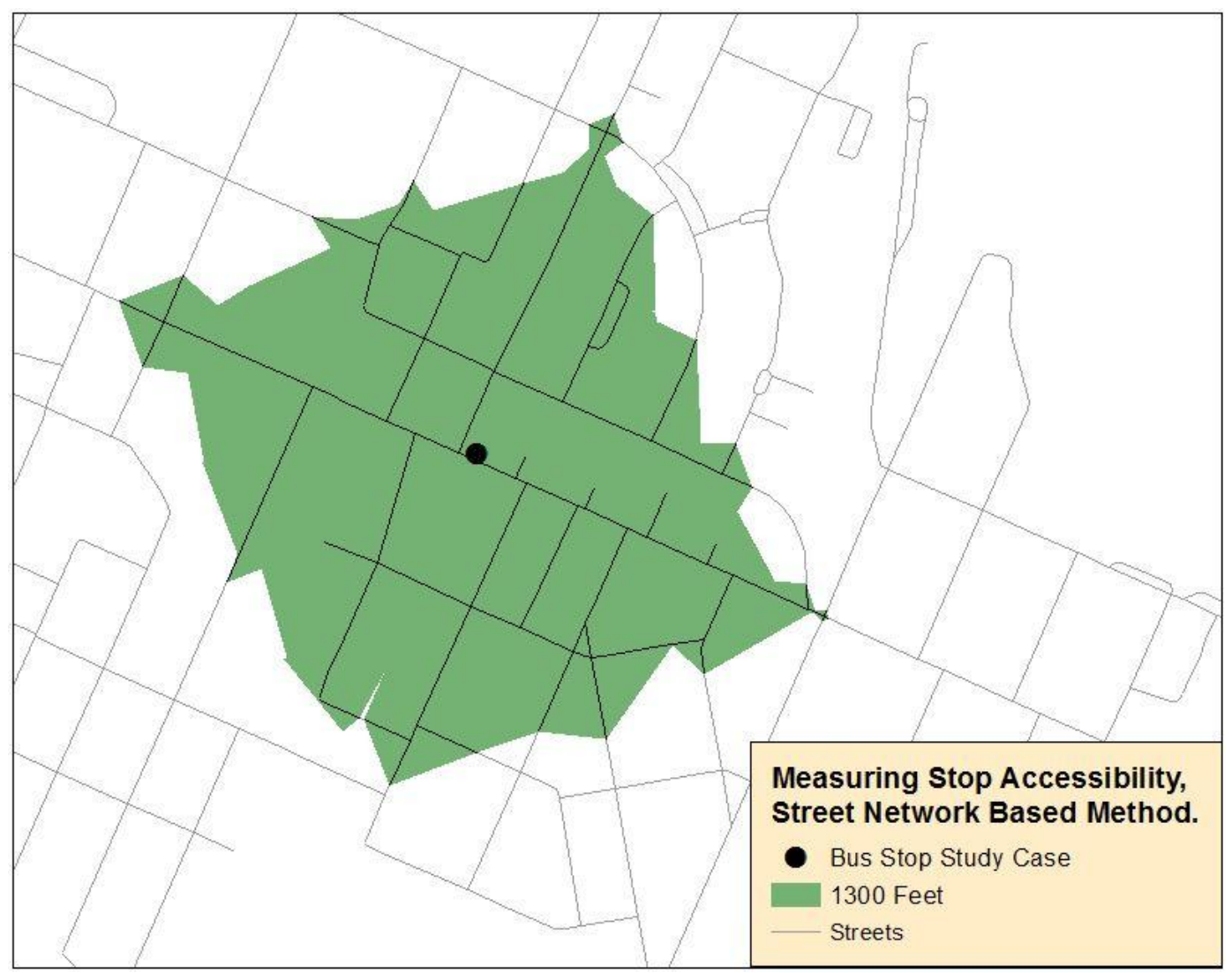

Figure 2-2: Access Coverage Area Using Service Area Solver

ArcGIS Network Analyst; Service Area solver is a suite of network analysis tools that consider the true street network and geographic obstacles. Figure 2-2 illustrates the service coverage of 1,300 feet generated by based on the real street network; path distance.

Compared to the circular buffer's service coverage (Figure 2-1), the street network based coverage is irregular shaped and coverage area is reduced from one square mile down to 0.1 square miles. Since walking distance is measured along the true street paths, this approach is more realistic.

\subsection{Criteria for Locating New Bus Stops}

Implementation processes for new bus stops need to consider the placement of the stop relative to the nearest intersection according to Washington Metropolitan Area Transit Authority (WMATA). It is important that bus stops are easily accessible places from different directions. Several guidelines and criteria were developed for placement and design of the bus stops. Placement guidelines include locations of bus stops and spacing between bus stops along a route. 
The criteria in this project were developed based on an optimum solution for new bus stop locations, which does not consider bus stop spacing factors such as safety, visibility, or comfort. Moreover, these criteria did not consider general jurisdictions for public transit bus stop facilities such as stop signs, shelters, or lighting.

Literature shows that the transportation authority in the county determines the bus stop locations according to Transport-Christchurch City Council guidelines. This determination process takes into account the goals that address traffic operations and passenger accessibility concerns. The Transit Cooperative Research Program (TCRP, 1996) in its Report 19 argued that locations of bus stops should be primarily determined by the development types including residential area, commercial, or nearness to the Central Business District (CBD). In addition, the placement of a stop should also be at main trip generators (TCRP, 1996).

The primary objective of this project was to find the optimal locations for new bus stops in specific areas in Chattanooga city that minimizes the number of bus stops needed to cover all or the greatest amount of unserved callers by the current CARTA bus services. Passengers' accessibility, street types, and the client's specific needs were taken into account. First, the proposed bus stops were expected to be located in the areas in the predefined ZIP codes that are not covered by the CARTA bus services and around defined manufacturers and enterprises. Second, the reasonable walking distances to bus stops are defined as 1,300 feet for the residential area and 600 feet for the CBD. Third, the new bus stops should be located on the streets that are suitable for bus routes.

Guidelines for suitable bus routes were developed by the WMATA in 2009. The WMATA reported that streets with speed limit of $40 \mathrm{mph}$ or less are suitable for bus routes. Major arterials with speeds of $45 \mathrm{mph}$ or greater should be avoided unless there is no choice. The streets that have traffic-calming measures, such as speed humps and traffic circles should also be avoided (MacKechnie, 2011). Generally, streets and/or roads that have speed limits of 30,35 or 40 are assigned for bus routes, which ensure not to locate bus stops on access ramps, highways, driveways and so on.

\subsection{Summary}

Spatial mismatch and job accessibility were discussed in this chapter. Literature showed that effective public transport bridges low income populations and job opportunities. Also, this chapter discussed the efficiency of the CARTA bus service to major employers in Chattanooga city. Using two approaches, the access coverage area of a bus stop through a study case was evaluated in this chapter. Service Area Solver which is a street network based method was used to evaluate the access coverage for a bus stop in this project. Finally, the theory and criteria for choosing the optimal locations in the predefined ZIP codes and around the defined manufacturers in Chattanooga city were discussed. 


\section{Chapter 3 - Systems Analysis and Design}

The goal of this project was to decrease the 2-1-1 callers' dependence on BSL program's social services by facilitating them to find jobs. The project aimed to produce recommended maps and provide reports that would enable decision-makers to locate new bus stops in the optimum chosen locations. This chapter elaborates on the project planning and design, which are the critical phases in any project. Section 3.1 addresses the problem this project attempted to solve. Section 3.2 analyzes the requirements for the system and data, explaining both the functional and non-functional requirements. The design of the system, showing how all of the major components fit together, is discussed in Section 3.3. Finally, the original project plan and how it was updated throughout the project is discussed in Section 3.4.

\subsection{Problem Statement}

People who call 2-1-1 and reside in areas with high unemployment, low educational attainment, and poor access to transportation depend on the BSL program's social services. The client aspired to reduce the amount of dependency on the BSL program's social services by increasing employment opportunities. In addition, the client wanted to improve the use of the CARTA bus services by connecting callers living in the predefined ZIP codes to locations with high employment opportunities. To do this, it is critical to determine the optimum locations for the new bus stops.

\subsection{Requirements Analysis}

The final products of this project were recommended maps, reports and file geodatabase that were developed based on the client's request and the requirements analysis. The functional requirements describe what actions the system will perform. The nonfunctional requirements describe how the system will perform these actions. This section outlines what was taken into consideration when creating the products for this project.

\subsubsection{Functional Requirements}

The system's functional requirements (Table 3-1) were determined based on the client needs. The first functional requirement was the system that would use data about BSL's callers provided by the client, and demographic data downloaded from American Community Survey (ACS) would also be used to make maps that provide evidence of spatial mismatch between 2-1-1 callers and specified job opportunities. The second requirement was that the system would provide the client with maps that show the lack of access to public transit and the areas that are not covered by the CARTA bus services. The client provided data of the CARTA bus stops and routes, which were mapped to determine the service areas for the current bus stops. The final functional requirement was to provide the client with maps that display the locations that need new bus stops. The system would provide maps and reports that support the client's decision for locating the proposed new bus stops. 
By focusing on the specific predefined ZIP codes and the locations of manufacturers, the client can make an informed decision when deciding where to locate new bus stops and deciding how to select the most efficient routes.

Table 1. Functional requirements.

\begin{tabular}{|l|l|}
\hline \multicolumn{1}{|c|}{ Requirement } & \multicolumn{1}{c|}{ Description } \\
\hline $\begin{array}{l}\text { The system will provide the } \\
\text { client with an expanded level } \\
\text { of visualization about the } \\
\text { effects of the spatial } \\
\text { separation between workplace } \\
\text { and residences. }\end{array}$ & $\begin{array}{l}\text { The client provided the callers' data, and the } \\
\text { demographic data was downloaded from } \\
\text { ACS. }\end{array}$ \\
\hline $\begin{array}{l}\text { The system will provide maps } \\
\text { and reports show the lack of } \\
\text { current bus services. }\end{array}$ & $\begin{array}{l}\text { CARTA bus stops and routes were provided } \\
\text { by the client; these will be used to examine } \\
\text { accessibility of current bus stops. }\end{array}$ \\
\hline $\begin{array}{l}\text { The system will provide maps } \\
\text { and reports to determine new } \\
\text { bus locations and their service } \\
\text { areas. }\end{array}$ & $\begin{array}{l}\text { The client desires to locate new bus stops in } \\
\text { the predefined ZIP codes and in areas of } \\
\text { specified job opportunities that are not } \\
\text { covered by CARTA bus system. }\end{array}$ \\
\hline $\begin{array}{l}\text { The system will provide the } \\
\text { client with transportation data. }\end{array}$ & $\begin{array}{l}\text { The data was imported from Esri data that } \\
\text { was used to find optimum locations for the } \\
\text { new bus stops determine their access } \\
\text { incorporate these stops. }\end{array}$ \\
\hline
\end{tabular}

\subsubsection{Non- Functional Requirements}

The non-functional requirements for this project are comprised of technical considerations based on client needs. For effective integration into the client's software, it was necessary that all hardware, software, and data in the system were compatible. This meant that the system needed to run on ArcGIS for Desktop, use computers with a Windows operating system, and required all data be in Esri format. ArcGIS for Desktop 10.1 supported the technical requirements for compiling data for the maps and reports (Table 3-2). 
Table 2. Non- functional requirements

\begin{tabular}{|l|l|}
\hline \multicolumn{1}{|c|}{ Requirement } & \multicolumn{1}{c|}{ Description } \\
\hline Hardware & PC-Intel with Windows operating system \\
\hline Software & ArcGIS for Desktop 10.1 \\
\hline Data & Esri format \\
\hline
\end{tabular}

\subsection{System Design}

The system design was determined based on the client's request and the requirements analysis. It was determined that the system would incorporate the data of 2-1-1 callers with the ACS data which could prove the geographic separation between residential areas and locations with more job opportunities. Also, the system was designed to incorporate the CARTA bus services data into a transportation network dataset. The network dataset could be used to evaluate accessibility to the CARTA bus services and examine how well these services connect callers living in the predefined ZIP codes to areas with specified job opportunities. In addition, the network dataset could be used also to propose new bus stops, create their service areas, and select new bus routes (Figure 3-1).

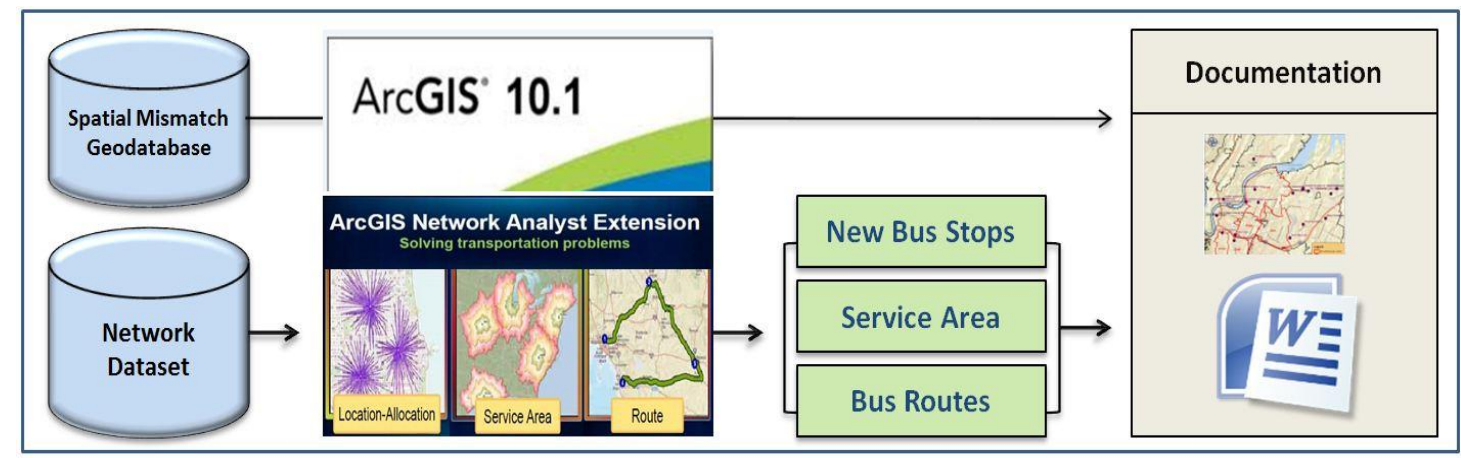

Figure 3-1: System Architecture

\subsection{Project Plan}

The project plan was designed to fulfill the client's major requirements and expectations within a given time. However, a few changes to the plan were made as the project progressed. These changes prevented the project from being completed in the given time frame. The plan was to conduct the analysis on the 2-1-1 callers who reside in the 37407 ZIP Code. Then, the plan was changed to include the 2-1-1 callers who reside in the ZIP Codes $37404,37406,37410$, and 37411 . The project plan initially consisted of six major phases (Figure 3-2). 


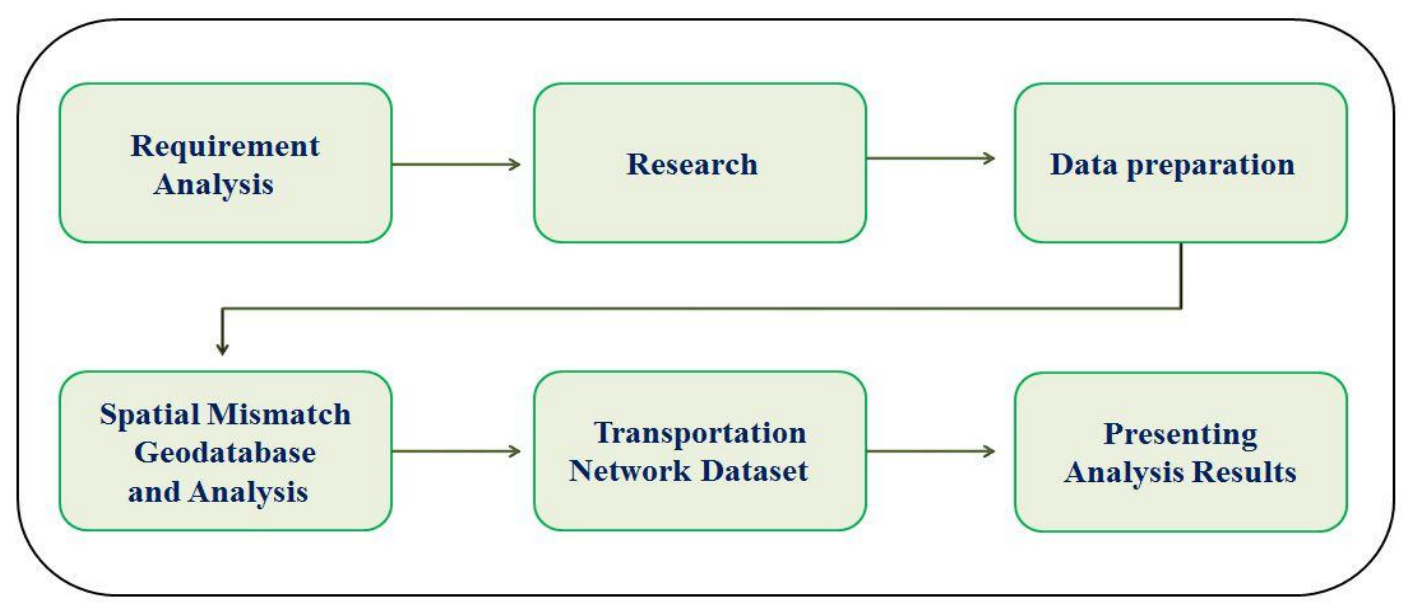

Figure 3-2: Project Plan Phases

\subsubsection{Phase 1 Requirements Analysis}

The first phase was to establish the system requirements. This process involved email and phone discussions with the client (Dr. Eileen Robertson) and the point of contact (Mr. Tomlinson Reed) to determine what functionality the system would need to achieve the desired goals.

\subsubsection{Phase 2: Research}

The second phase of the project was to conduct three types of research. First, methods for analyzing the spatial mismatched needed to be researched. This would allow the client to visualize geographic separation between people who call 2-1-1 and prospective job opportunities. Second, research for evaluating the actual access coverage areas for a bus stop was performed. Throughout the process, it was determined that the development of a network dataset would be the best way to evaluate the access coverage for the bus stops when considering the actual spatial geography obstacles and actual street network surrounding each bus stop. Third, research was performed to find guidelines and regulations for the location of bus stops to develop the criteria that were taken in account when choosing the optimum locations for the proposed new bus stops.

\subsubsection{Phase 3: Data Preparation}

The third phase involved data preparation and conversion. Preparation for spatial mismatch involved editing and converting the callers' data and demographic data for successful maps construction. Examination of the callers' data showed that some callers' attributes were not completed. This data lacked attributes essential for geocoding and were provided in three separated Excel worksheet files. The demographic data were downloaded from the ACS in CSV format and then imported into an Excel worksheet. Information about the places with high employment opportunities was provided by the client and the data was compiled from Manta website. The data was organized in an Excel worksheet and the essential attributes fields for geocoding were added. The 
transportation data was gathered from two sources. The client provided the CARTA bus services. The bus stops were in texts files, and bus routes were in Esri shapefile format.

The street shapefile was imported from Esri data that was provided by the University of Redlands MS GIS program. All data was projected in NAD 1983 State Plane Tennessee FIPS 4100 Feet. Data preparation and conversion were conducted to clean up the source data and import it into an ArcGIS environment. Detailed information about data preparation was provided in Chapter 4.

\subsubsection{Phase 4: Spatial Mismatch Geodatabase and Analysis}

Once the data was cleaned up and prepared, the spatial mismatch file geodatabase was built. The geodatabase was built in an Esri file geodatabase and it contains the base level data. The data was stored in several datasets, such as callers' dataset, demographic dataset, census levels' dataset, and boundaries dataset. All layers in this geodatabase were used to analyze the impact of the spatial mismatch. Another geodatabase was built. This contains the CARTA bus stops and routes that were provided by the client. The data was used to evaluate the accessibility to the current bus stops and examine how well CARTA bus services provide the callers with access to locations with more job opportunities.

\subsubsection{Phase 5: Transportation Network Dataset}

The fifth phase in the project was to build the transportation network dataset. The Chattanooga Network Dataset was built using the Streets feature class as the network feature source. The Network Analyst Extension in ArcGIS 10.1 was used to perform three types of analysis; the Service Area, Location-Allocation, and Route Solvers. The Service Area Solver was used to evaluate the accessibility to the current bus stops and examine how well CARTA bus services provide the callers with access to locations with more job opportunities. Also, it was used to create the service areas for the proposed bus stops. The Location-Allocation Solver was used to find the optimum locations for the proposed new bus stops in the predefined ZIP codes and around the defined manufacturers and enterprises. The Route Solver was used to select the optimal routes that incorporate the new bus stops. Additional transportation network dataset was built to use the street junctions. The Streets and/or roads with speed limit of 30, 35, $40 \mathrm{mph}$, which is considered suitable for bus routes, were used as network feature source.

\subsubsection{Phase 6: Presenting Analysis Results}

The sixth phase was to present the analysis results: the analysis of spatial mismatch, current bus stops evaluation, proposed locations for new bus stops, and suggestions for new routes. All results were displayed as layers in ArcMap 10.1; a project reports and a poster of the results were also created to explain the project procedures and illustrate the analysis results. To ensure that the development process could be replicated, and to provide complete and detailed metadata, all methodologies and analysis were documented during the project. The purpose of this documentation is to allow the client to make updates as needed and to ensure that all data was used correctly and that all limitations were recognized. Training is not required because the client has experience using ArcGIS. 


\subsection{Summary}

The client was looking for a GIS solution that would decrease the dependencies on the BSL program's social services by finding jobs for 2-1-1 callers. The developed system included recommended maps and reports as well as the network dataset that was created with provided CARTA bus services data and Esri data. This system is compatible with the client's technical infrastructure. As a result, the system can be fully integrated into the client's computing environment and will be ready for staff use once it is implemented. 


\section{Chapter 4 - Database Design}

An important part of this project is the database, which exists in an Esri ArcGIS file geodatabase format. The geodatabase contains the variety of data needed for the project. The following were imperative while designing the geodatabase: the conceptual data model, the logical data model, the data sources, the data collection methods, and the data scrubbing, loading, and data preparation.

\subsection{Conceptual Data Model}

To ensure system functionality, the conceptual data model describes the data and its attributes needed. The system needed to incorporate all required data, which included demographic data, locations with more job opportunities, bus stops, bus routes, and streets. The conceptual model presented in this project provides the structure and association of related entities involved in this project (Figure 4-1). There are six entities: 2-1-1 callers (people), Origin Bus Stop, Streets, Route, Destination Bus Stop, and Job Opportunity Locations. Conceptually, 2-1-1 callers would walk about 1,300 feet to an origin bus stop to ride a bus. The bus driver drives the bus through streets that assigned to be bus routes. The bus stopped at the destination bus stop and the 2-1-1 callers would walk 600 feet from the destination bus stop to get to the locations of more job opportunities. Callers associate with the origin bus stop by "Walk 1,300 feet" relationship, as one or more 2-1-1 callers who fall in service area of that bus stop and walk to one bus stop. The bus stops and street have a many-to-many relationship because many bus stops could be located on one street or more. The street and route have a manyto-one relationship because one street or more have one route. The destination bus stop and location with potential jobs have a one-to-many relationship because on bus stop could serve one location with potential jobs or more. 


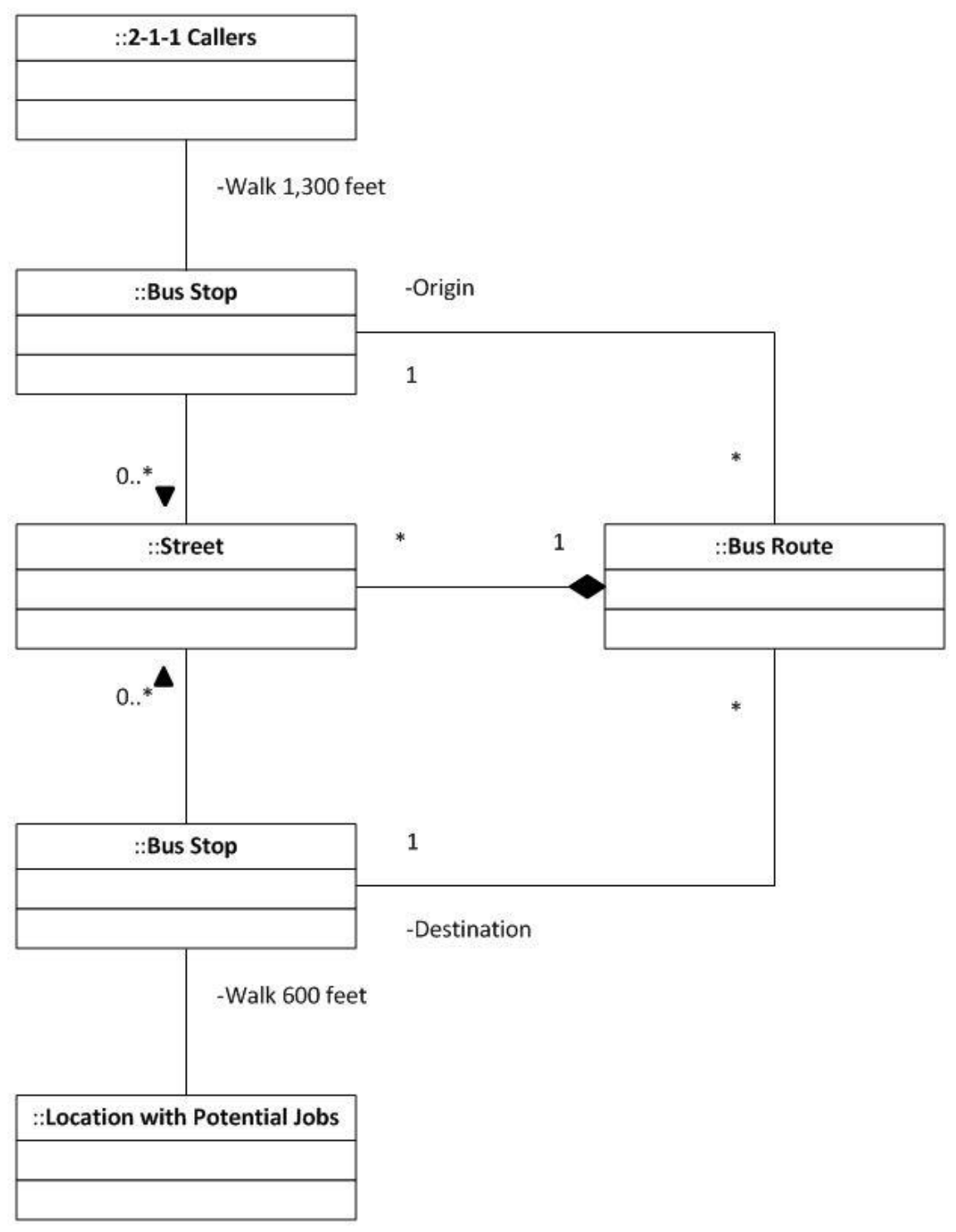

Figure 4-1: Satisfactory Route Conceptual Data Model

\subsection{Logical Data Model}

The logical data model provides the basic system implementation and was constructed once the conceptual data model was developed. An Esri file geodatabase that could be integrated into the client's computing environment was chosen to host all the data. The logical data model in this project is described in two parts: Demographic Geodatabase Logical Model and Transportation Geodatabase Logical Model. 


\subsubsection{Demographic Geodatabase Logical Model}

The demographic logical data model was constructed to contain the demographic information by census tract including employment status, educational attainment level, and poverty (Figure 4-2).

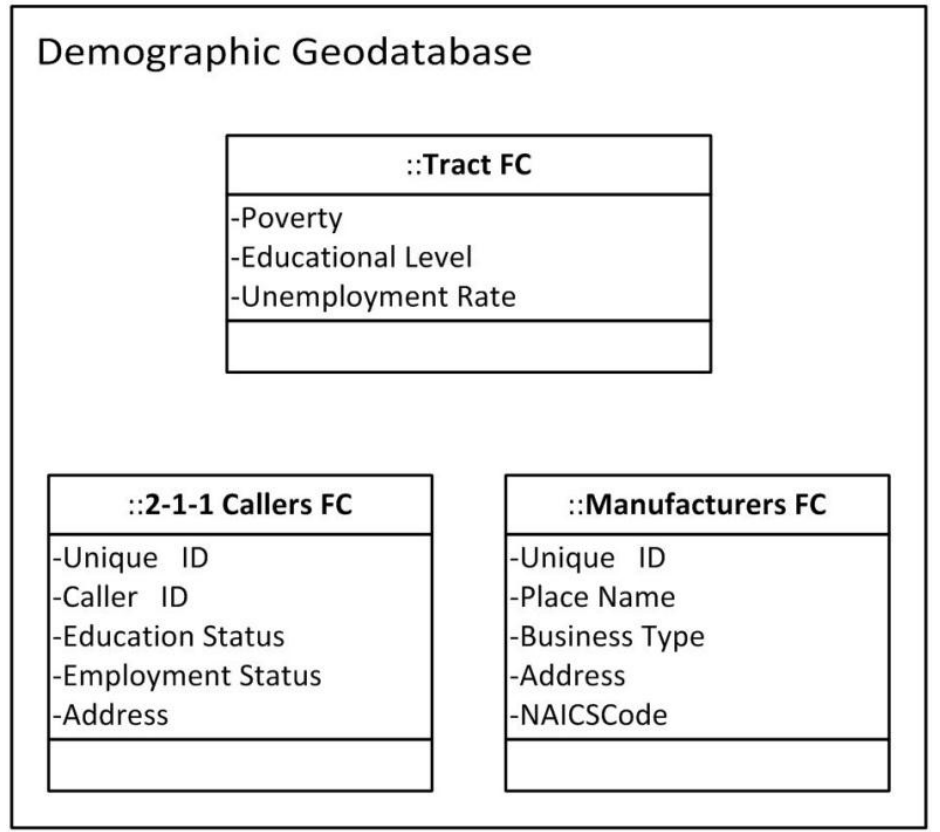

Figure 4-2: Demographic Geodatabase Logical Model

In order to develop feature class that could be integrated into the client's computing environment, a geodatabase was developed with a feature dataset. The data were downloaded from ACS in A comma-separated values (CSV) format and then exported into an Excel worksheet. The Excel worksheet was joined to the tract feature class using the GeoID key attribute in the ACS table and tract feature class. The data then was exported into feature class and stored in a file geodatabase. This process was used to create the Poverty, Employment, and Education Level feature classes. The 2-1-1 callers' data were provided by the client in an Excel worksheet. After extensive preparation, the Excel worksheet was added to ArcGIS and geocoded using ArcGIS Online geocoding service. The Callers shapefile was projected in NAD_1983_StatePlane_Tennessee_FIPS_4100_Feet Coordinate System, exported into the file geodatabase, and stored as a point feature class. The manufacturers' information were collected and stored in an Excel worksheet. The same process used with Callers feature class was applied to Manufacturers feature class. 


\subsubsection{Transportation Geodatabase Logical Model}

The transportation logical data model (Figure 4-3) includes two kinds of data: the CARTA bus stops and routes, and the network dataset.

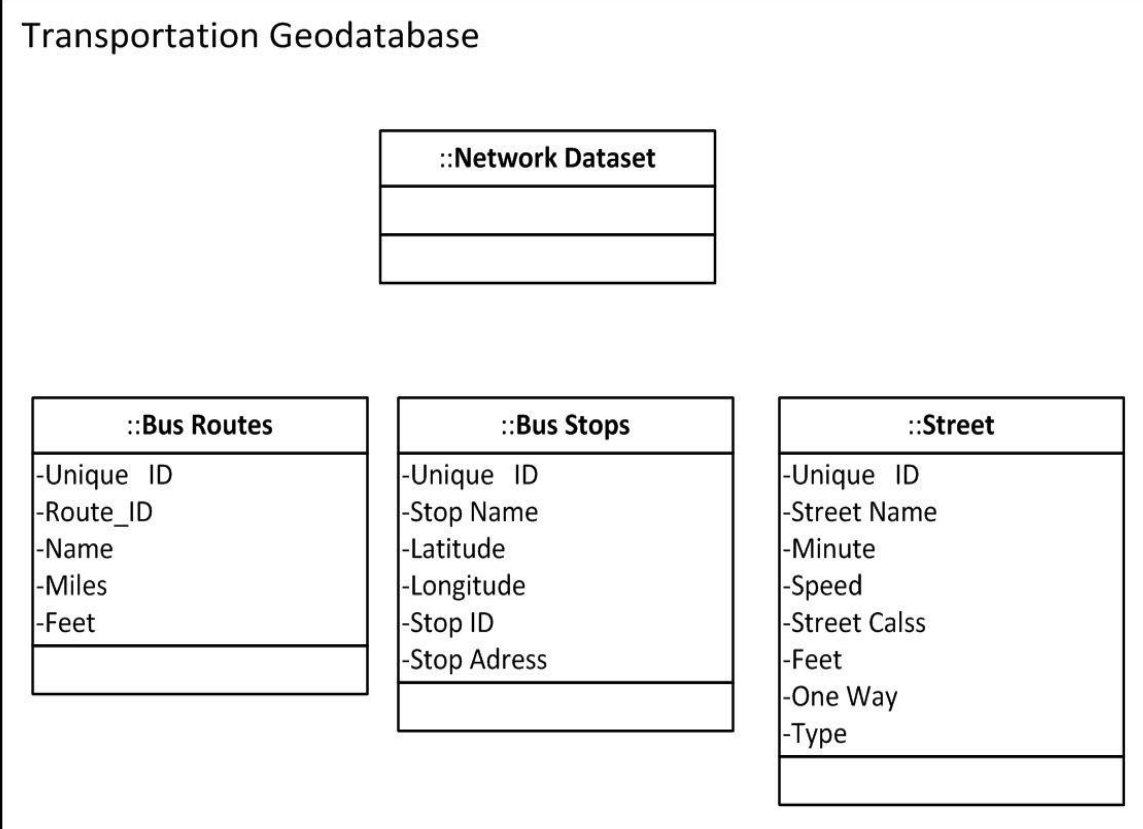

Figure 4-3: Transportation Geodatabase Logical Model

The client provided the CARTA bus stops in a text file and the routes in shapefile format. The bus text file was converted and organized into an Excel worksheet. The Excel worksheet was added to ArcMap and converted into a XY Event table in the North America NAD 1983 Geographic Coordinate System. Then, the table was exported into a shapefile and then projected into the NAD_1983_StatePlane_Tennessee_FIPS_4100_Feet Coordinate System. The shape file was exported and stored in the geodatabase as a point feature class. The routes were also projected in NAD_1983_StatePlane_Tennessee_FIPS_4100_Feet Coordinate System, exported, and stored in the geodatabase as a linear feature class. Second, the Network Dataset was built in order to use the Network Analyst solvers. The Street feature class was extracted from Esri data and it was used as source feature to build the Network Dataset. Once the Network Dataset was built, the Network Analyst solvers; Service Area, Location-Allocation, and Route solvers were used to conduct the analysis. The Service Area solver was used to evaluate the accessibility of the current bus stops, examine the efficiency of the CARTA bus services, and create service areas for the new bus stops. The Location-Allocation solver was used to find the optimum locations for the proposed bus stops. The Route solver was used to select the optimal routes to incorporate the proposed bus stops. 


\subsection{Data Sources}

The data for this project was obtained from several sources. The administrative census boundaries; County, ZIP Code, Census Tract, and Blocks polygon feature class; and Street line feature class were exported from Esri 2011 data into the file geodatabases that were used in this project. These dataset were released in December 2011. The University of Redlands MS GIS program provided access to the Esri data. All data are in the NAD_1983_StatePlane_Tennessee_FIPS_4100_Feetcoordinate system.

The client provided data about the 2-1-1 callers in 2009, 2010, and 2011 in Microsoft Excel worksheets. The client also provided data about the CARTA bus stops in text files, and the CARTA bus routes in a shapefile format. Moreover, the client defined some major manufacturers and enterprises that would be desired by the 2-1-1 callers.

The demographic data in this project (data from 2006-2010) was downloaded from the Census Bureau's American Community Survey (ACS) website. Also, the data about employment status, educational attainment level, and poverty level was downloaded from Census Bureau's American Fact Finder (http://www.census.gov/\#). ACS demographic data is widely used and it produces population, demographic and housing unit estimates for the nation, states, counties, cities, and towns.

\subsection{Data Collection Methods}

Only the manufacturers point feature class was collected in this project. The client specified a few names of the major manufacturers and enterprises that have more job opportunities, such as Amazon and Volkswagen. A more in-depth research about economic growth in the city was then conducted. With the client's agreement, the research came up with other names of the top manufacturers and enterprises in the city. The name, address, and the attributes about these manufacturers and enterprises were downloaded from Manta's website http://www.manta.com/mb_51_ALL_JQ5/chattanooga_tn. Manta Inc. is the largest online community dedicated to small business and helps them profit, connect, and grow.

\subsection{Data Scrubbing and Loading}

Since the data for this project was obtained from several sources, each source was scrubbing and loading in different ways.

\subsubsection{Esri Data}

Esri dataset was released in December 2011 and access to this data was provided by the University of Redlands MS GIS program. The administrative census boundaries and street network feature class were exported from Esri data into the file geodatabase (.gdb). The administrative census boundaries of counties, ZIP codes, tracts, block groups, and blocks were extracted for Hamilton County and Chattanooga City.

The Select By Attribute tool was used to extract Hamilton County from the Counties feature class and extract Chattanooga City from Cities feature class. The Select By Location tool was used to select form ZIP Codes, Tracts, Block Groups, and Blocks features classes that intersect with the Chattanooga city boundaries. Because city 
boundaries are not coincident in ZIP Code feature classes, there are a few ZIP codes that share boundaries with other cities. For example, Red Bank, Ridge side, and East Ridge (inner cities) are located within Chattanooga city boundary, and they share ZIP codes. Because the client wanted to study Chattanooga specifically, the Census Tract, Census Block Groups, and Blocks feature classes that are located in the inner cities were removed through the editing session in ArcMap. Therefore, there are a few empty boundaries inside Chattanooga when using tracts, block groups, or blocks feature classes.

The Select tool was used to extract Street feature class along and around Chattanooga City and inner cities to insure street network connectivity when creating the network dataset.

\subsubsection{Client Data}

The client provided three types of data formats; Shapefile, Text, and Excel format. The CARTA bus routes were provided in shapefile format. This data was projected in NAD_1983_StatePlane_Tennessee_FIPS_4100_Feet Coordinate System. It was exported into the file geodatabase and stored as a line feature class.

The CARTA bus stops data was provided in a zipped file that contained several files in text format. The text file contains several attributes of the current 1,304 bus stops. The data was converted and organized into an excel worksheet so that they could be readable by ArcMap 10.1. The Excel worksheet was added to ArcMap, converted into a XY Event Source, and given the North America NAD 1983 Geographic Coordinate System using the Display XY Data tool. Then, the table was exported into a shapefile. Because the shapefile had the GCS_North_American_1983 Geographic Coordinate System, the shape file was then projected into NAD_1983_StatePlane_Tennessee_FIPS_4100_Feet Coordinate System.

The data about 2-1-1 callers was provided in three Excel files for the years 2009, 2010, and 2011. All files were reviewed and refined with the client because there were few incomplete records. The data included the following attributes about 2-1-1 callers: ClientUid, Education, Employment Status, YearID, Address, and Age. The Address attribute was copied to another column so that it could be parsed into three attributes: ZIP Code, City, and State. The purpose of parsing this field is to make it readable by ArcMap during the geocoding process. The three Excel files were then compiled into one Excel worksheet. The new worksheet was geocoded using ArcGIS10.1 Online geocoding to create the Callers point feature class. The Education attribute for 2-1-1 callers was then classified into four classes by adding a Subtype in ArcMap. These classes are Less High School, High School, Some College, and Bachelor and above; the percentage for each class was calculated. Likewise, the Employment Status Attribute for 2-1-1 callers was classified into the following classes: Employed Full Time, Employed part time, and Unemployed; the percentage was calculated for each class. The Education and Employment Status attributes were classified for analysis purpose, as described in Chapter 5.

\subsubsection{American Community Survey (ACS) Data}

American Community Survey (ACS) data was downloaded from Census Bureau's American Fact Finder (http://www.census.gov/\#). The data was downloaded in CSV files 
format and then it was merged into a single Excel worksheet. After cleaning up the data, attributes should not have punctuation marks otherwise the Join function would not be able to read it. The Join function (in ArcMap10.1) was used to join these tables to the tract level. People living in poverty tend to be clustered in certain neighborhoods rather than being evenly distributed across geographic areas. Employment attributes provide information important to economic planners and policy makers; it allows them to evaluate local workforce characteristics. The education attributes convey the educational attainment of a local workforce and can give policy makers insight on how a specialized industry can be sustained in the future. The poverty attributes show the distribution of families below the poverty line.

\subsubsection{Locations with Specified Job Opportunities}

The manufacturer's data was collected and stored in an Excel worksheet, and then it was geocoded using ArcGIS Online geocoding and projected into the correct coordinate system. The data included attributes, such as Company Name, NAICS Code, Business Type, Address, ZIP Code, City, and State. After geocoding the manufacturer locations, the manufacturers feature class was exported into KML format and displayed on Google Earth to ensure that they were located correctly to their locations. The data was then stored in the Chattanooga File Geodatabase.

\subsection{Data Preparation}

Since the Network Analyst Extension, ArcGIS 10.1 was used to build Chattanooga Network Dataset, some preparation were made. Street feature class was used as the main source feature class to build Chattanooga Network Dataset. The Chattanooga Network Dataset was to perform network analyses in ArcMap 10.1 using the Network Analyst Solvers; Service Area Solver, Location Allocation Solver, and Route Solver to street network. An additional Network Dataset was built to use the street and/or road locations as candidate locations when choosing the optimum locations for the new bus stops.

\subsubsection{Street Feature Class}

The street data came with a number of attributes to describe the street names and a number of additional attributes were necessary for building network dataset. In addition, the street has the necessary attributes including Feet, Mile, Hours, Minutes, One-way, Speed_MPH, F_ZLEV, T_ZLEV that needed to build the network dataset. All attributes were already calculated by the data source; Esri. The needed attributes including Feet, Mile, Hours, Minutes was checked by using the Calculate Geometry tool.

The Feet attribute was recalculated using the Calculate Geometry tool to insure the accuracy when using this attribute to examine the accessibility to the current bus stop and determine the areas that are not served by the CARTA bus services. Moreover, this attribute was used to determine the access coverage of the current and proposed bus stops and to specify the impedance cutoff to locating the optimum locations for the proposed bus stops.

The Mile, Hours, and Minutes attributes in addition to the Speed_MPH attribute were used when using Route Solver to determine the distance and time of the new routes. 
The Oneway attribute was used to determine directionality for streets that have one-way driving restrictions. This is essential to prevent routing along prohibited streets. The Speed_MPH attribute described the speed (in miles per hour) for every line segment. These speeds were already calculated by Esri and were checked by examining CFCC codes. This attribute was used to determine the street and/or roads with speed limit of 30, 35 , and $40 \mathrm{mph}$ that assigned for bus routes. Street Class attribute was created to classify the streets by creating subtypes (Figure 4-4).

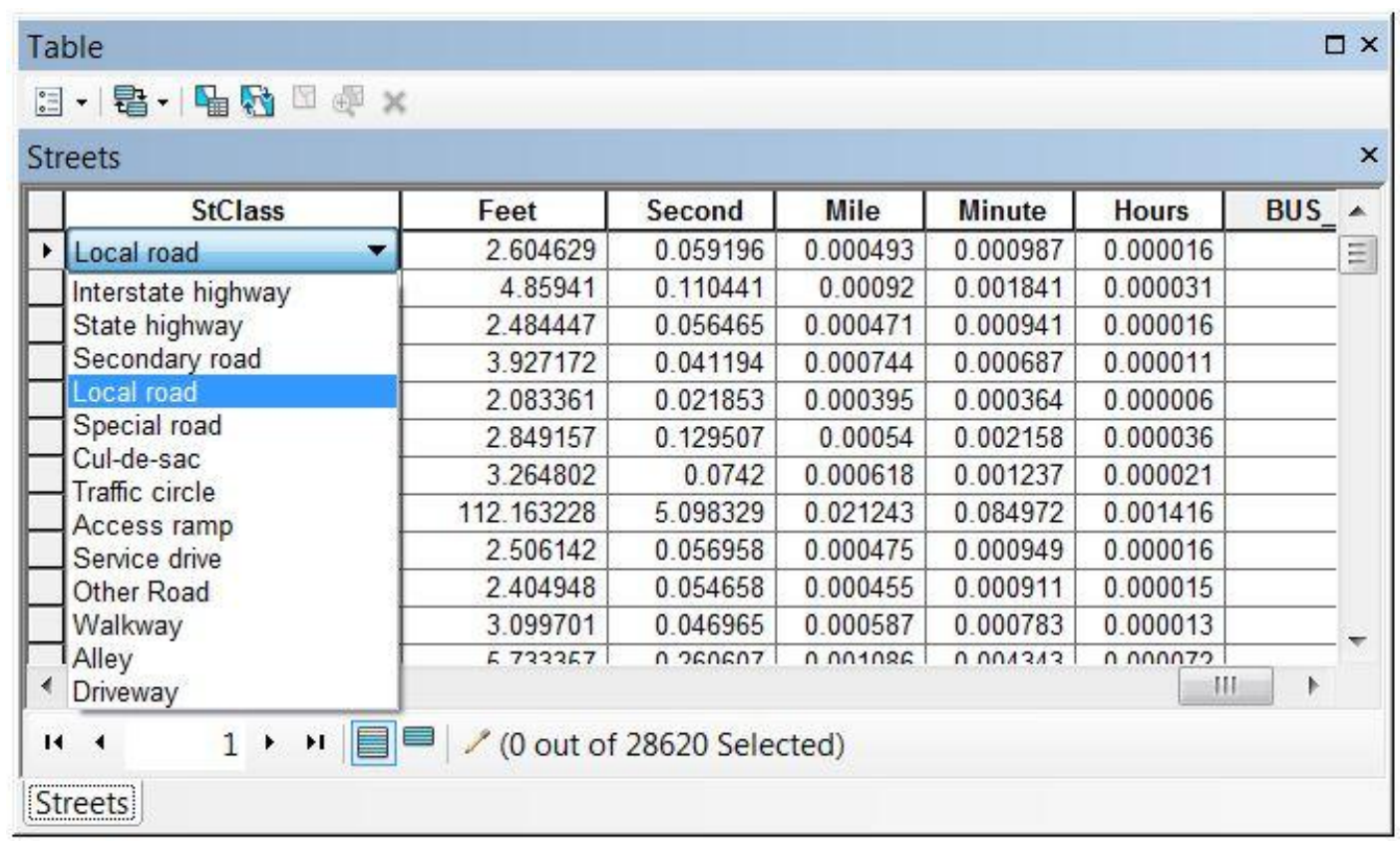

\section{Figure 4-4: Street Subtypes}

Based on CFCC codes attribute in the street feature and based on, TIGER/Line File Census Feature Class Codes (CFCC) website http://proximityone.com/tgrcfcc.htm, the street was classified into 13 subtypes. Street Class contains codes that stores features into categories such as local road and secondary roads and it is useful for formatting directions or refining global turn penalties when building the network dataset. It was created to use junctions of the street and/or roads that are assigned for bus route with speed limit of 30,35, or $40 \mathrm{mph}$ when locating the new bus stops. The last two attributes added were F_ZLEV and T_ZLEV. These attribute corresponded with the endpoints of each feature, and were used to ensure accurate connectivity between road segments. Thus, if there were connectivity between road segments, the elevation values would be the same for the shared endpoints. However, if there were no connectivity between road segments, such as in the case of overpasses, elevation values for the common endpoint would be different. 


\subsubsection{Network Dataset}

Using ArcCatalog 10.1, the network dataset was built and parameters for properties of the network for the network dataset were set in each panel in the wizard. The network Dataset named Chattanooga_Dataset_ND was built to perform network analyses using the Network Analyst Solvers. The street feature class participated in the Chattanooga Network_Dataset_ND as network source (Figure 4-5).

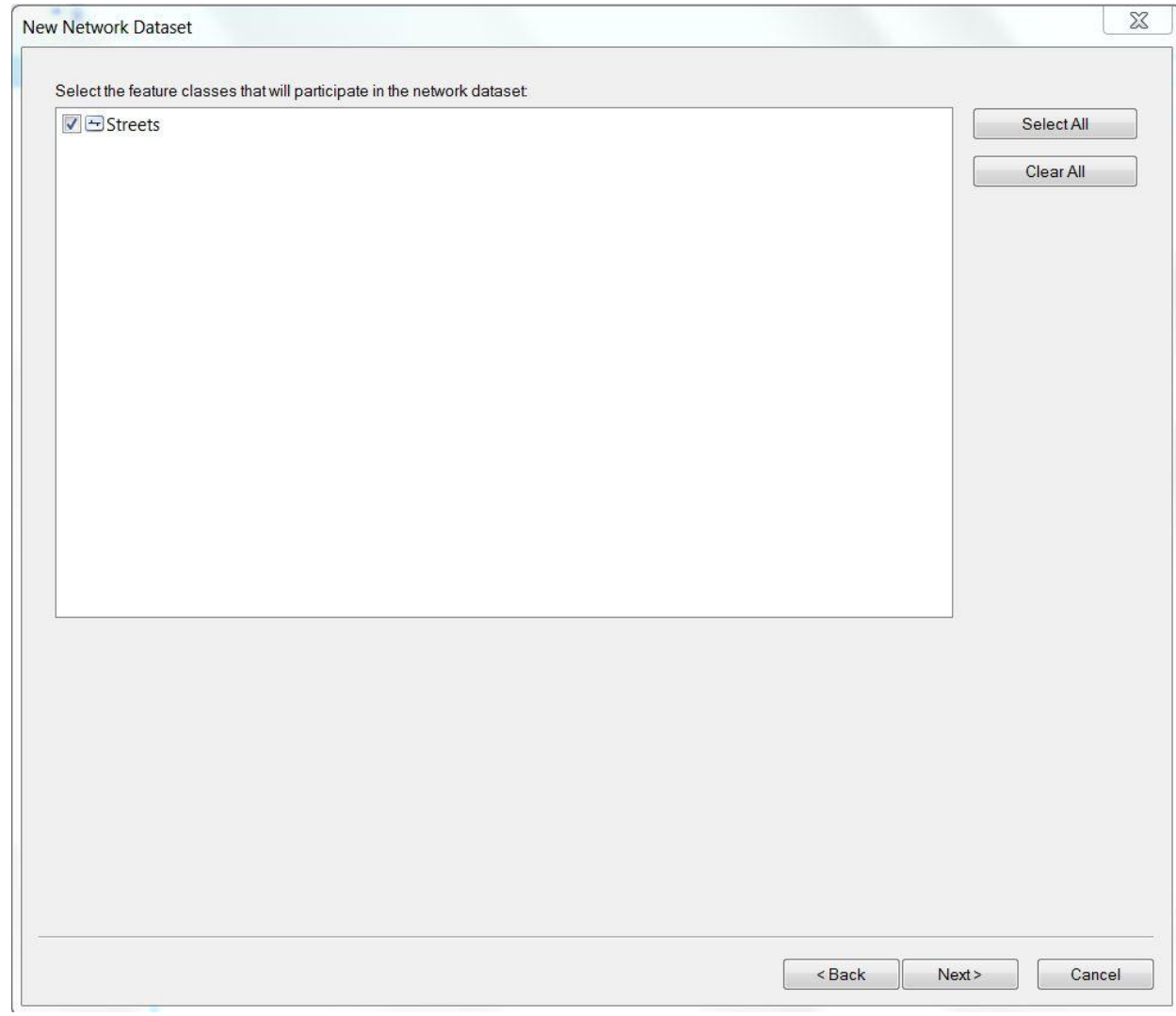

Figure 4-5: Network Dataset Source

The connectivity for Chattanooga Dataset ND was set. Network connectivity defines how line and point features connect to each other within the network (Figure 4-6). The connectivity for Chattanooga Dataset ND was set. Network connectivity defines how line and point features connect to each other within the network. 


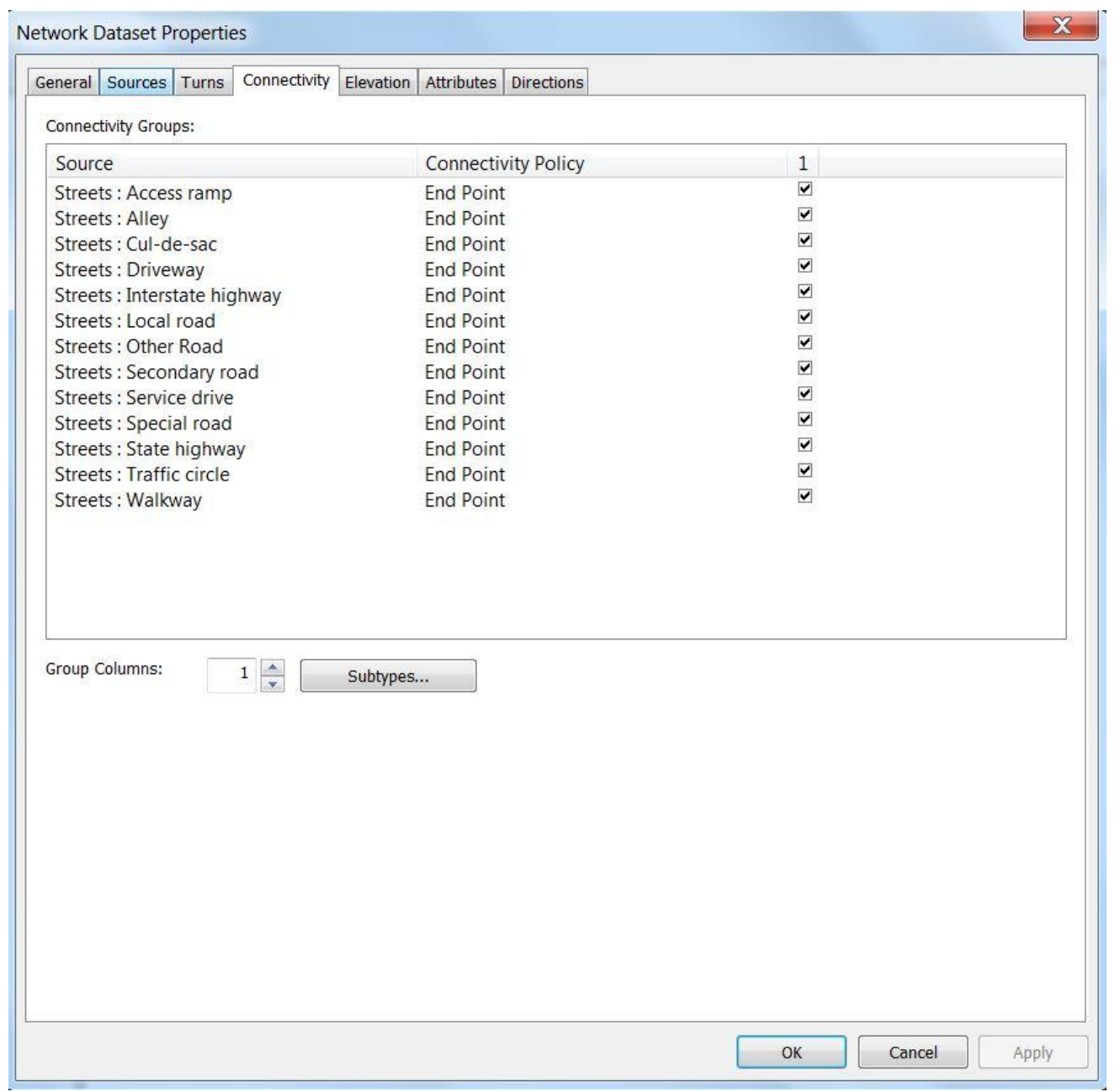

\section{Figure 4-6: Network Dataset Connectivity}

The network connectivity was defined for the street (network source feature) and its connectivity was set. The Street subtypes were used to specify the connectivity policies. Although all subtypes participate in connectivity group1, a different connectivity policy can be applied to each subtype (13 subtypes). For example, Local road was set Any Vertex policy. By doing this, all of the features in the local road subtype would be enabled to connect to each other in the network at any coincident vertex. Conversely, features in the other subtypes would only connect to each other at coincident endpoints.

Choosing any vertex policy means that local road may cross each other and none of them participate in overpass/underpass situations at intersecting intermediate vertices. Network dataset attributes was defined for Chattanooga Network ND (Figure 4-7). 


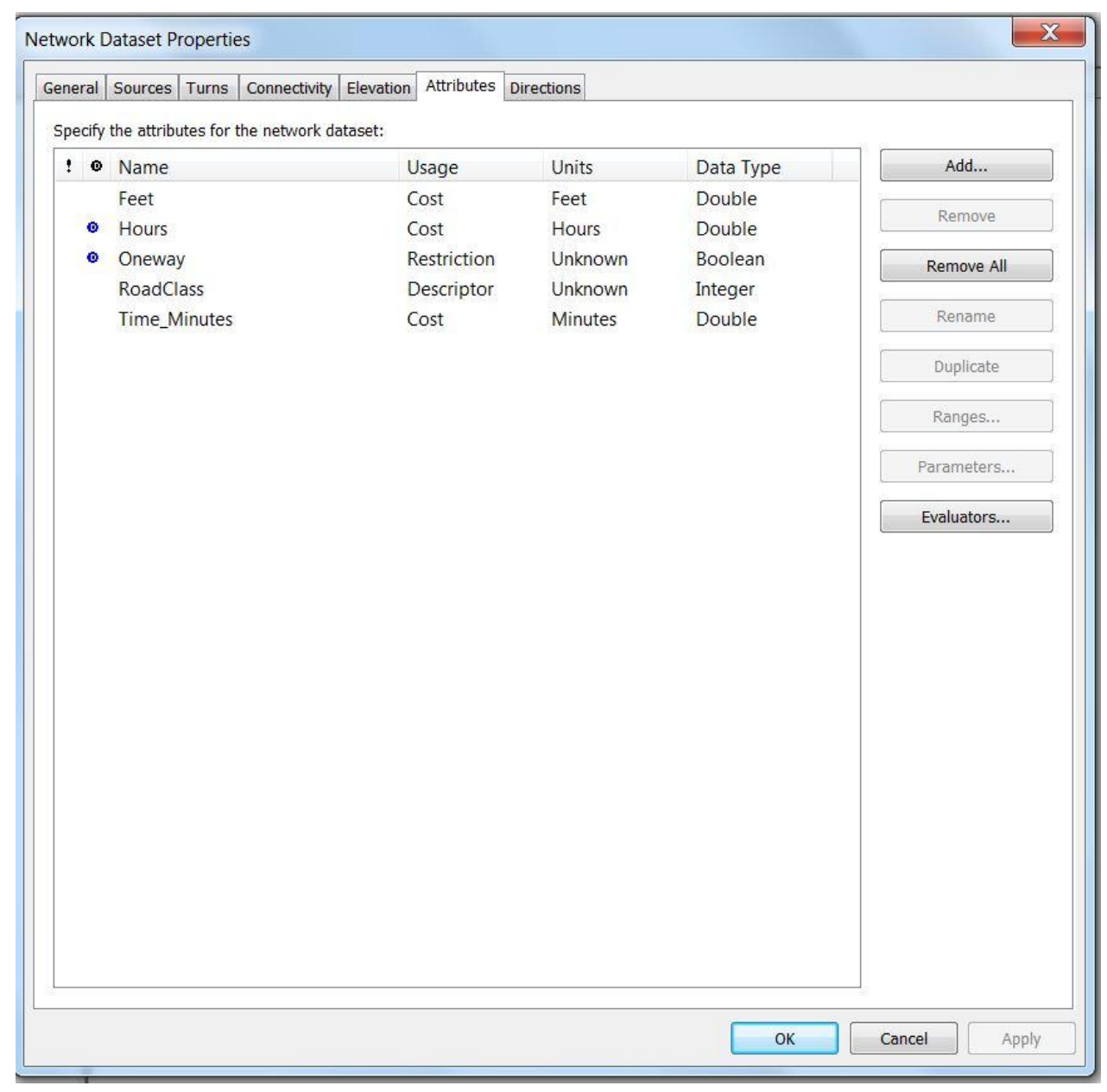

Figure 4-7: Network Dataset Attributes

Network dataset attributes were defined for Chattanooga Network ND. Network dataset attributes are properties associated with network elements; edges, junctions, and turns. These attributes can be used to help control navigation through the network. The Feet and Hour cost attributes were created when preparing the street feature class.

Time_Minutes cost attribute was created using Add and Evaluators tabs (Figure 4-8). 


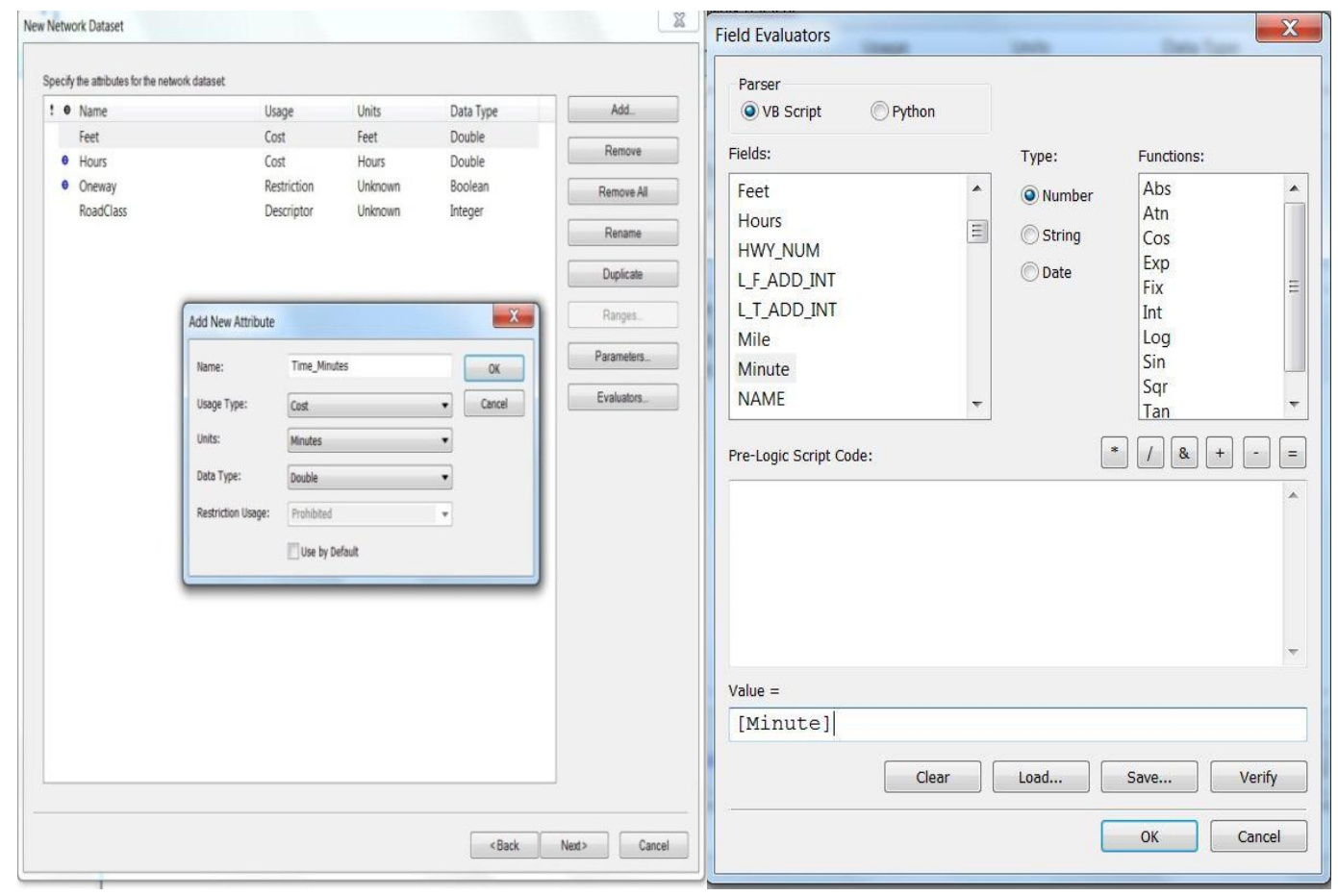

Figure 4-8: Time Minutes Cost Attribute

The Evaluator Function determines the value of Time_Minutes attribute for the street feature class; the network dataset source feature. The use of these attributes was described in street preparation (section 4.6.1). The Oneway restriction attribute was set for Chattanooga Network Dataset (Figure 4-9). 


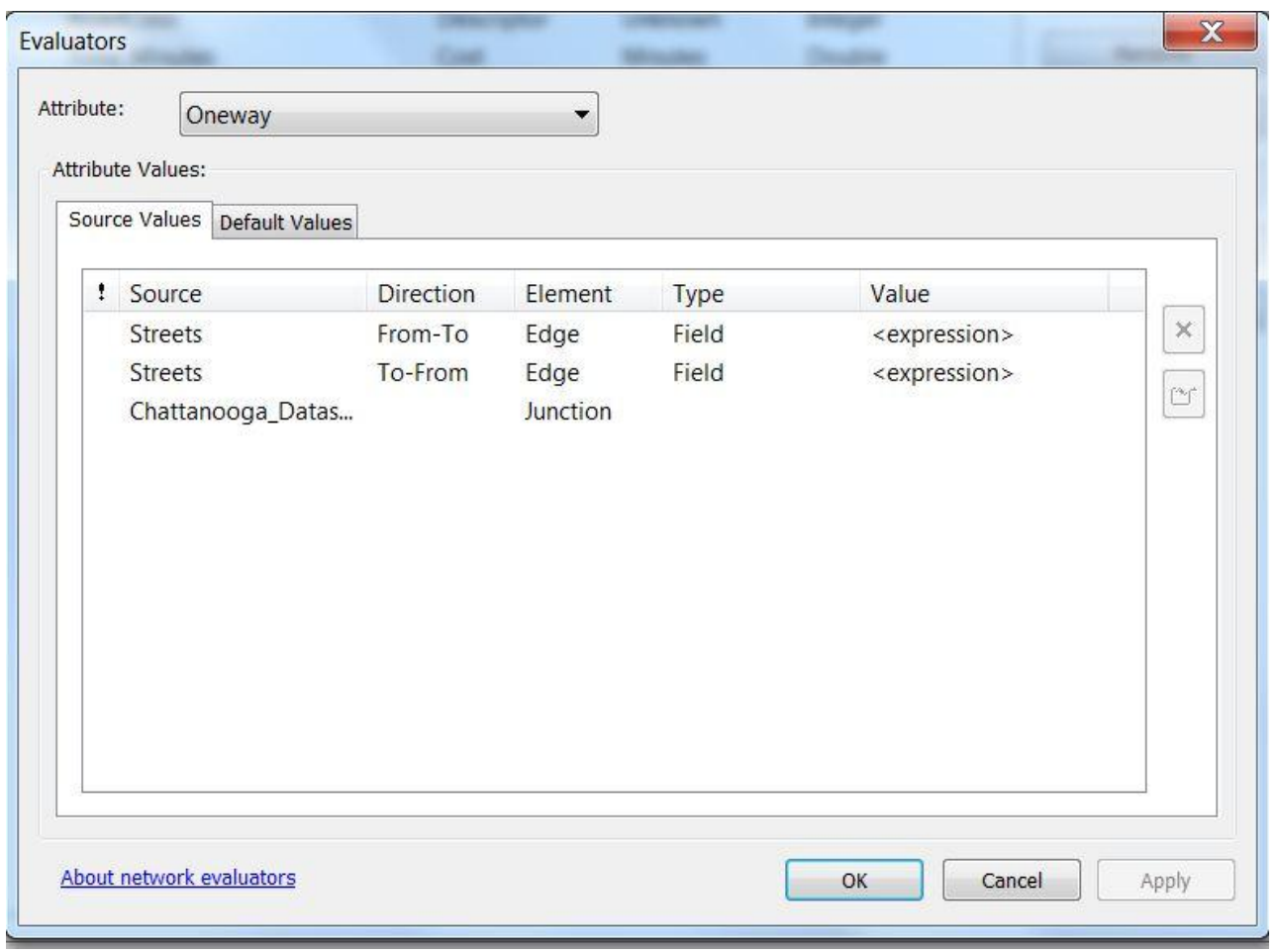

Figure 4-9: Oneway Restriction Attribute

The street feature class is listed tow times because it contains line features which become edge element, and edges have different attributes values for each direction. The Oneway restriction attribute exists in the attribute filed table for the street feature class. The field contains several commonly used edge directional values: To-From and FromTo Some VB Script was loaded by the Evaluator function and applied to some streets' Oneway attribute field (Figure 4-10). 


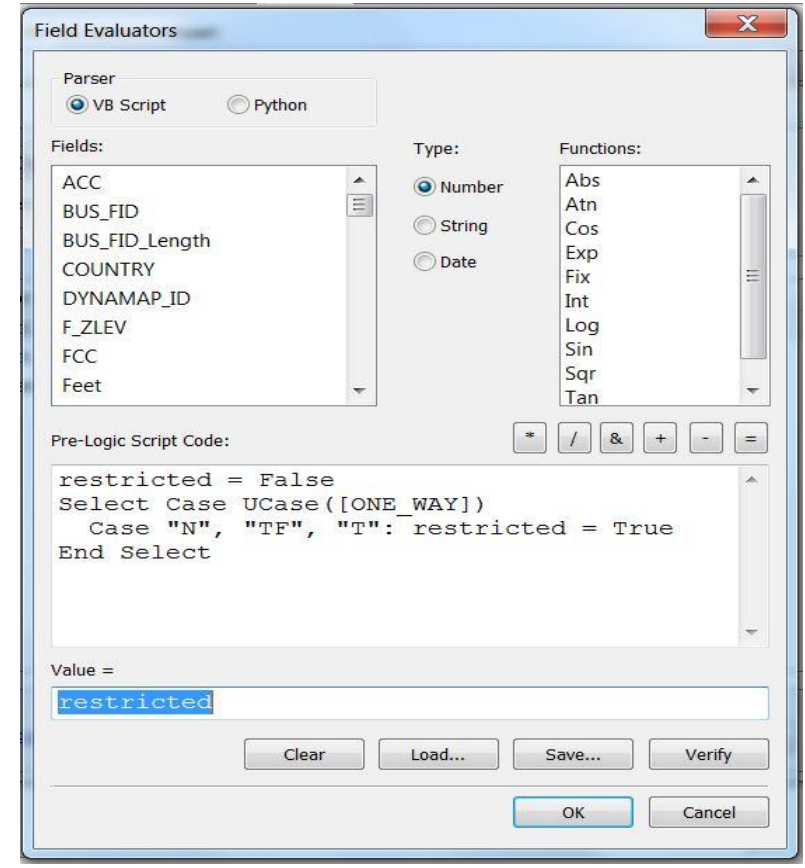

Figure 4-10: Oneway Evaluator

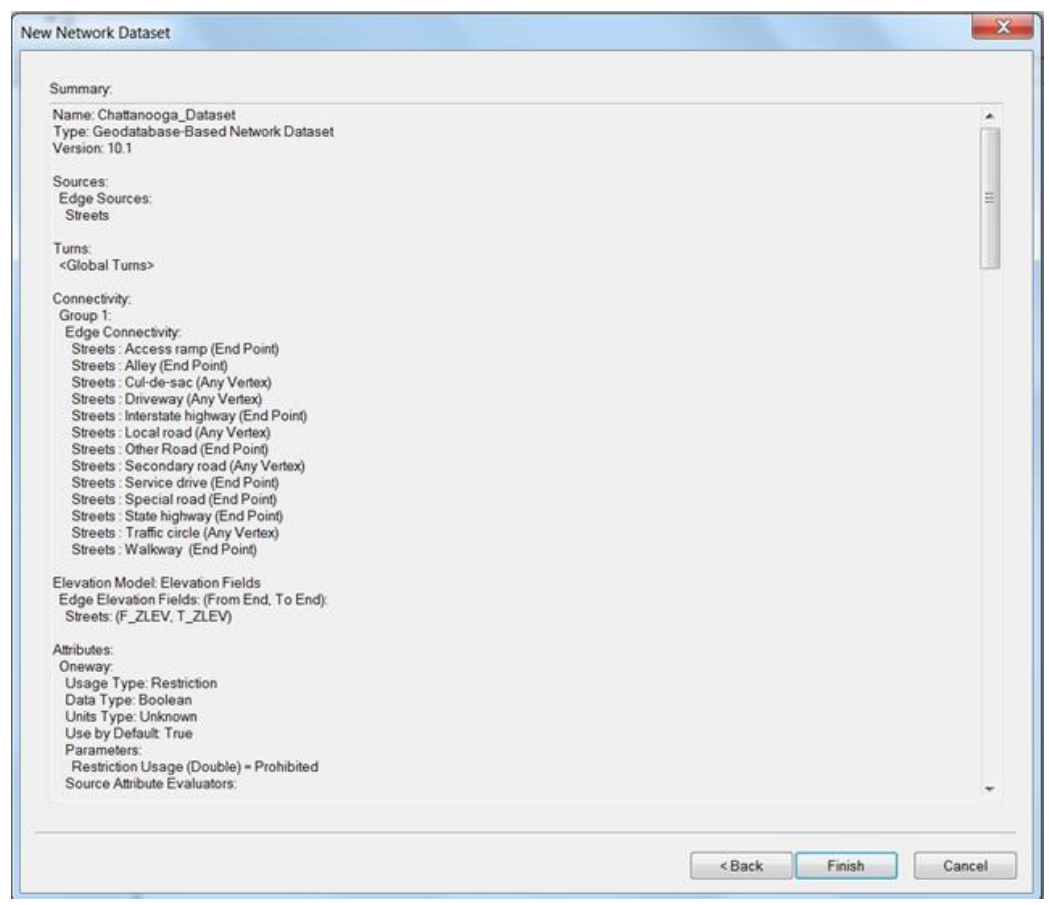

Figure 5-11: Chattanooga Network Dataset Summary 


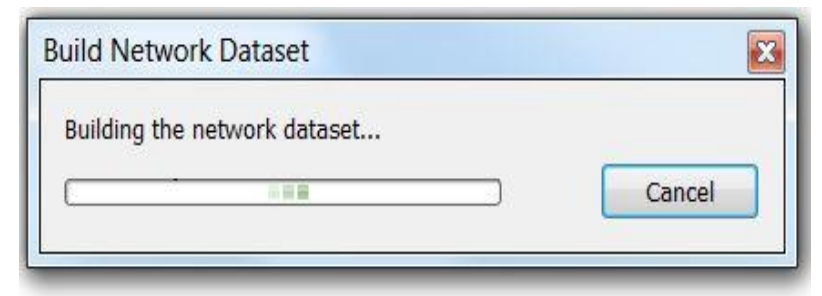

Figure 5-12: Progress Window

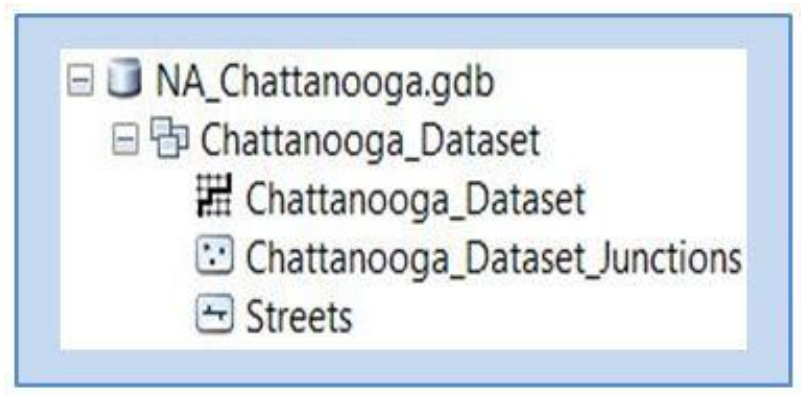

Figure 5-13: Chattanooga Network Dataset

\subsubsection{Additional Network Dataset}

An additional Network Dataset was built use junctions of the street and/or road that suit for bus routes with speed limit of 30,35 , and $40 \mathrm{mph}$. This would help to choose the optimum locations for the proposed new bus stops street and/or road that fit to be bus routes when using Location Allocation. By this, streets/roads like drive way, interstate highway, cul-de-sac, or access ramp would be avoided in the analysis and thus not to propose a bus stop on these roads.

\subsection{Summary}

In this chapter, the database's conceptual and logical models were described The conceptual data model describes the data and the attributes needed to ensure system functionality. The logical data model provides the basic system implementation, and it was developed once the conceptual data model was established. Data sources, collection, and methods are also discussed in this chapter. Different data scrubbing and loading from several data source was explained. In the chapter's first section, the conceptual model is explored using UML diagrams to show the relationships the database will accommodate. The second section explains the attributes used in the GIS to maintain the relationships identified in the conceptual model. The third section outlines what the GIS' data sources are and how the data was collected. The forth section of the chapter discusses how the data was transformed for successful ingestion into the GIS. The final section described 
data preparation and building Chattanooga Network Dataset. Additional dataset was also described in this chapter. 


\section{Chapter 5 - Implementation}

This chapter focuses on the analysis methods used in this project. Several ArcGIS tools were used to analyze the effects of spatial mismatch, measure and evaluate the actual service coverage for the current bus stops, find the optimum locations for new bus stops, and select the optimal routes. As detailed in the functional requirements, it was necessary to provide the client with recommended maps and reports that would enable decisionmakers to find the optimum locations for new bus stops in the predefined ZIP codes and around the locations with more job opportunities.

\subsection{Spatial Mismatch}

Different methods were used to analyze the effects of spatial mismatch on 2-1-1 callers living in the predefined ZIP codes. Spatial mismatch was analyzed through demographic information for 2-1-1 callers from 2009 to 2011, and census tracts from 2006 to 2010. First, the distribution of 2-1-1 callers among the city was examined with a focus on the predefined ZIP codes. Second, whether Chattanooga city has neighborhoods of concentrated poverty and whether these callers fall in concentrated poverty were investigated. Third, census tract employment status from 2006 to 2010 was compared with 2-1-1 callers' employment status. Forth, the percentage of over 25 year old with education level of high school or less was studied and compared with the callers' educational level. Based on the census demographic data, whether there is a relationship between employment status and education status for people who lived in the predefined ZIP codes was also examined. Finally, the 2-1-1 callers' accessibility to the CARTA bus services and whether they can be connected with major employer through public transit were revealed. The analysis results are detailed in Chapter 6.

\subsection{Network Analyst Solvers}

Using the Network Analyst Extension in ArcGIS 10.1, the Chattanooga Network Dataset was built as discussed in Chapter 4. Network Analyst provides various functional solvers to conduct analyses based on street network, including finding optimal solutions for site selection, creating service areas, and determining optimal routes. Each Network Analyst solver has a network analysis layer, which is a composite layer made of sublayers to store input, parameters, and results of the corresponding network analysis. The solvers were used in this project to create the actual service areas of the bus stops, find the optimum locations for new bus stops, and select the optimal bus routes.

\subsubsection{Service Area Solver}

The Service Area solver was used to create the service areas of the proposed new bus stops in the predefined ZIP codes and in central business districts. The service areas of the bus stops were created based on travel along the street network paths, not just straight-line distances. The service area of a bus stop encompasses all accessible streets that are within a specified travel distance. For this project, the service areas of the proposed bus stops were created based on the typical walking distance threshold of 1,300 feet in urban areas and 600 feet in central business districts. 
Figure 5-1 shows the Network Analyst interface for the Network Analyst solvers. For this project, Chattanooga Network Dataset was used to perform the required analyses.

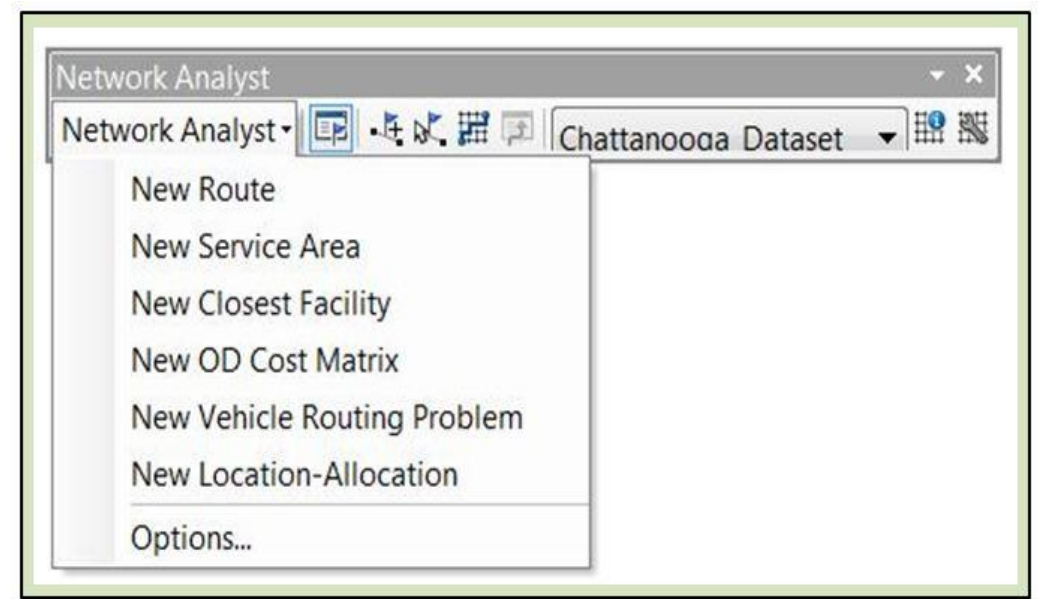

Figure 5-1: Network Analyst Toolbar

The access coverage areas of the proposed bus stops in the predefined ZIP codes were created based on the typical walking distance of 1,300 feet. The current bus stops were loaded as facilities through the Network Analyst window (Figure 5-2).

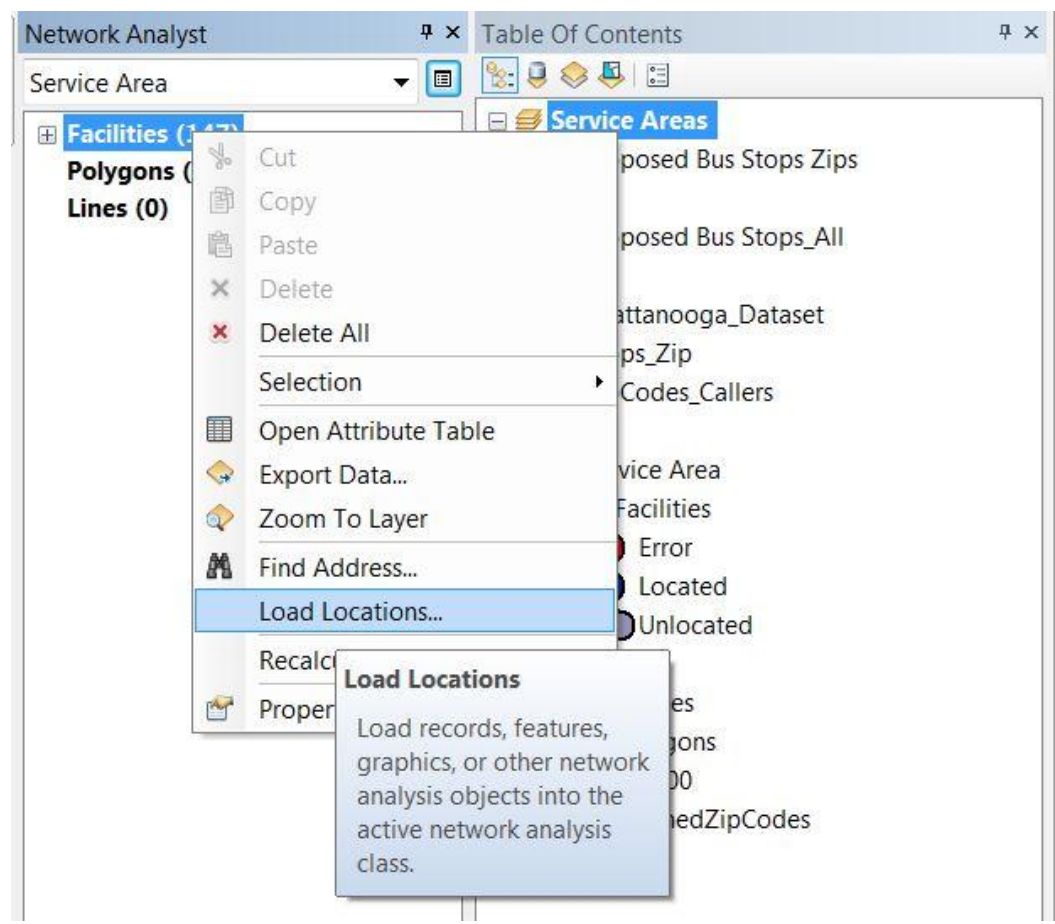

Figure 5-2: Network Analyst Window

Parameters and properties for the Service Area solver were set up through the Service Area Analysis Layer Properties (Figure 5-3). 


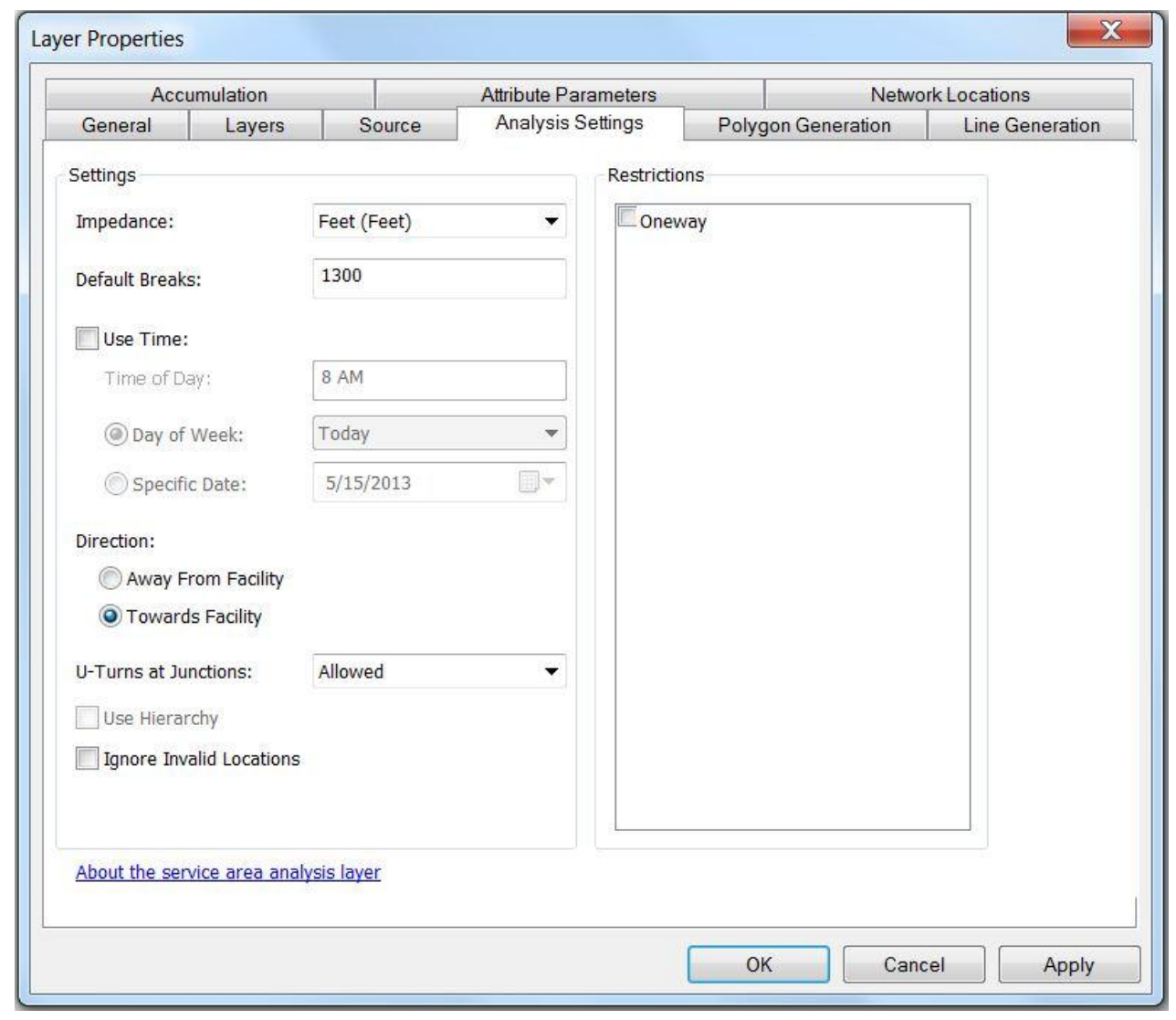

Figure 5-3: Setting Analysis Parameters

Impedance was set to 1,300 feet which is the reasonable walking distance in urban areas. The Towards Facility option was checked for Direction parameter to create a service area by accumulating feet in the direction toward the bus stop. The U-Turns at Junction parameter was set to Allow option from the drop-down arrow and the Oneway option was unchecked for Restriction parameter so that the bus ridership can reach the bus stop from all directions.

The analysis was run by clicking the Solve button (Figure 5-4). The result of the analysis contains the aggregated service area of all proposed bus stops was added into the map.

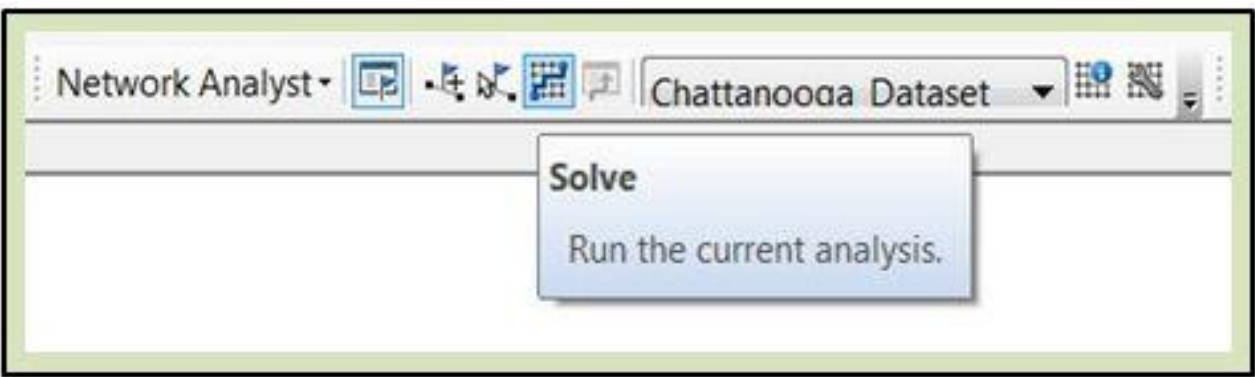

Figure 5-4: Solve Button 
The Service Area solver was also used to create the service area for the proposed bus stops in the central business district. The impedance value was set to 600 feet which is the reasonable walking distance in the central business district. The analysis results are detailed in Chapter 6.

\subsubsection{Location-Allocation}

The Location-Allocation Solver in this project was used to find the optimum locations for new bus stops in the predefined ZIP codes and the areas with specified job opportunities. In particular, minimize facilities problem type was used in this project. This type of problem determines the minimum number of facilities among the candidate locations to cover required demands and finds the optimal spatial configuration of these facilities. In this project, the 2-1-1 callers who were not served by the CARTA bus service were treated as demands and new bus stops were taken as the facilities to be sited. The effective coverage range of bus stops was set to 1,300 feet. The street junctions that were generated by the additional network dataset were treated as candidate locations for new bus stops.

First, the candidate facility locations (the street junctions) and demands (the 2-1-1 callers) were loaded from the Network analyst window (Figure 5-5).

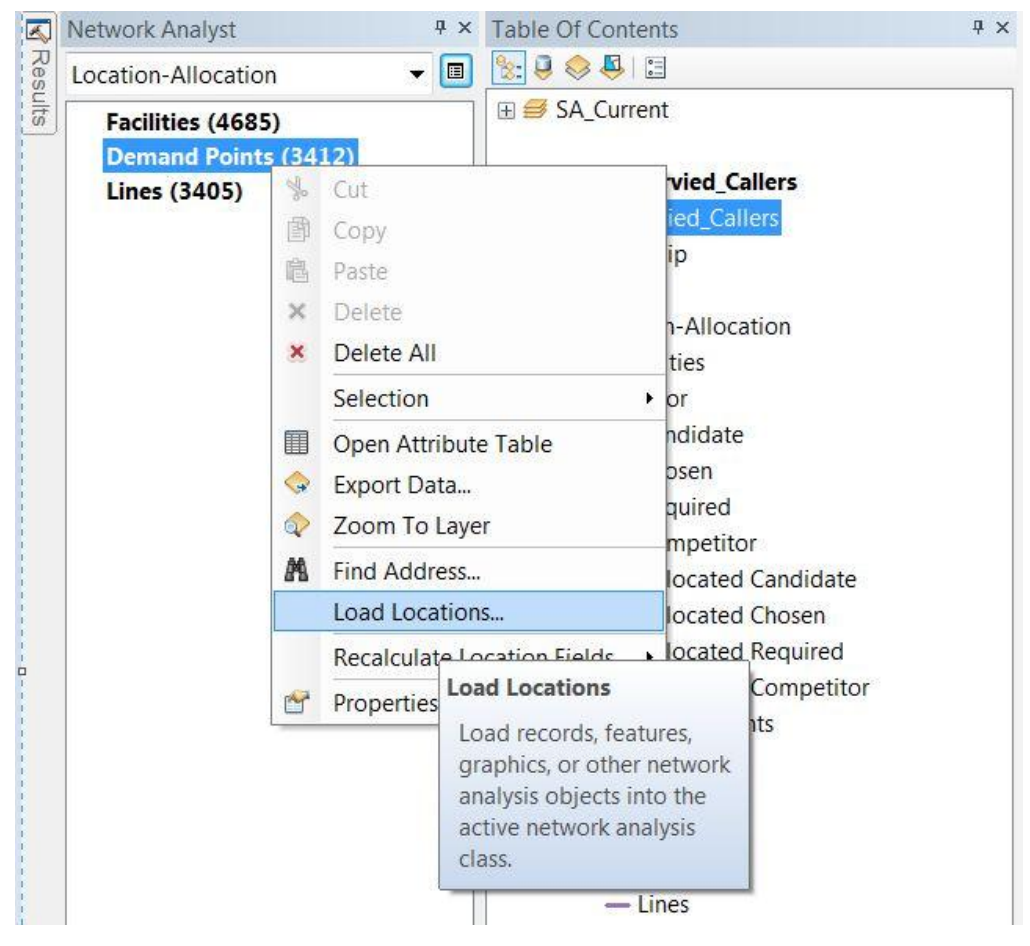

Figure 5-5: Loading Facilities and Demands Points

The impedance parameter was set to feet from the layer properties. The Demand to Facility option was checked for Travel From parameter. U-turns was set to be allowed and straight lines were chosen to link each bus stop to the demands assigned to it. 
Under the Advance Settings tab (Figure 5-6), the Problem Type parameter was set to Minimize Facilities and the impedance cutoff was set to 1,300 feet, which assumes that any demand within 1,300 feet from a facility is covered.

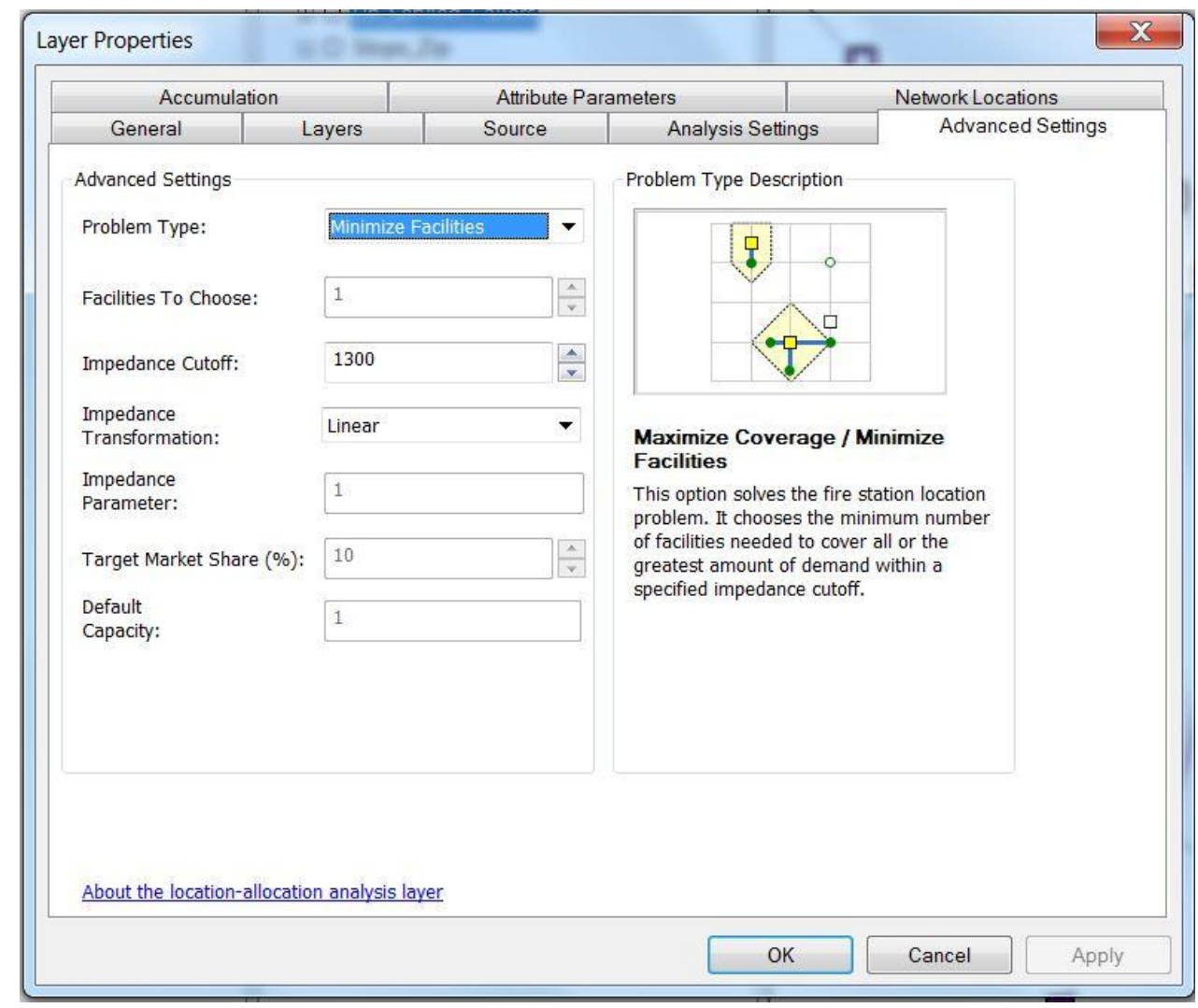

Figure 5-6: Advance Settings

The Location-Allocation Solver for Minimize Facilities was also used to locate new bus stops in the central business districts. For this problem, the major locations with more job opportunities specified by the clients were treated as demands and impedance cutoff was set to 600 feet.

The analysis result shows that over 147 new bus stops would be required to cover all 2-1-1 callers not served by the CARTA bus stops. In practice, it might be more cost effective to reduce the number of required bus stops if most of demands are still covered. Therefore, the same analysis was conducted at block and block group level respectively. The results are presented in Chapter 6.

\subsubsection{Route Solver}

The optimal bus routes that incorporate the proposed bus stops were calculated by the Route Solver. Generally, the Route solver finds the quickest or shortest route, depending on the various attributes. There are four types of attributes: cost, restriction, descriptor, and hierarchy. The cost impedance attribute, including time and distance, is the most important attribute. In this project, using the travel time as the cost attribute would 
minimize the driving time which is a function of distance and speed or speed limits. In this case, each edge needs an associated driving time.

The Restriction attributes allow one to model various restrictions, such as one-way streets, blocked intersections, and turns prohibited by law. The Descriptor attribute is a particular characteristic of the network that is not actually used by the solver. It is often used by another restriction attribute to model more complex restrictions such as bridges or overpasses.

The Hierarchy attribute is the order or rank assigned to network elements. When a street feature class has an attribute that breaks the roads down into three or more classes, such as local, secondary, and primary, a hierarchy attribute tends to reduce the time it takes to solve an analysis across a large network. It also simulates how drivers generally elect to travel on highways and interstates because navigating on higher-order roads is more predictable than on lower-order roads.

Several parameters and properties were set before Route Solver was executed. Once the proposed bus stops feature class was created, the route network analysis layer was added to the map display from Network Analyst toolbar and the proposed bus stops were loaded. The route layer properties dialog box was then opened to set the parameters and properties for the Route Solver (Figure 5-7).

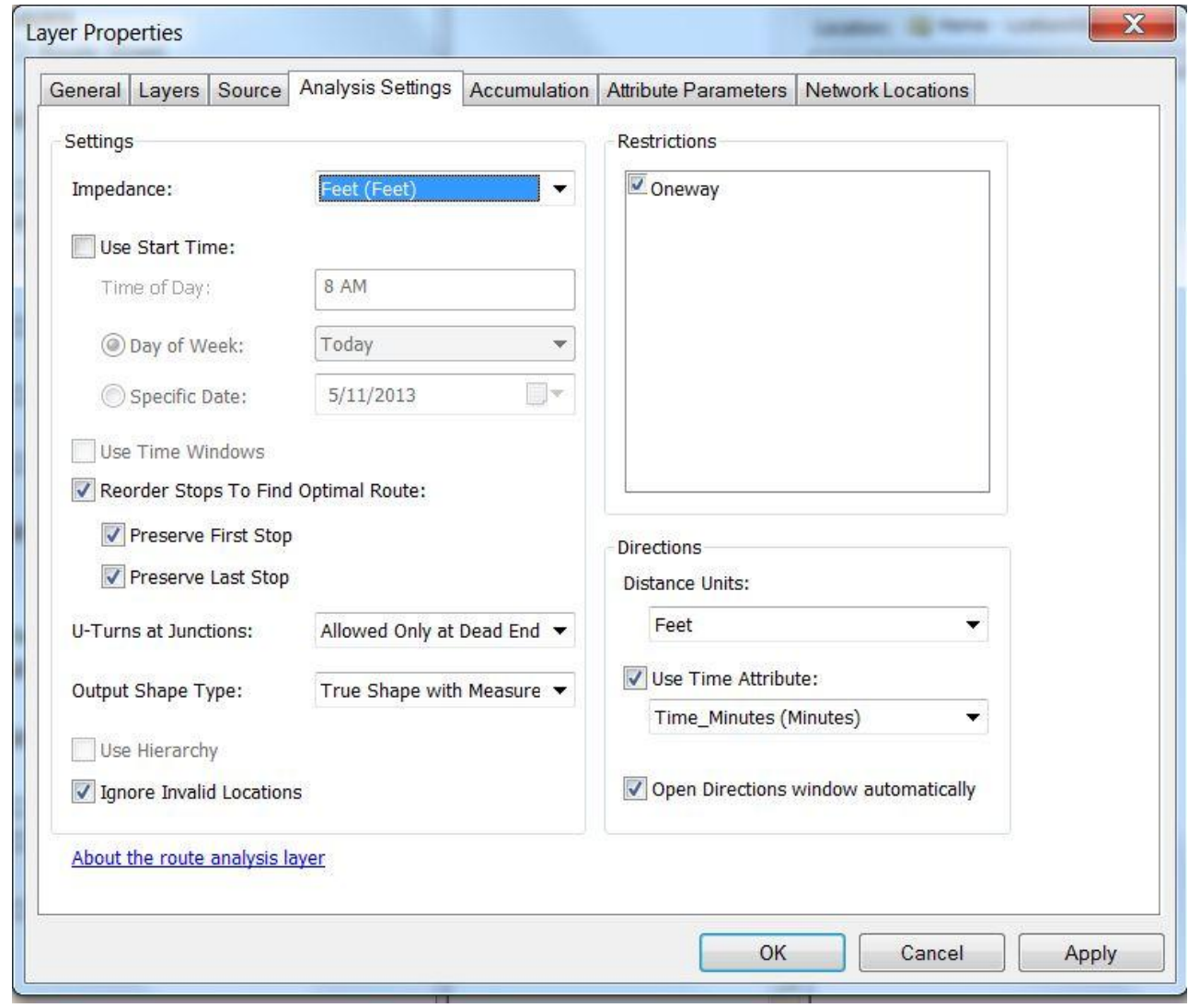

Figure 5-7: Route Solver Analysis Setting 
Under Analysis Settings tab, the Impedance was set to feet. The Reorder Stops To Find Optimal Route parameter was checked to allow Network Analyst to find the ordering of the bus stops that yields the shortest route. U-turns at Junctions parameter was set to Allowed only at Dead Ends option. This means U-turns are prohibited at all junctions, except those that have only one adjacent edge; a dead end (ArcGIS Help10.1) (Figure 5-8).
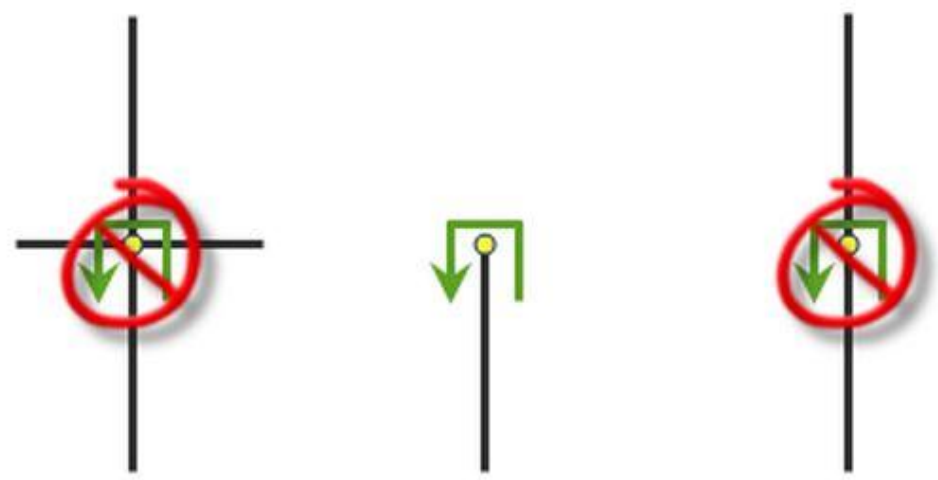

Figure 5-8: U-turns at Dead Ends. Data source; ArcGIS Help10.1

The Output Shape Type parameter was set to True Shape with Measures option. This option gives the exact shape of the resulting route with route measurement for linear referencing. The measurement increases from the first stop and records the cumulative travel distance. The Ignore Invalid Locations parameter was checked. This property allows invalid network locations and solves the analysis layer from valid network locations only. If this option is not checked and there are unlocated network locations, the solver will fail. The distance parameter was set to Feet as units, and Use Time Attribute option and Open Direction window automatically were checked. The Direction window displays the time in minutes and the length in feet for each segment of the route (Figure $5-9)$. 


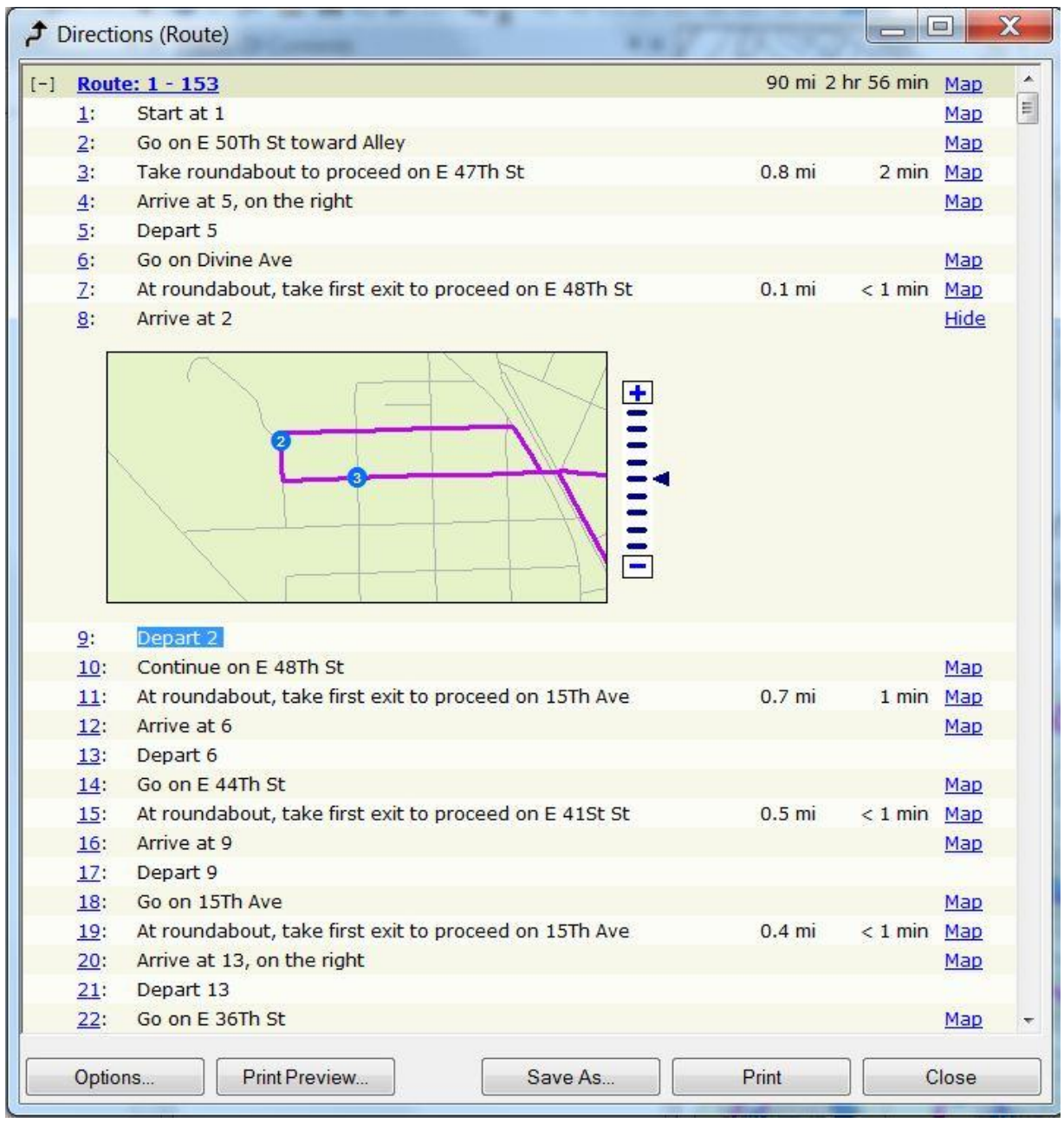

Figure 5-9: Direction Window

\subsection{Summary}

This chapter gave a quick overview on the tools and functions that were used to formulate the final solution of this project. A toolbox was created to store the Data Management Toolsets and Tools that were used in this project. Network Analyst extension was used to create the Chattanooga Network Dataset which was described in Chapter 4. The Network Analyst Solvers; Service Area, Location-Allocations, and Route Solvers were used in this project. The solvers were used to create service areas for the current and proposed bus stops, find the optimum locations for the new bus stops, and select the optimal routes that incorporate the new bus stops. The analysis methods and results are detailed in Chapter 6. 


\section{Chapter 6 - Results and Analysis}

Once the spatial mismatch geodatabase was built, the next step was analyzing spatial mismatch between the places with job growth and the residential communities where the callers reside. Once deficiencies in the CARTA bus service were identified, new bus stop locations and new bus routes were proposed to facilitate 2-1-1 callers' access to the potential job locations.

\subsection{Analyzing Spatial Mismatch}

Research has identified residential location and access to transportation as key factors influencing labor force participation. Poor access to public transit prevents many lowincome individuals from having access to entry-level job opportunities because they may not have other means to get to job locations. The overall goal of the BSL program was to decrease the 2-1-1 callers' dependencies on social services by connecting the callers with the areas where employment prospects are better. In order to accomplish this, program officials need to answer several questions, including the demographic characteristics and spatial distribution of the 2-1-1 callers; the spatial distribution of major employers for these callers; and the service coverage of the CARTA bus system.

\subsubsection{Demographic of the Callers}

In this project, census tracts were used as main geographic level for mapping and analyzing the demographic data that were extracted from American Community Survey (ACS) 2006-2010 5-Year Estimates. In addition, the client provided data about the people who call the BSL program or the 2-1-1 callers, and the CARTA bus stops and routes.

\subsubsection{Spatial Distribution of 2-1-1 Callers}

The first step of the analysis was to visualize where the 2-1-1 callers reside in the city. ArcGIS Online geocoding was used to map the 2-1-1 callers' distribution. A set of maps were produced to show different information about distribution and attributes of 2-1-1 callers. 


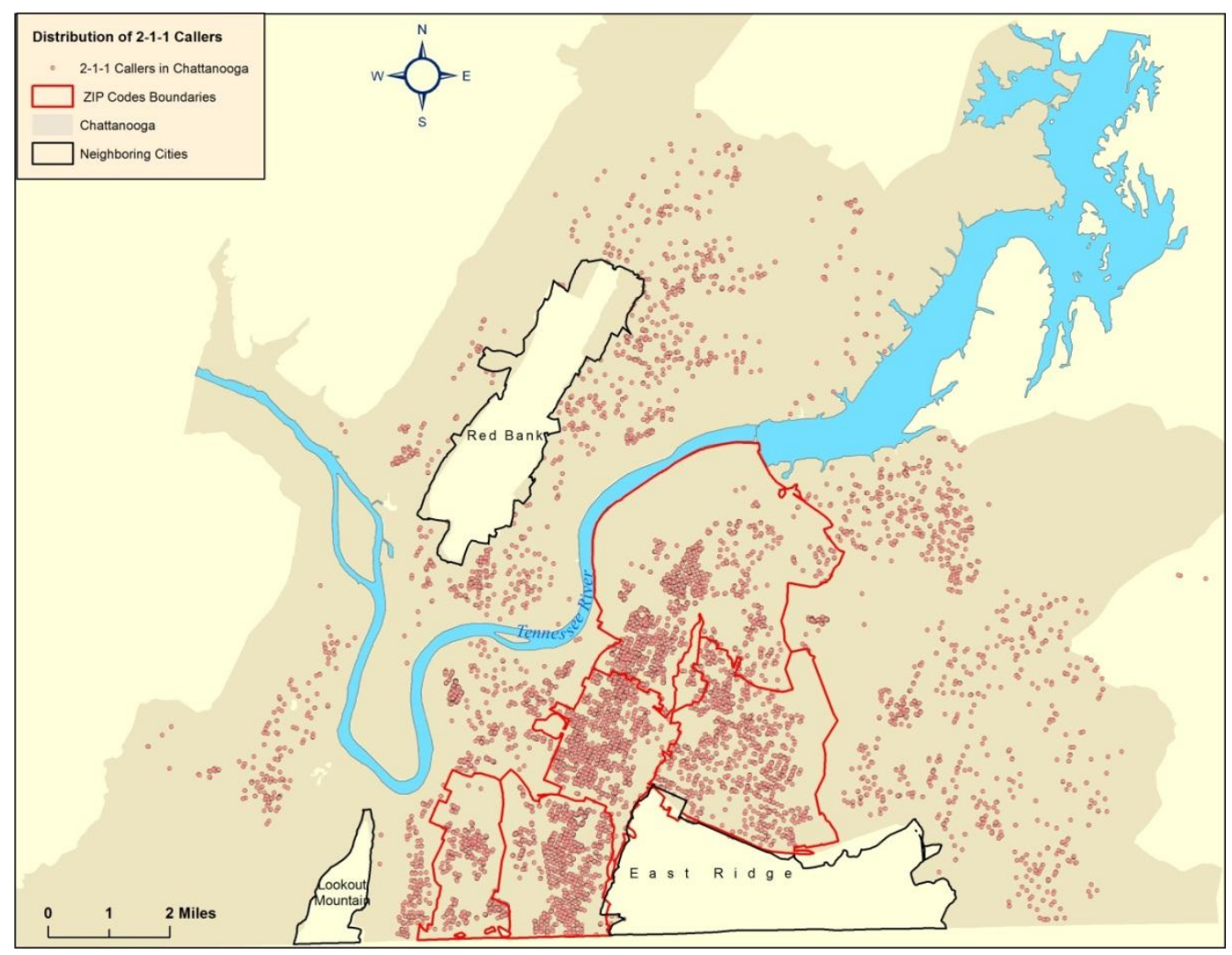

Figure 6-1: Distribution of 2-1-1 Callers in Chattanooga

The caller dataset included the received calls from 2009 to 2011, which totaled over 35,000 calls from different cities in Hamilton County. More than $75 \%$ of calls were received from Chattanooga city and $81 \%$ of those calls were received from the predefined ZIP codes. Figure 6-1 shows that the callers concentrate in the neighborhoods that are within the ZIP codes 37404, 37406, 37407, 37410, and 37411. Table 3 also illustrates the clusters of the callers.

Table 3. Total and Percentage of 2-1-1 Callers

\begin{tabular}{|l|c|c|}
\hline \multicolumn{1}{|c|}{ Geographies } & Total Callers & Percentage \\
\hline Hamilton County & 35,255 & $100 \%$ \\
\hline Chattanooga City & 19,919 & $75.54 \%$ \\
\hline The predefined ZIP codes & $\begin{array}{c}12,187 \\
\text { Out of } 19,919\end{array}$ & $61.83 \%$ \\
\hline
\end{tabular}




\subsubsection{Poverty Level}

The second step was to examine the economic status of the 2-1-1 callers. Since the income information of the callers was not available, the generalized income status of their residential neighborhoods was used as a proxy.

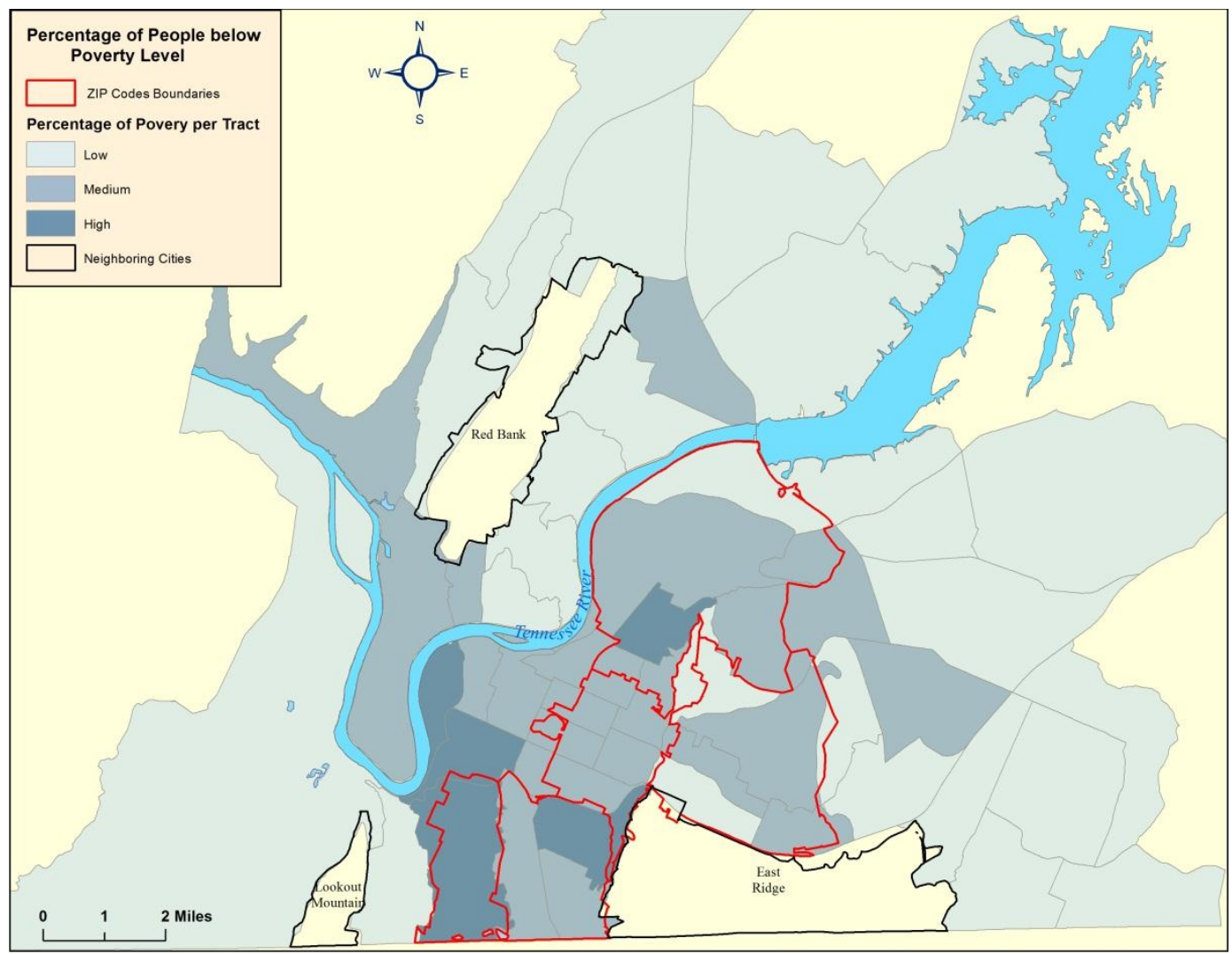

Figure 6-2: Percentage of Families below Poverty Level per Tracts

Figure 6-2 shows the distribution of families below poverty level between 2006 and 2010 across different census tracts. Most tracts in the predefined ZIP codes have high or medium percentages of families below poverty level, which suggests that the callers in the predefined ZIP codes very likely have low income and therefore might not have their own private vehicles to travel around the city.

Overlaying the 2-1-1 callers on the top of the map in Figure 6-2 illustrates the distribution of the callers against the poverty pattern in the city (Figure 6-3). More than $75 \%(15,000$ out of 19,919) of the 2-1-1 callers lived in the neighborhoods of high and medium poverty, which also indicates their low-income economic status. 


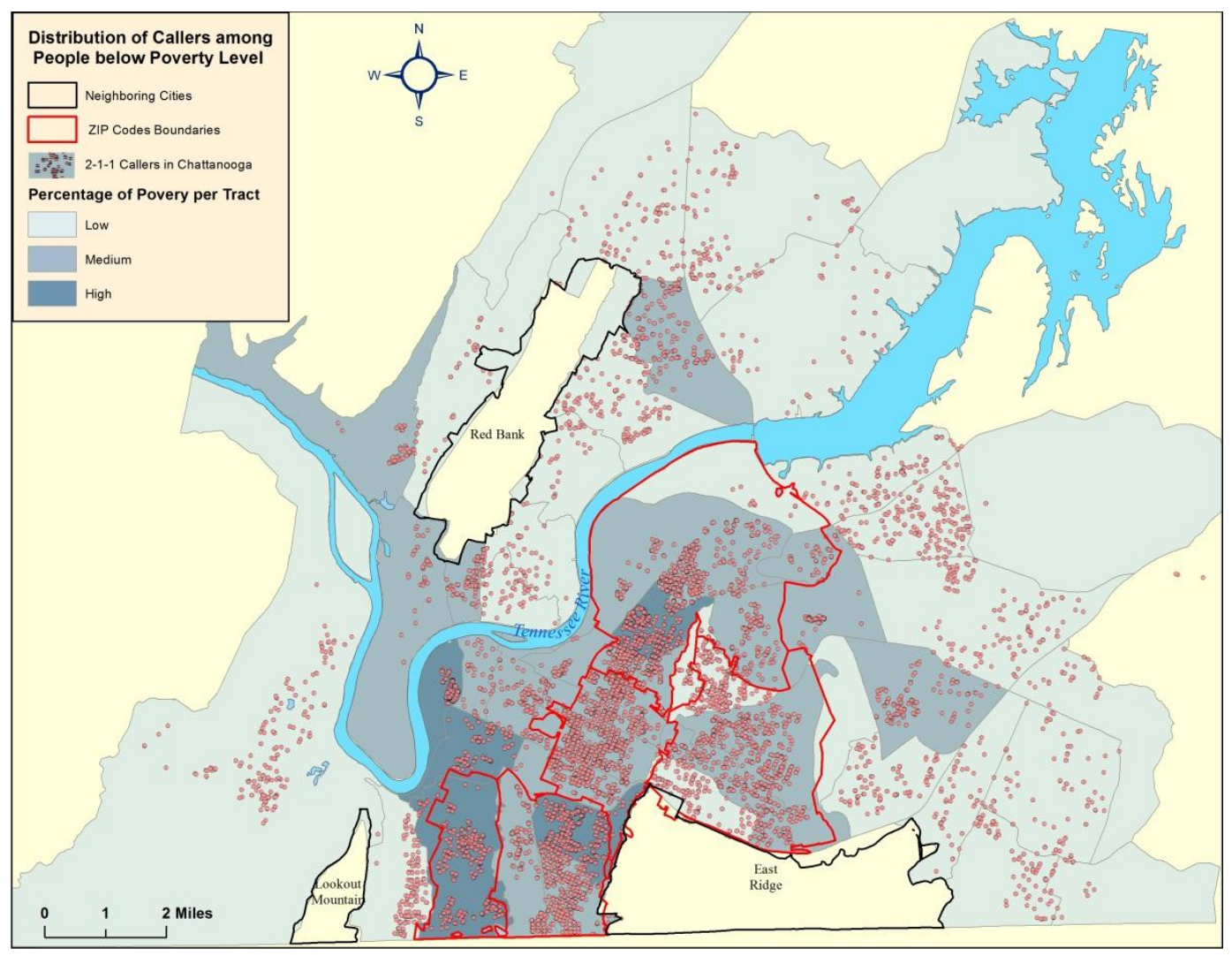

Figure 6-3: Distribution of 2-1-1 among Families below Poverty Level

\subsubsection{Unemployment Rate}

The third step was to examine the employment status of the callers. First, the distribution of unemployment rate in the city during 2006 to 2010 was studied. Figure 6-4 describes unemployment rate during the four years at the census tract level. 


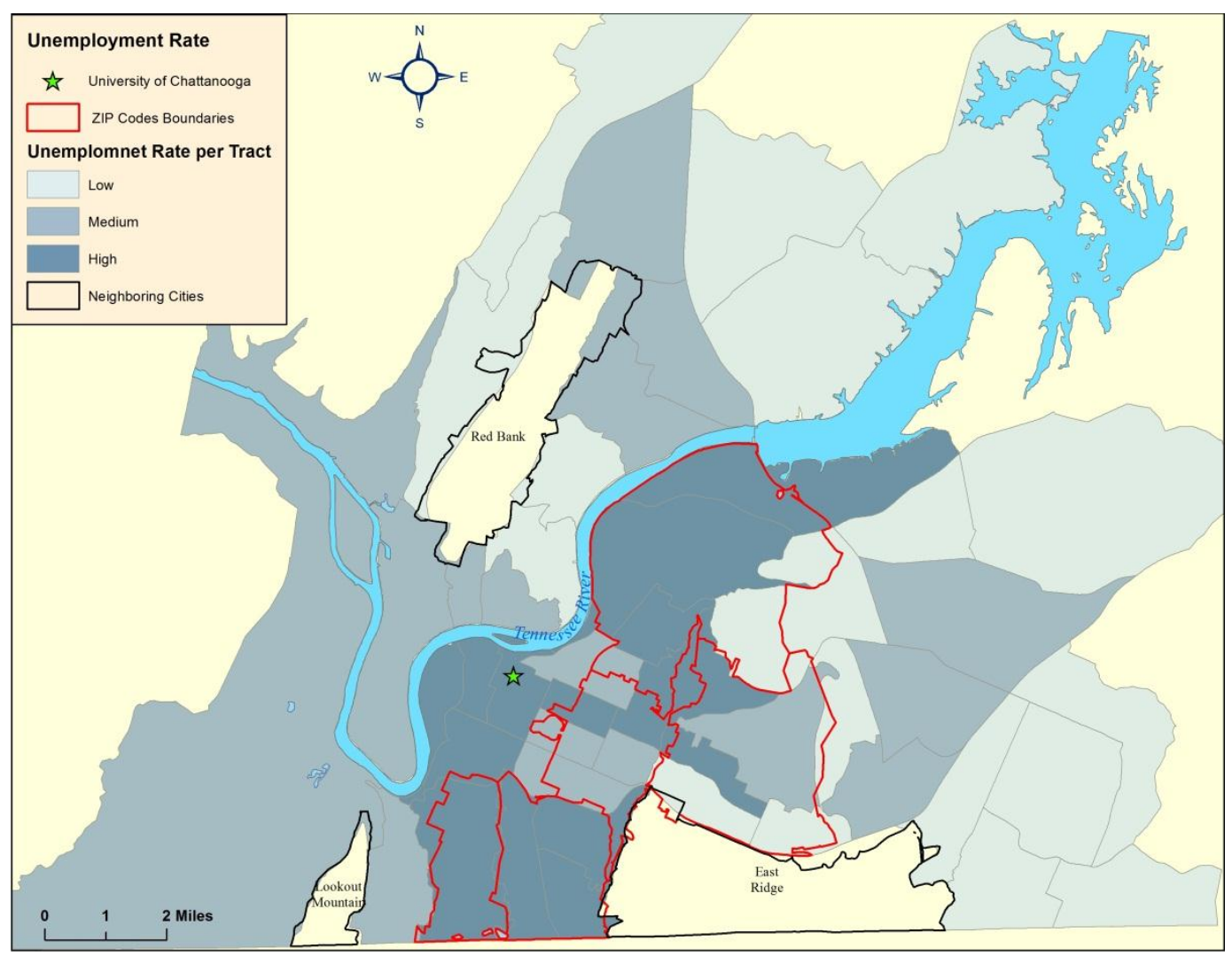

Figure 6-4: Unemployment Rate in the City per Tracts

Similar to the pattern shown in Figure 6-2, the majority of the census tracts with high employment rate fall in the predefined ZIP codes, suggesting the callers in the defined study area are likely to be unemployed. A few census tracts that have high and medium unemployment rates, but fall out predefined ZIP codes are located at University of Chattanooga.

Since data about employment status of the callers were recorded in the dataset, callers' employment status was mapped against the generalized unemployment rate distribution in the city (Figure 6-5). 


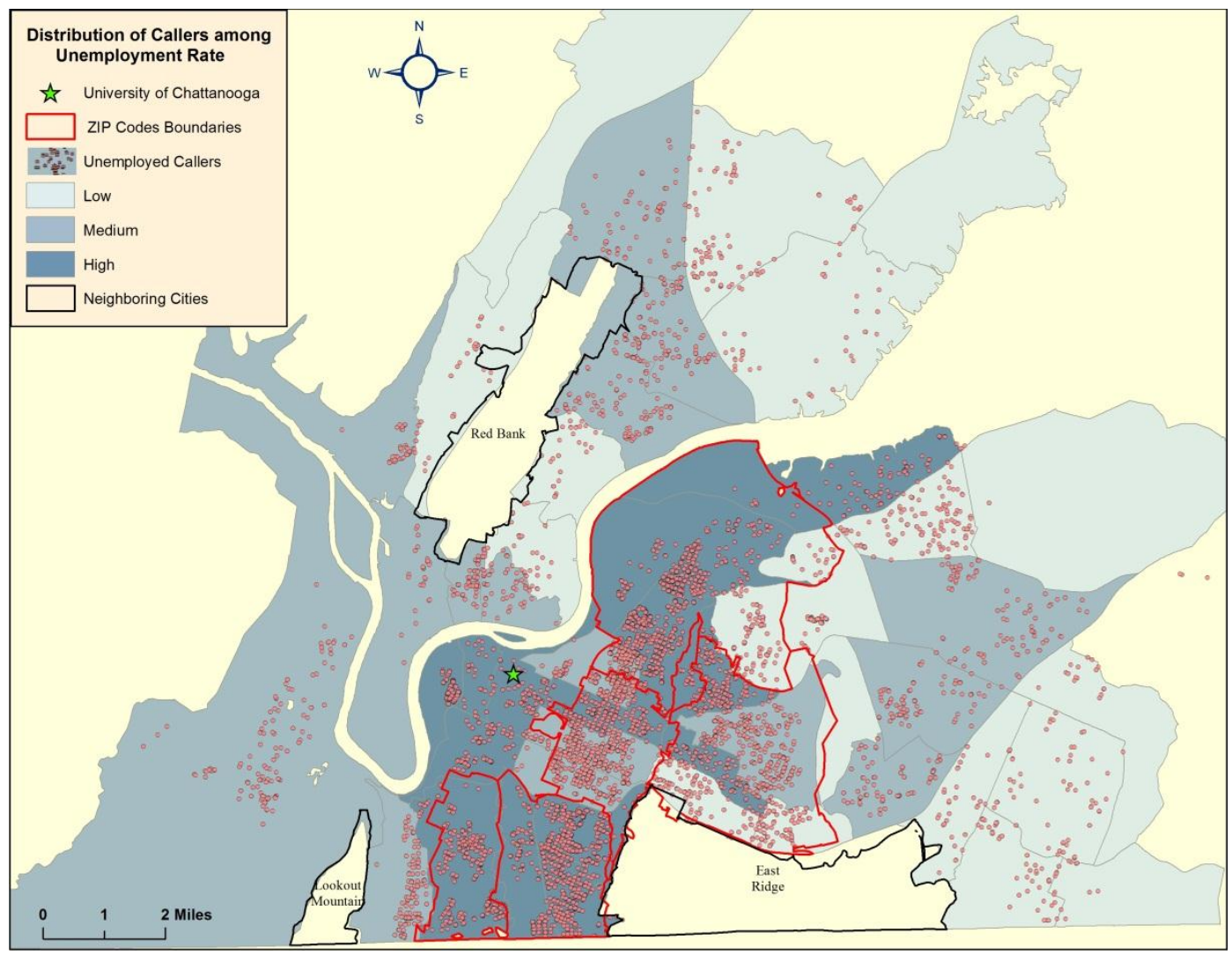

Figure 6-5: Unemployed Callers' Distribution among Unemployment Rate

Figure 6-5 shows that more than $60 \%(12,187$ out of 19,919$)$ of the callers in the city lived in the predefined ZIP codes. Only $11 \%$ of callers lived in the tracts with low employment rate. Combined with the earlier findings, it seems that people who lived in the neighborhoods with low employment rate and low income were more likely to call for help. For the predefined ZIP codes, unemployed callers dominate most of the tracts in the predefined ZIP codes. In fact, the unemployed callers account for about $80 \%$ of the recorded callers, which matches the generalized pattern of unemployment rate at the census tract level.

\subsubsection{Educational Attainment}

The fourth step was to examine the educational attainment level for the population of age of 25 years or older. Education is often a variable considered in spatial mismatch studies since less educated individuals often face challenges of finding entry-level jobs that are located away from their home, and are, therefore, more likely to be unemployed. 


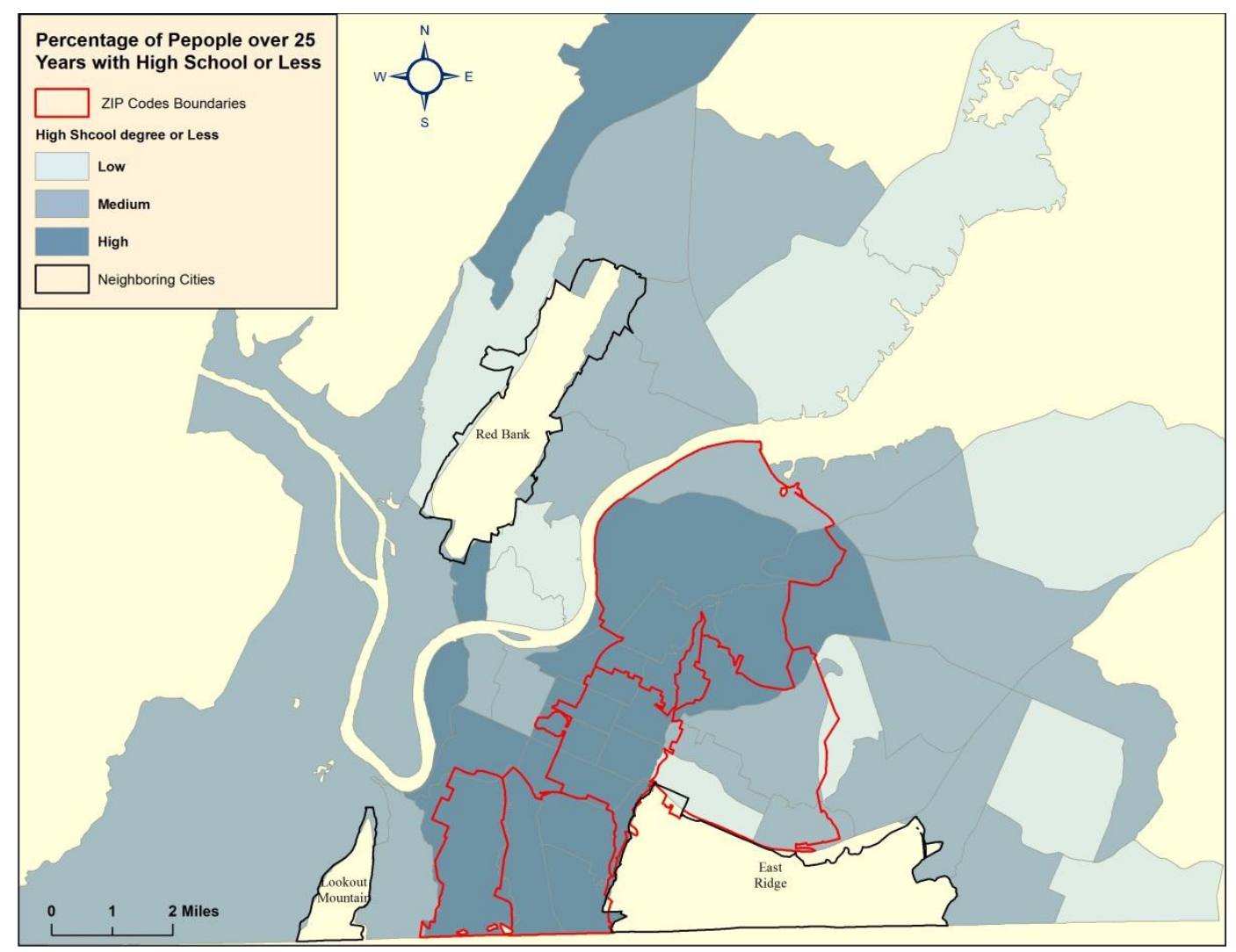

Figure 6-6: Population with High School Degree or Less, Chattanooga

Figure 6-6 shows that most of the tracts that fall in the predefined ZIP codes have high percentage of people with high school degree or less. Combined with the findings about unemployment rate, it appears that unemployment rate is positively related to low education attainment. The statistics shows that about $60 \%$ of the population in the predefined ZIP codes had a high school degree or less.

The analysis also looked into the education status of the 2-1-1 callers. The education status attribute for the 2-1-1 callers was classified into four classes: less than high school degree, high school degree, some college or associate degree, and bachelor' or higher degree. 


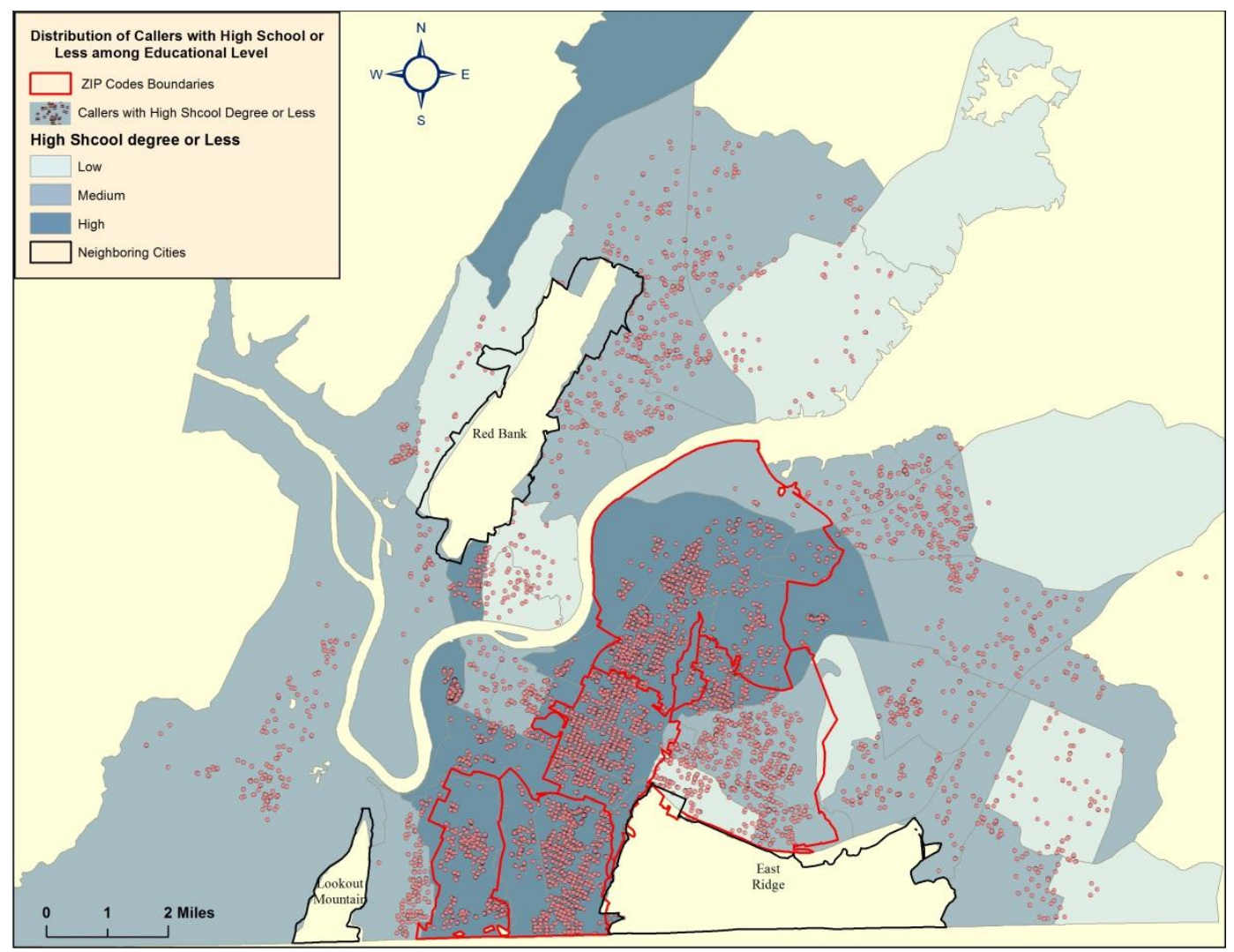

Figure 6-7: Callers with High School Degree or Less

Figure 6-7 displays the callers who have high school degree or less in the city. About $80 \%,(15,829$ out of 19,919$)$ of the callers in the city had high school degree or less. For callers in the predefined ZIP codes, about $74 \%(8,978$ out 12,187$)$ had high school degrees or less. It is obvious that the majority of the callers have a low education background, which may hinder them from finding jobs that require high professional skills.

In summary, most of the 2-1-1 callers are low-income, low-educated, and unemployed individuals concentrated in the predefined ZIP codes which are also lowincome, low-educated, and highly unemployed neighborhoods. The socio-economic characteristics may contribute to the dependencies of the 2-1-1callers on the BSL program. These dependencies can be reduced if they can have access to the locations with more jobs that do not require high educational attainment or professional skills. In this case, it was necessary to identify such areas and find out how public transit can provide service to connect these people with potential jobs.

\subsubsection{Potential Job Opportunities}

The client identified key employers, such as Volkswagen and Amazon, which might hire people with low education attainment and entry-level skills. Several other manufacturers and enterprises were suggested to the client based on growth in the eastern and northern 
areas of Chattanooga. A total of 19 manufactures and enterprisers were approved by the client.

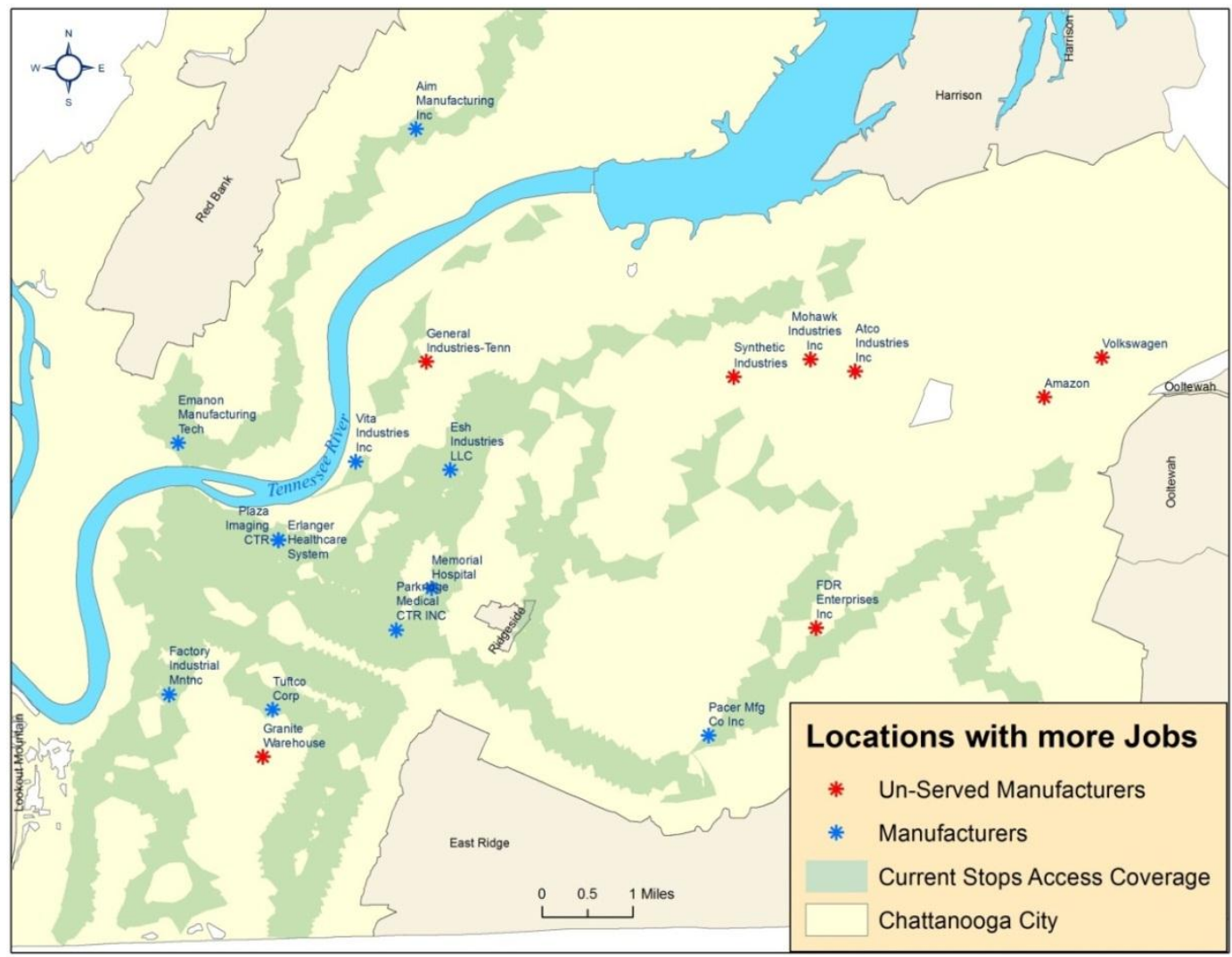

Figure 6-8: Locations with more Job Opportunities

Figure 6-8 shows the locations of the 19 targeted employers and how well these employers are served by the current CARTA public transit system. Eight out of nineteen locations, shown in red are not served by the CARTA current bus services; whereas 11 locations, shown in blue, are covered. However, the manufacturers with a high potential to hire, such as Volkswagen and Amazon, are not in the service range of the CARTA bus services. In fact, the Chattanooga city was ranked 91 out 100 among the nation large metro areas with respect to its public transit coverage (Tomer, Kneebone, Puentes, and Berube, 2011). Therefore, it is necessary to enhance the public transit coverage such that low-income individuals can have access to the potential employers.

\subsubsection{The CARTA Bus Stop Services Area}

The analysis investigated whether 2-1-1 callers in the predefined ZIP codes area have appropriate access to the CARTA bus services. The actual service areas of current bus stops were generated using Service Area solver. 


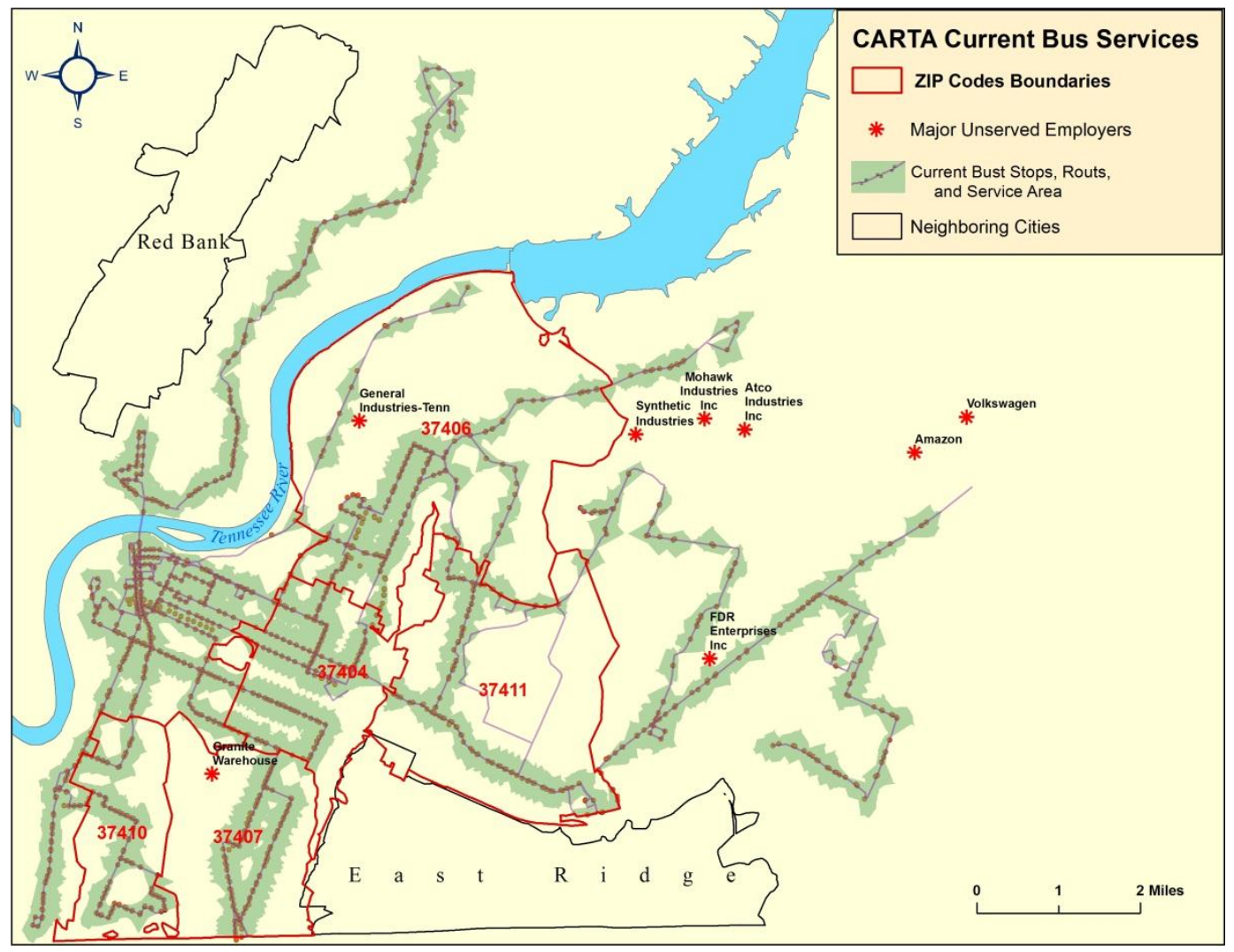

Figure 6-9: The CARTA Bus Service

Figure 6-9 shows the current bus routes and the service areas of the current bus stops. It can be seen that several ZIP codes are not well served, such as 37406, 37407 , and 37410. In particular, there are no bus stops at all in 37411. 


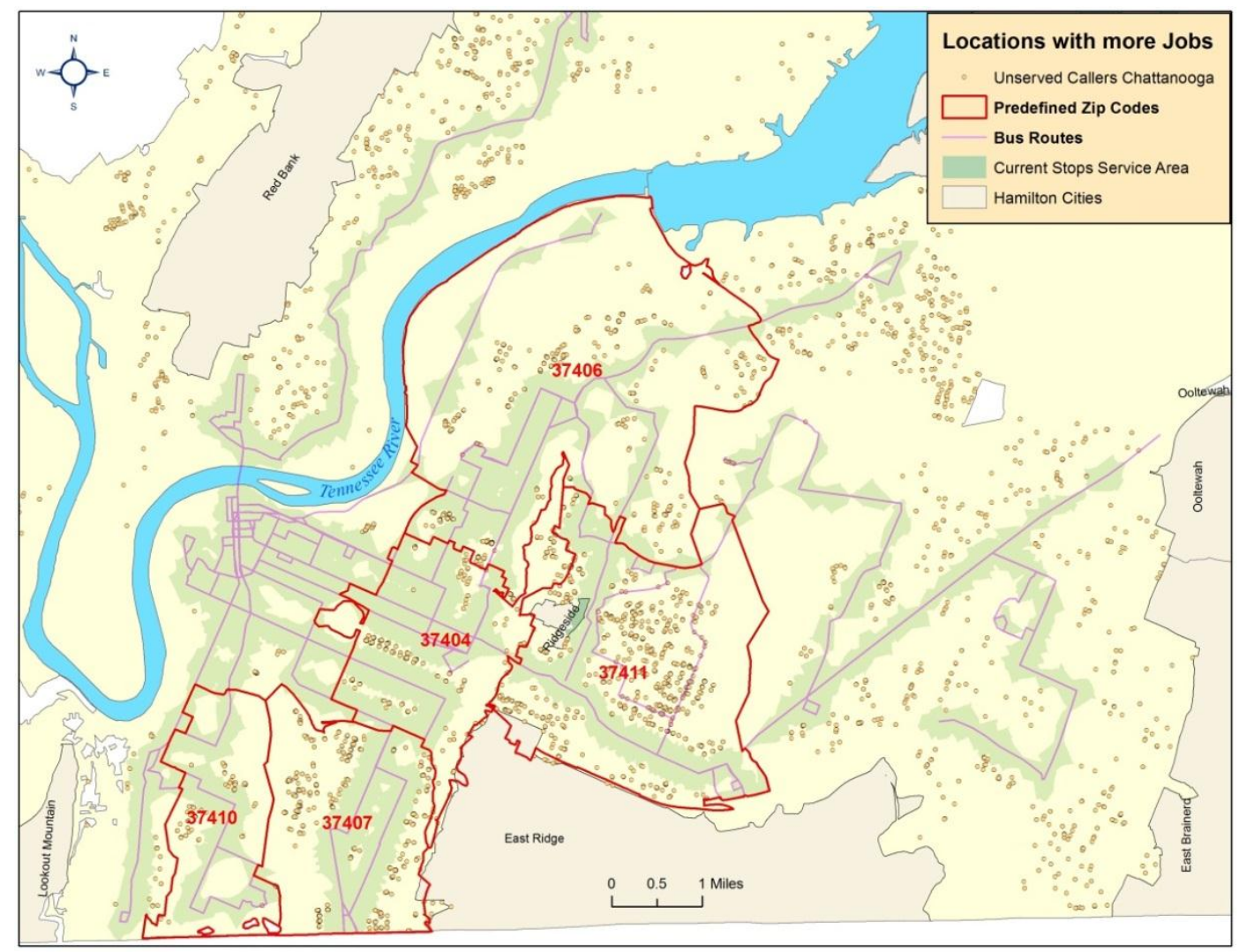

Figure 6-10: Distribution of Unserved Callers and Current Bus Services

About $36 \%$, (7,090 out of 19,919) of all 2-1-1 callers live outsides the bus stop service areas and $65 \%$ of them are unemployed and have educational degree of high school or less. In the predefined ZIP codes, there are about $30 \%,(3,412$ out of 12,187$)$ of the callers live outside the service areas and $68 \%$ of them are unemployed with an educational degree of high school or less.

Overall, the analyses in this project identified the physical separation between the 21-1 callers' residential areas and the locations with better job prospect as well as deficiencies in the current CARTA service. To better connect the targeted population with job locations, new bus stops and bus routes in the predefined ZIP codes and around the job locations were proposed in this project, which will be further explained in the following sections.

\subsection{Proposed Bus Stops Locations}

Literature has suggested guidelines for choosing suitable sites for new bus stops (see Chapter 2). Generally, bus stops locations are determined by transporting authority based on the goals addressing for both traffic operation and passenger accessibility. The following criteria have been taken in consideration in this project when proposing new bus stops in the predefined ZIP codes and in the area with specified job opportunities:

1. New bus stops in the predefined ZIP codes should serve the areas not covered by the current CARTA bus service. 
2. There should be bus stops around the defined manufacturers and enterprises.

3. The walking distance to the bus stops in the predefined ZIP codes should be based on the typical walking distance in urban areas, which is 1,300 feet.

4. The walking distance to the bus stops in the job locations should be based on the typical walking distance in central business districts, which is 600 feet.

5. The walking distance should be calculated based on the actual street network.

6. The proposed bus stop must be located on streets/roads that are suitable for bus route with speed limit of 30,35 , or $40 \mathrm{mph}$.

Based on the criteria for new bus stops, the optimum locations were determined using the location-allocation solver. The Minimize Facilities type was used in this analysis as the problem type. Minimize the Facilities problem type chooses the minimum number of facilities (bus stops) needed to cover all or the greatest amount of demands (callers who are not served) within a specific impedance cutoff. The junctions of streets and/or roads with speed of 30,35, and $40 \mathrm{mph}$ were treated as candidate locations for new bus stops in the predefined ZIP codes. The current bus stops in the predefined ZIP codes were loaded as required facilities.

The analysis was conducted with two different types of demands: under-served callers and block centroids not in the service range. It is more cost effective to reduce the number of required bus stops if most of demands are still covered in practice. Therefore, the same analysis was conducted at these two geographic scales to compare the results.

First, the analysis was conducted for the under-served callers in the predefined ZIP codes. For this case, there were 3,412 under-served callers treated as demands. The location-allocation solver chose 147 locations for new bus stops in the predefined ZIP codes (Figure 6-11). 


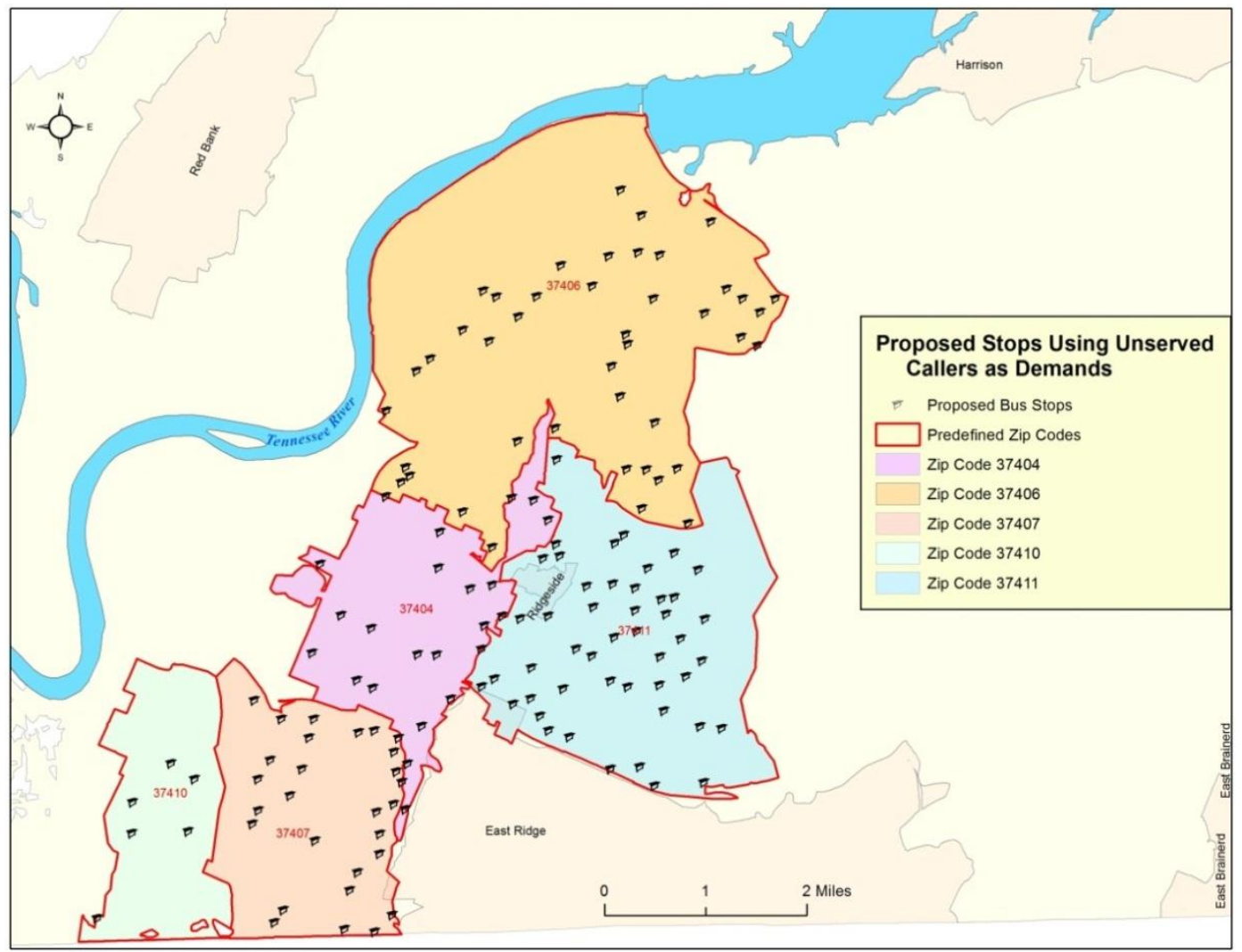

Figure 6-11: The 147 Proposed Bus stops Using Unserved Callers as Demands

Figure 6-12 shows a closer view of the assignment between proposed bus stops and under-served callers. 


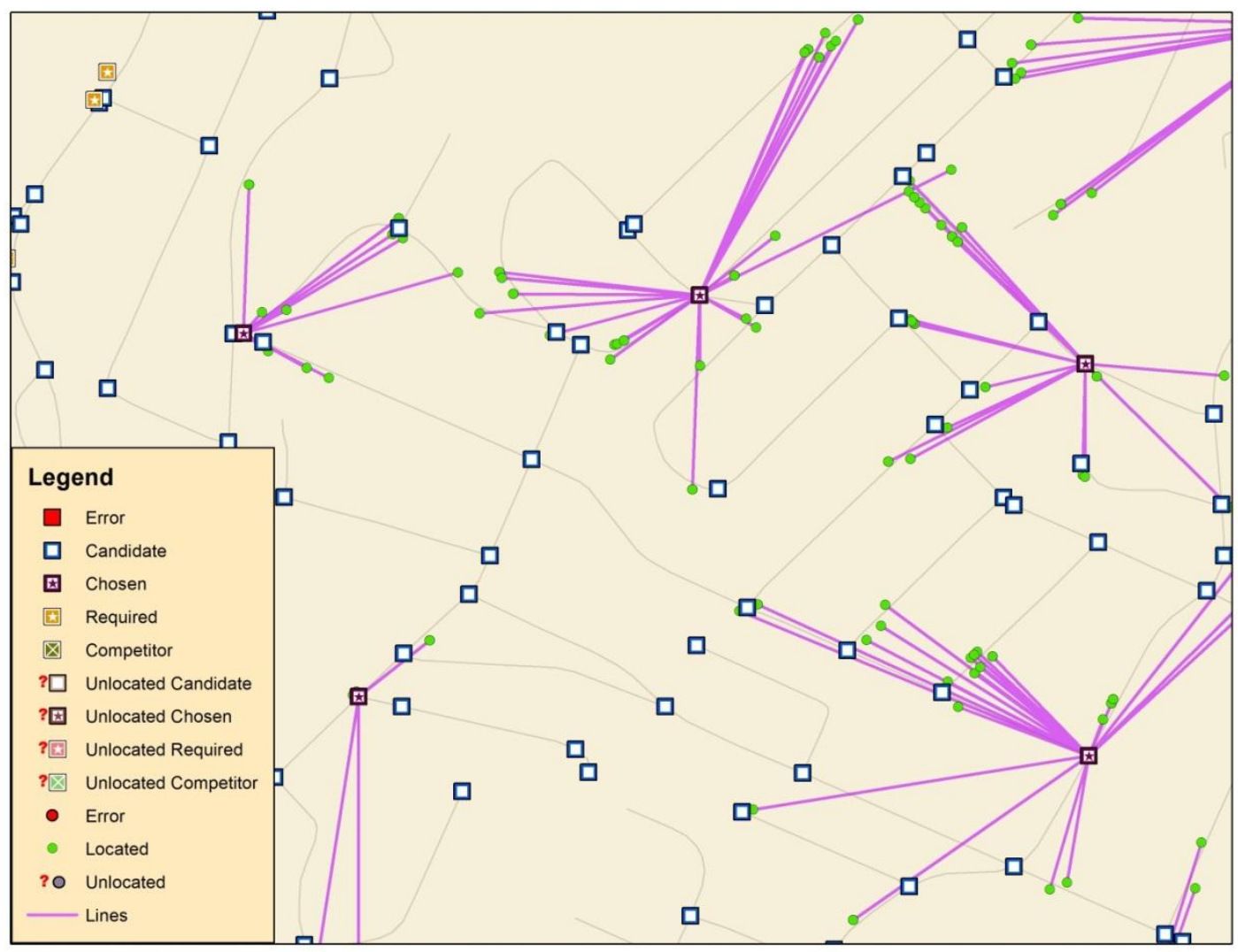

Figure 6-12 Proposed Bus Stops in the Predefined Zip Codes

The service area solver was used to create service areas of the 147 proposed bus stops in the predefined ZIP codes based on the reasonable walking distance in urban areas: 1,300 feet (Figure 6-13). 


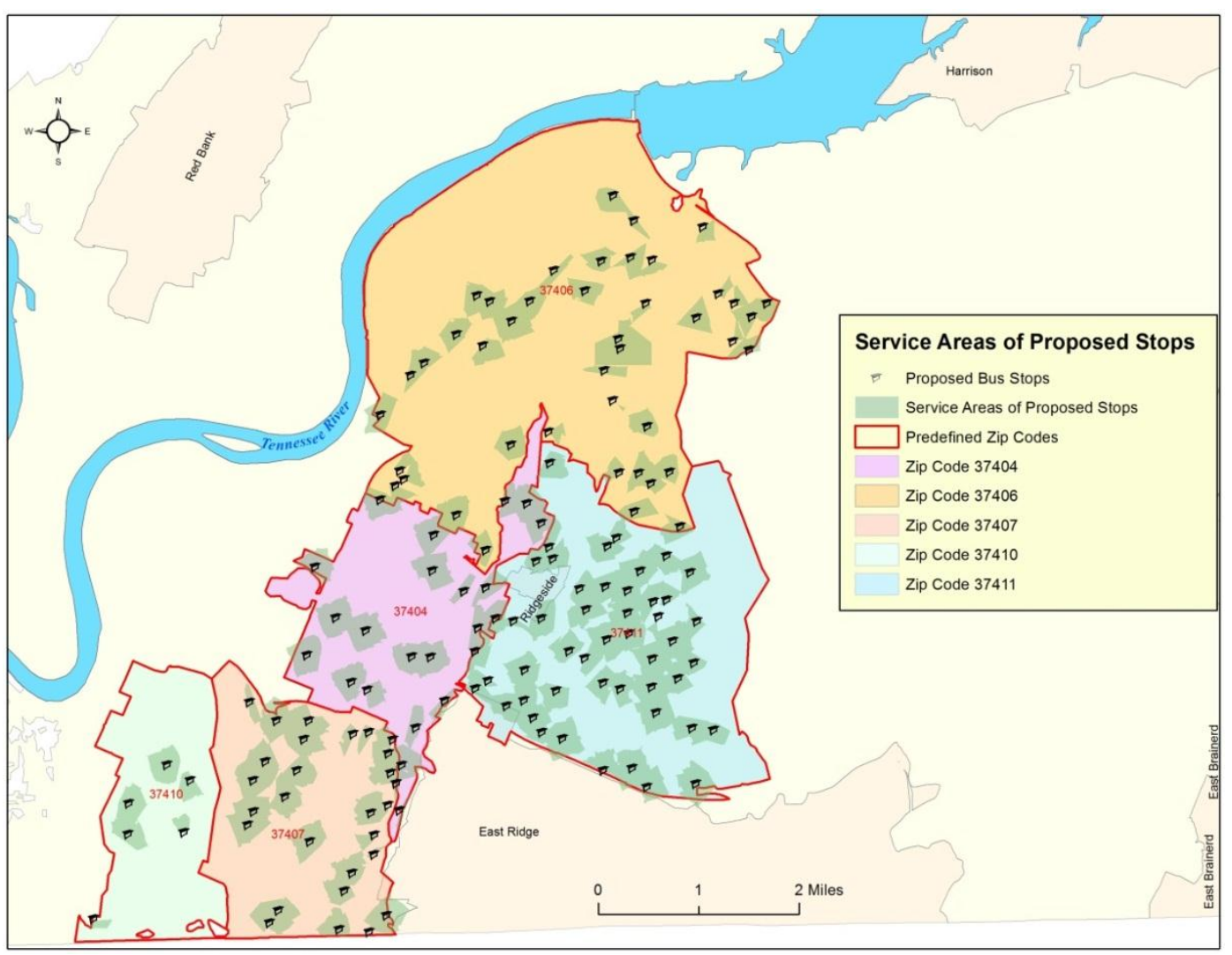

Figure 6-13: Service Areas of the 147 Proposed Bus Stops

Figure 6-13 shows the service areas of the 147 proposed bus stops in the predefined ZIP codes. With these new bus stops, $91 \%$ (3,099 out of 3,412) of under-served callers were covered and $48 \%$ (9.3 of 19.2 square miles) of the total under-served area in the predefined ZIP codes are now served.

Second, the location-allocation solver was loaded with the block centroids where under-served callers live as demands. There were 477 block centroids and 131 proposed bus stops were returned by the solver (Figure 6-14). 


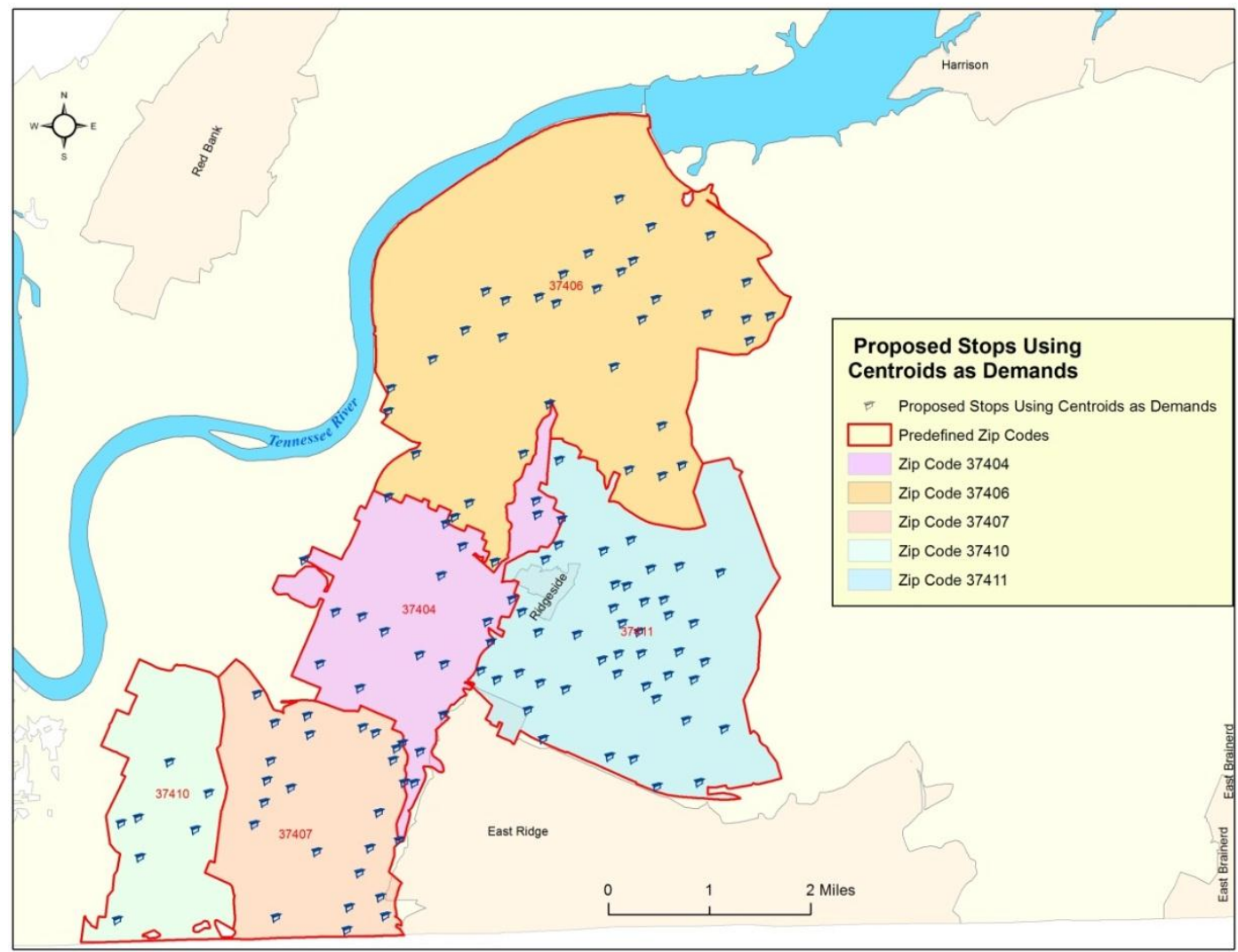

Figure 6-14: The 131 Proposed Bus stops Using Block Centroids as Demands

The service area solver was also used to create service areas for the 131 proposed bus stops by using block centroids where under-served callers live as demands based on the reasonable walking distance in urban areas; 1,300 feet (Figure 6-15). 


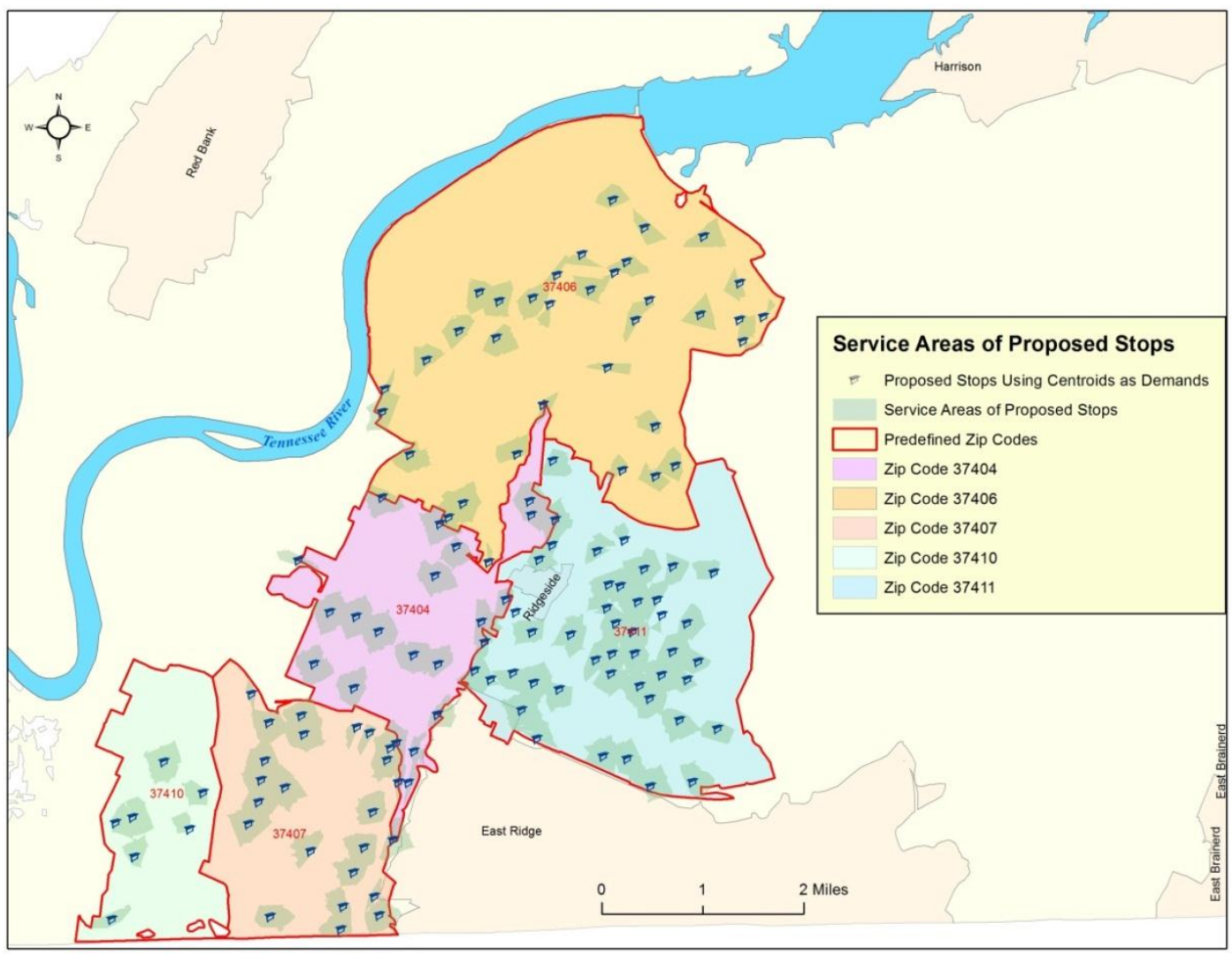

Figure 6-15: Service Areas of the 131 Proposed Bus Stops

Figure 6-15 shows the service areas of the 131 proposed bus stops in the predefined ZIP codes using the 477 block centroids as demands. The analysis shows that $75 \%$, or 360 out of 477 under-served centroids, are covered by the new bus stops and the proposed bus stops will cover 8.4 of 19.2 square miles, or $44 \%$, of the under-served area in the predefined ZIP codes.

The proposed bus stops in the areas with specified job opportunities were conducted with a cutoff distance of 600 feet. There were eight job locations that are not covered by the CARTA bus services, which were used as demands. 


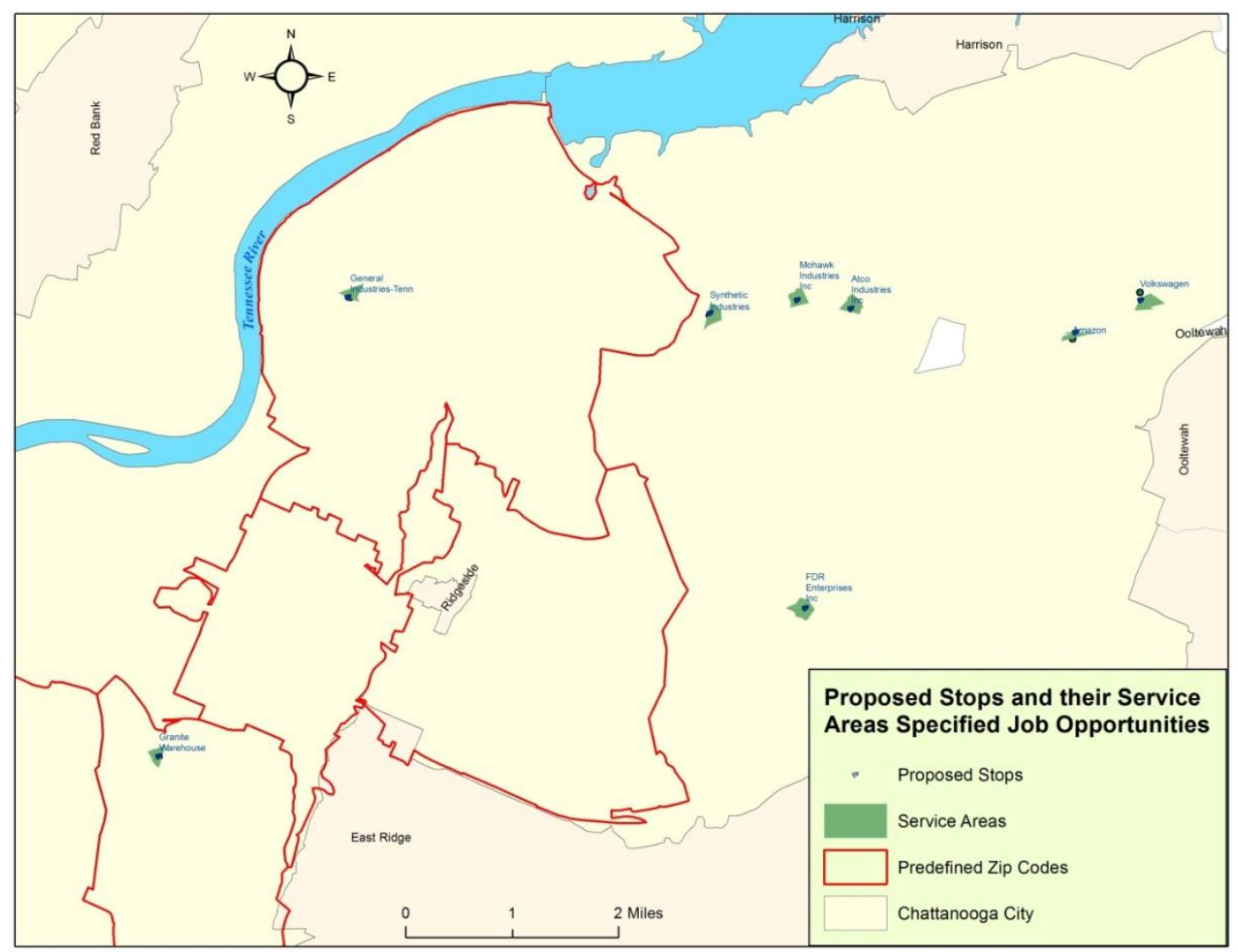

Figure 6-16: Proposed Stops and Service Ares around Major Employers

Figure 6-16 shows the proposed bus stops and their service areas around the major locations of job opportunities. By implementing the proposed bus stops, 2-1-1 callers living in the predefined ZIP codes who seek for job opportunities could utilize bus services to get to job opportunities.

\subsection{Recommended Bus Stops and Routes}

Among the proposed 147 bus stops in the predefined ZIP codes, some bus stops will just serve a few under-served callers. To enhance the efficiency of proposed bus stops, further analysis was conducted to identify the bus stops that can serve at least 25 under-served callers and the street segments that are important for connecting the under-served callers and targeted manufactures were recommended.

\subsubsection{Recommended Bus Stops}

To calculate how many callers would be covered by each proposed bus stop, the service areas for each proposed bus stops was spatially joined with under-served callers. The bus stops that can serve at least 25 callers were recommended as the most important locations for future bus stops. 


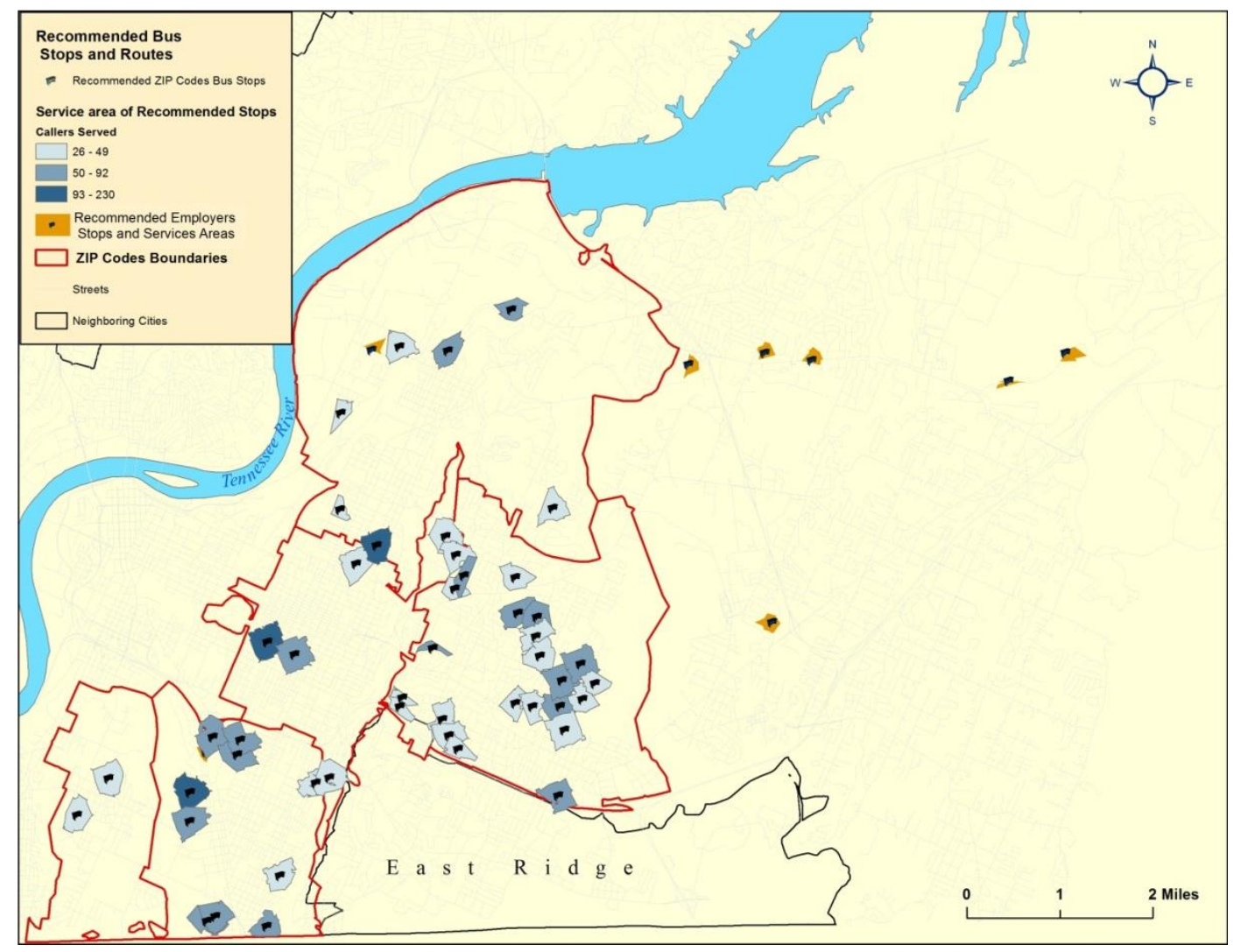

Figure 6-17: The Most Recommended Bus Stops

Figure 6-17 shows the recommended 47 bus stops in the predefined ZIP codes and the eight proposed bus stops around the major employer locations. The next step was to connect those 47 bus stops with the eight proposed bus stops around the major employer locations.

\subsubsection{Shortest Paths between Callers and Manufacturers}

The route solver finds the quickest or shortest route, depending on the impedance attribute (time or, distance) that is chosen to solve the problem. The time impedance attribute was used in this project to find the quickest paths along the proposed bus stops. The route solver generated the shortest path from each bus stop in the residential area to each bus stop around major employer location. For example, Figure 6-18 shows the shortest paths between the 47 bus stop in the predefined zip codes and the bus stop for Amazon. 


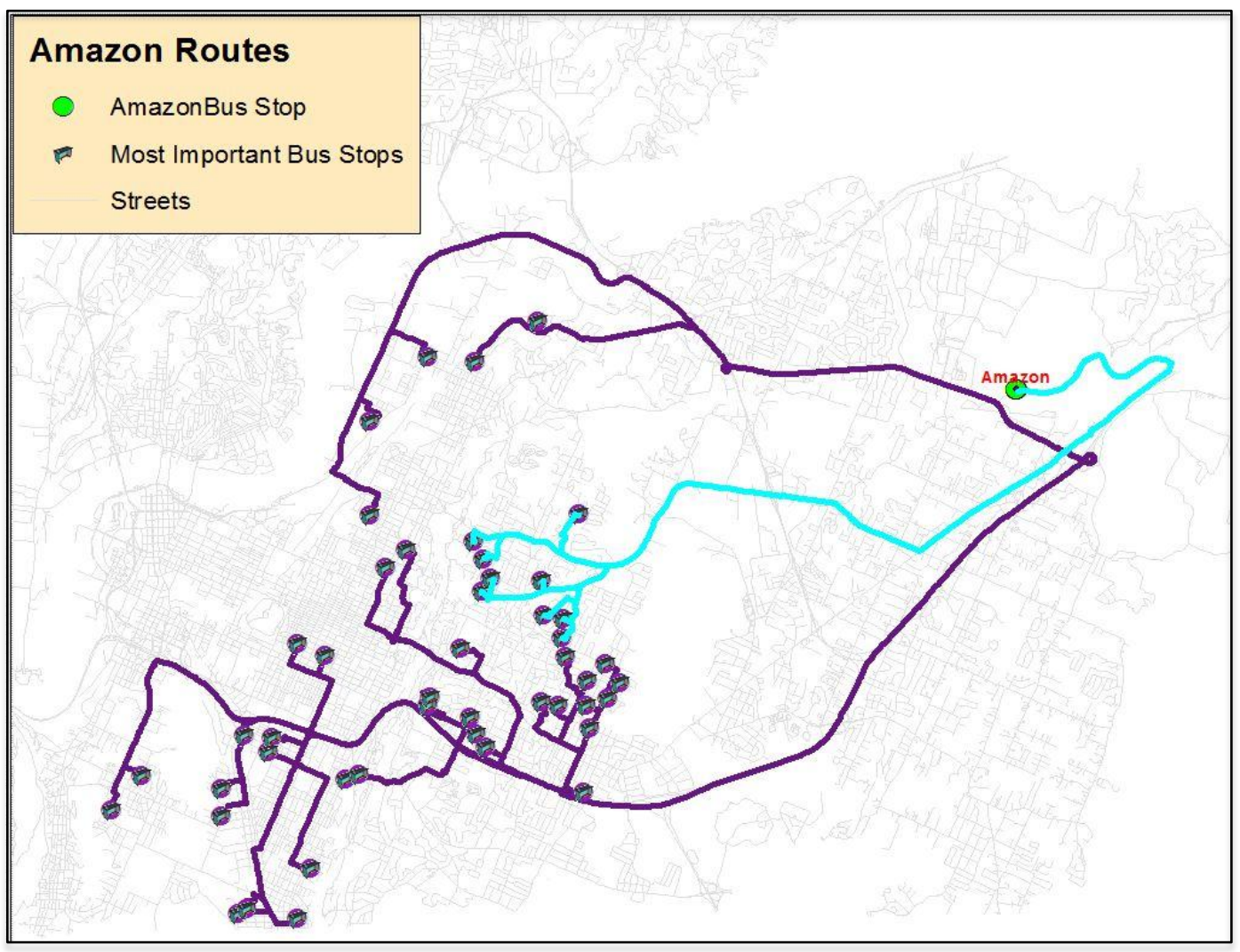

Figure 6-18: the Shortest Paths from Recommended Bus Stops to Amazon

By applying the same analysis to the other seven bus stops around the major employers, and merging them together, the streets connecting the under-served callers with specified employers were obtained. However, some of the streets were more important than others because they either were included in more individual shortest paths or they may have higher traffic volume. To differentiate these streets, all the shortest paths were spatially joined to the street network. Each street segment was then calculated for how many shortest paths were overlaying it. 


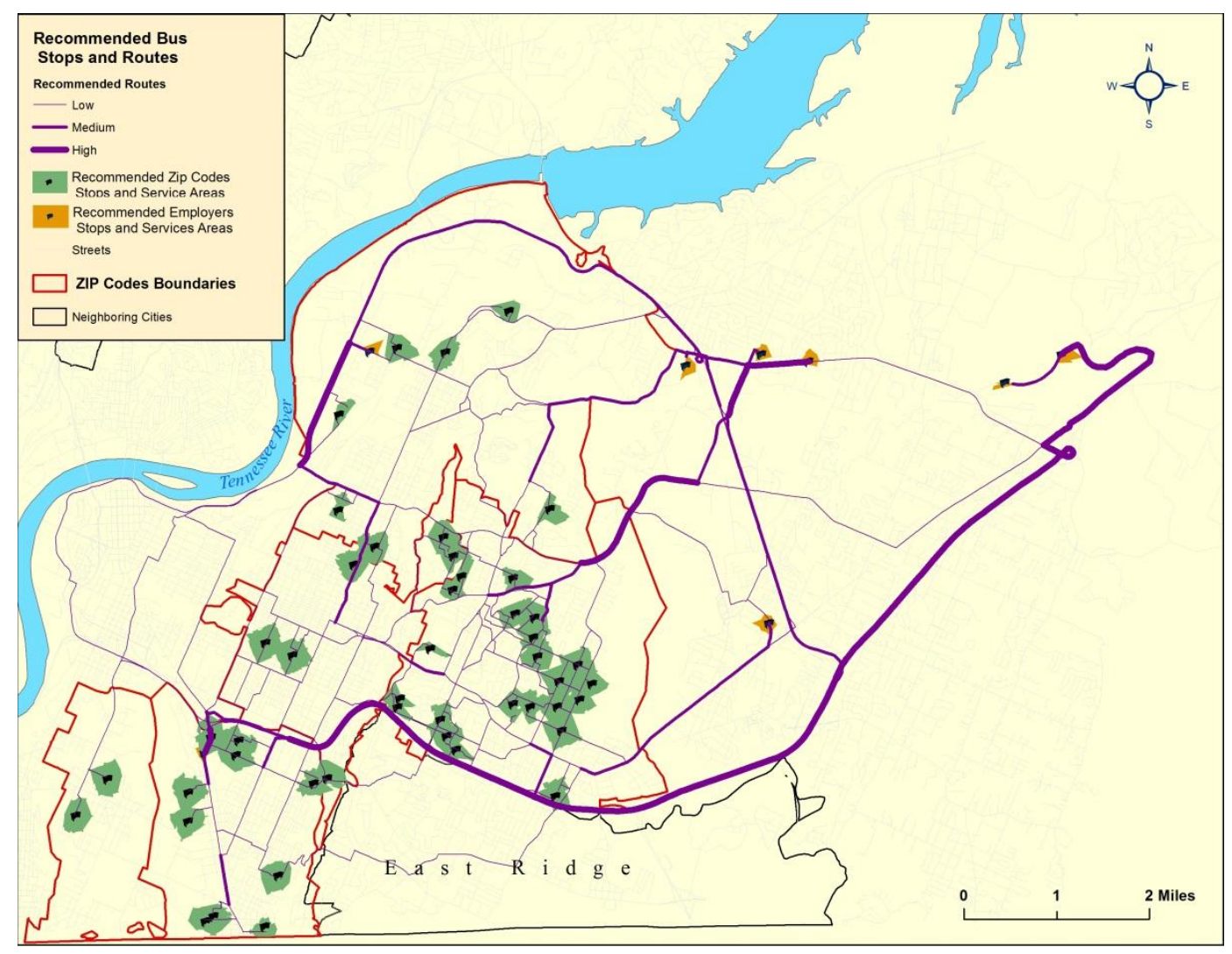

Figure 6-19: Recommended Street Segments to be included in the Future Routes

Figure 6-19 displays recommended streets to be considered in the future bus routes design based on their potential traffic volume. Although final bus routes were not planned in this project, this analysis results will provide insight for the city planners to design their future bus system.

\subsection{Summary}

In this chapter, socio-economic characteristics and spatial distribution of the 2-1-1 callers were examined. Evidence of spatial mismatch between 2-1-1 callers and prospective job opportunities in Chattanooga, Tennessee was identified. Since the 2-1-1 callers did not currently have access to the major employers, such as Volkswagen and Amazon, through public transit, it was necessary to consider expanding the current CARTA bus service.

The location allocation solver was used to find the optimal locations of the proposed bus stops. The Minimize Facilities problem type was chosen and the junctions of streets and/or roads with speed of 30,35, and $40 \mathrm{mph}$ were treated as candidate locations for the proposed bus stops. The analysis was conducted at two different scales: individual under-served callers and block centroids.

In the predefined ZIP codes, 147 proposed bus stops were located, among which 47 bus stops can serve at least 25 under-served callers. These important bus stops were used for the shortest paths analysis. Using the shortest path analysis, the street segments that will carry under-served callers were calculated and differentiated by its traffic volume. 


\section{Chapter 7 - Conclusions and Future Work}

This chapter reviews the project's results and capability to address client's needs as determined in Chapter 3. In addition, recommendations for potential future applications and work are provided.

The project's purpose was to reduce 2-1-1 callers' dependencies on the BSL program's social services by enhancing their accessibility to employment opportunities through the CARTA bus service. To do so, the project identified the under-served areas by the CARTA bus services, chose the optimal locations for new bus stops, and suggested new optimal routes to incorporate the proposed bus stops. The new bus stops were proposed in both the predefined ZIP codes and around major employers' locations. The proposed new bus stops and routes would encourage 2-1-1 callers from the predefined ZIP codes to utilize the CARTA bus services and find job opportunities in areas with high job prospects. Eventually, this would achieve the BSL's overall goal to reduce the 2-1-1 caller's dependencies on the BSL's services.

The final deliverables for the project included a file geodatabase, maps with proposed stops and most important bus stops in the predefined ZIP codes, proposed bus stops around major employers, recommended routes that connect each stops in residential areas with individual employers. In addition, the deliverables included written reports on the project's finding. The file geodatabase contained several feature classes, such as the caller's feature class showing the 2-1-1 callers' distribution within Hamilton County including Chattanooga, the current bus stops feature class, and the proposed new bus stops feature class that illustrated their distribution within Chattanooga. The file geodatabase also contained a network dataset and accompanying network analysis feature class for routes that incorporated chosen bus stops, and the maps and reports with recommendations for new bus stop optimal locations and suggested routes.

Possible future work includes designing practical bus stops. The analysis criteria used in this project were developed based on the optimal locations for new bus stops. A more accurate representation would consider other factors, such as the safety and visibility. Further, although the shortest paths that link under-served callers with the targeted employers were suggested, actual bus routes need to be designed in the future.

Since the street network in Chattanooga was used to create the transportation network dataset and the final solution was applied to specific ZIP codes within the city, the solution could be used for the whole city. This would enable city planners to minimize the number of bus stops and still cover all residential areas and central business districts.

Future work could also include developing a web service with the transportation network and service area solvers. The web service could then provide bus information on bus schedules, such as arrival time, departure time, stop sequence, and stop locations. In addition, historical traffic information can be added to optimize routes for significant time periods given expected traffic delay to create more accurate arrival times. 



\section{Works Cited}

Belwal, R. \&. (2010). Public Transportation Services in Oman. The Journal of Public Transportation, 13(4), 1-15.

Dittmar, H. \& Ohland, G. (2004). Planning Commission TOD Committee Walking Distance Research. Washington, D.C.: Island Press.

Eichenthal D., Tharp B.\& Rehberg E. (2006, Jule 18). Neighborhood and Community Development in Chattanooga. Chattanooga: Benwood Working Paper 2006-02. Retrieved from http://www.ochscenter.org/documents/economy_stateoftheregion2010.pdf

El-Geneidy, A. M., Horning, J. \& Krizek, K. (2010). Analyzing transit service reliability using detailed data from automatic vehicle locator systems. Journal of Advanced Transportation, 45(1), 66-79.

Esri. (2013). ArcGIS Forums 10.1. Retrieved from http://forums.arcgis.com/forums/217ArcGIS-10.1-for-Server-Installation

Esri. (2013). ArcGIS10.1 . Retrieved from

http://resources.arcgis.com/en/help/main/10.1/index.html\#//004700000045000000

Esri. (2013). ArcGIS10.1 Help. Retrieved from http://resources.arcgis.com/en/help/main/10.1/index.html\#//004700000048000000

Ihlanfeldt, A. (1994). The Spatial Mismatch Between Jobs and Residential Locations Within Urban Areas. Cityscape, 1(2), 219-244.

Jargowsky, P. (2002). Sprawl, Concentration of Poverty, and Urban Inequality. Urban Institute. Dallas: Russell Sage Foundation.

Li, P., Abarbanell L., Gleitman, L. \& Papafragou, A. (2011.). Spatial Reasoning in Tenejapan Mayans. Journal of Cognition, 120(1), 33-53.

Michaelides P., Roboli A. \& Marinos T. (2003). Evaluating the Technical Efficiency of Trolley Buses in Athens, Greece. Journal of Public Transportation, 13(4), 93107.

Moss, P., Salzman, H.\& Tilly, C. (2000.). Limits to Market-Mediated Employment: From Deconstruction to Reconstruction of Internal Labor Markets. In F. Carré. (Ed.), Nonstandard Work: The Nature and Challenges of Changing Employment Relationships (pp. 95-121). Champaign, IL: Industrial R.

Murray, A. \& Wu, X. (2003). Accessibility tradeoffs in public transit planning. Journal of Geographical System, 5(1), 93-107.

Ochs Center for M. (2010). Economic Report for State of the Chattanooga Region 2010. Chattanooga, TN. Retrieved June 18, 2013, from http://www.ochscenter.org/documents/economy_stateoftheregion2010.pdf

O'Neil, C. (2012, July 12). Chattanooga poor in connecting jobs, workers via public transport. Retrieved July 18, 2013, from Timesfreepress.com: http://www.timesfreepress.com/news/2012/jul/12/chattanooga-transit-troublesjobs-workers/

O'Sullivan, S. \& Morrall, J. (2003). Walking Distances to and from Light-Rail Transit Stations. Journal of the Transportation Research Record, 1538(1), 19-24.

Rehberg, E. (2009, Jule 18). Demographic Change State of Chattanooga Region Report 2008. 3-19. Chattanooga, TN, Chattanooga. Retrieved Jule 18, 2013, from The 
OCHS Center for Metropolitan Studies:

http://www.ochscenter.org/documents/economy_stateoftheregion2010.pdf

Sels, J., Fitzgerald, D., Borrone, L., Hoel, L., Linton, G., Skinne,r R. \& Wormley, D. (1996). Transit Cooperative Research Program TCRP, Report 100. Washington, D.C: NATIONAL ACADEMY PRESS.

Tomer A., Kneebone E., Puentes P. \& Berube A. (2010). Missed Opportunity: Transit and Jobs in Metropolitan America. Brookings Institution. Washington D.C: Brookings Institution.

Washington Metropolitan Area Transit Authority. (2009). Guidelines for the Design and Placement of Transit Stops. Bethesda, MD. Retrieved June 18, 2013, from http://www.wmata.com/pdfs/planning/WMATA\%20GuidelinesDesign\%20and\%20Placement\%20of\%20Transit\%20Stops.pdf 